\title{
Microsimulation and Policy Analysis
}

Francesco Figari

ISER, University of Essex

University of Insubria

\section{Alari Paulus}

ISER, University of Essex

Holly Sutherland

ISER, University of Essex

No. 2014-23

June 2014

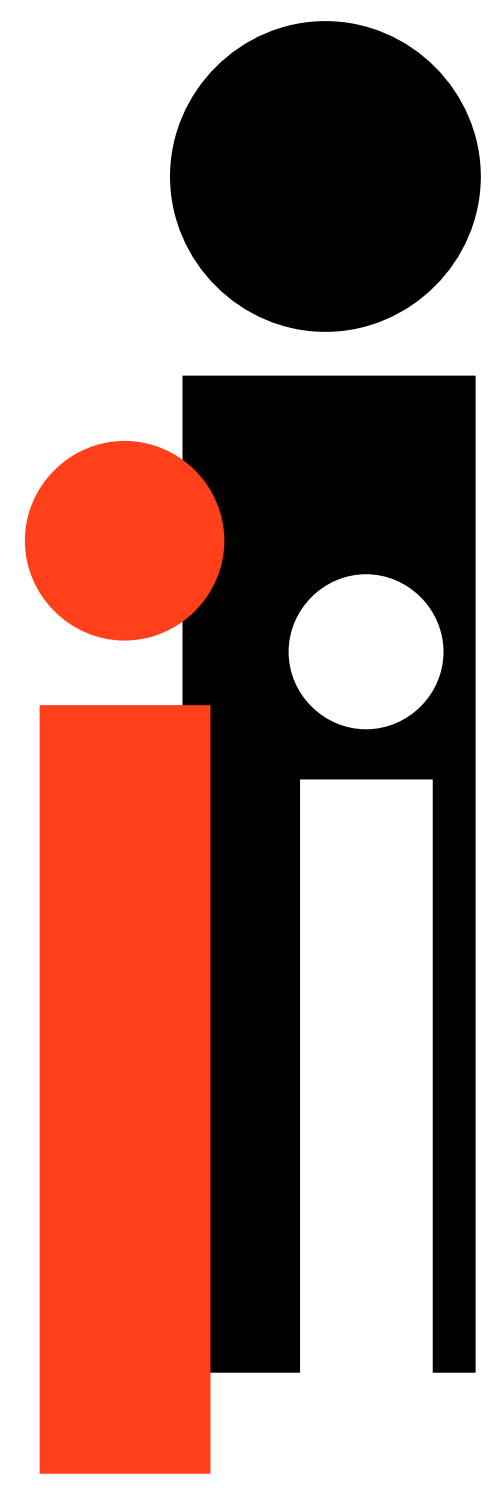

INSTITUTE FOR SOCIAL \& ECONOMIC RESEARCH 


\section{Microsimulation and Policy Analysis}

\section{Non-technical summary}

This paper is prepared as a chapter forthcoming in the Handbook of Income Distribution, Volume 2 (edited by A. B. Atkinson and F. Bourguignon, Elsevier-North Holland).

Microsimulation methods are increasingly used to study the effects of policies on the income distribution contributing both to policy debates and academic literature. In general terms, microsimulation refers to modelling changes in the state or behaviour of micro-level units. We provide an overview of approaches that address questions related to the impact of taxbenefit policies on household income distribution.

We first discuss how microsimulation modelling contributes to the analysis of the income distribution more broadly, pointing out that it can enrich survey and administrative data by checking its consistency, adding further details and enhancing analytical flexibility. In addition, it provides the basis for calculating indicators that cannot otherwise be estimated directly from micro-data such as measures of work incentives, net support for children and automatic stabilisers embedded in tax-benefit systems.

We then focus more specifically on the role of microsimulation in policy evaluation. Taxbenefit models can provide information on household disposable income and its components under various policy scenarios and as such constitute a unique tool for ex ante policy analysis, though equally can be used for ex post analysis. We review the formal framework underlying such microsimulation-based decomposition analysis of income distribution and suggest a broader perspective to accommodate a wider range of applications. Our main emphasis is on static modelling methods, though we also consider extensions accounting for behavioural reactions and links with macroeconomic models. As microsimulation models are often concerned with current and future policies, we discuss various approaches to predict the income distribution given that data providing information on the current situation becomes available with a time lag, distinguishing between nowcasting and forecasting.

We emphasise the role of comparative analysis as cross-country differences in tax-benefit systems and population structures provide a basis to assess the robustness of results and generalise conclusions. We provide empirical illustrations drawing mainly on analysis using the EU-wide tax-benefit model EUROMOD. Covering 27 countries and made generally accessible this is now one of the most widely used models.

There are many remaining challenges to providing estimates of the effects of policy and policy changes that can be used with confidence within policy analysis and we consider three major issues: reconciling the simulated income distribution and that measured using the original micro-data; accounting for benefit non take-up and tax non-compliance, as well as validating and assessing the statistical reliability of microsimulation estimates.

While our main focus is on the distribution of household disposable income and its components at the national level, we also discuss approaches which extend the scope of modelling in various dimensions. We review attempts to obtain a broader measure of income by including non-cash benefits and indirect taxes; highlight the main modelling features of dynamic (longitudinal) modelling to capture long-term impacts of policies; and consider the use of microsimulation to explore the effects of policies at sub- and supra-national level.

We conclude by summarising our view of the achievements of microsimulation for policy analysis to date and by exploring the outlook for future developments along two dimensions: the need for data improvements and methodological developments; and the need to consider ways to organise development, maintenance and access to microsimulation models for policy analysis purposes. 


\title{
Microsimulation and Policy Analysis*
}

\author{
Francesco Figari $^{\mathrm{a}, \mathrm{b}}$, Alari Paulus ${ }^{\mathrm{b}}$ and Holly Sutherland ${ }^{\mathrm{b}}$ \\ ${ }^{\text {a }}$ University of Insubria \\ ${ }^{\mathrm{b}}$ Institute for Social and Economic Research (ISER), University of Essex
}

\begin{abstract}
We provide an overview of microsimulation approaches to assess the effects of policy on the income distribution. We focus mainly on the role of tax-benefit policies and review the concept of microsimulation and how it contributes to the analysis of the income distribution in general and policy evaluation in particular. We consider the main challenges and limitations and discuss directions for future developments.
\end{abstract}

JEL: C81, D31, H30, I30

Keywords: Microsimulation models, Income distribution, Tax-benefit policies

* A chapter forthcoming in the Handbook of Income Distribution, Volume 2 (edited by A. B. Atkinson and F. Bourguignon, Elsevier-North Holland). We wish to thank Tony Atkinson, François Bourguignon and Brian Nolan for their comments and suggestions on early drafts of this chapter. We are also grateful to Paola De Agostini, John Creedy, Mathias Dolls, Carlo Fiorio, Horacio Levy, Marcello Morciano, Andreas Peichl, Iva Tasseva and Alberto Tumino for comments and useful discussions, information or permission to make use of their analysis. Paulus and Sutherland acknowledge support for this work from the core funding of the Research Centre on Micro-Social Change by the UK Economic and Social Research Council (grant RES-518-28-001). 


\section{Table of contents}

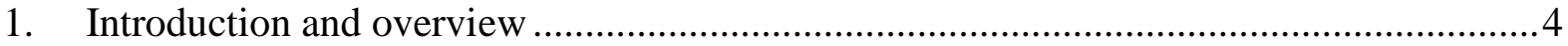

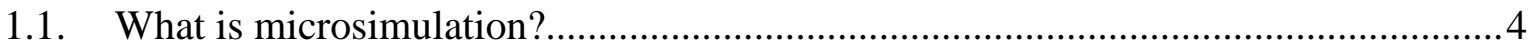

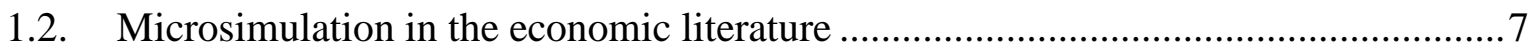

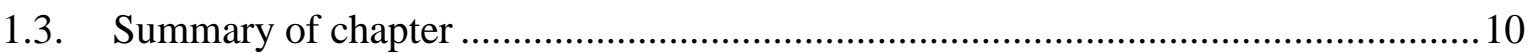

2. What does microsimulation add to analysis of the income distribution and re-

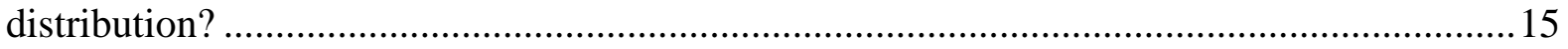

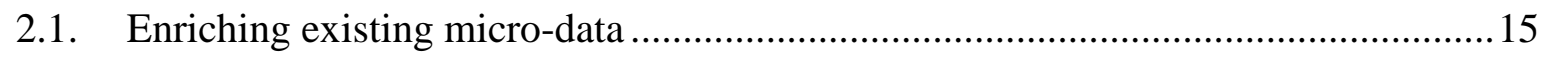

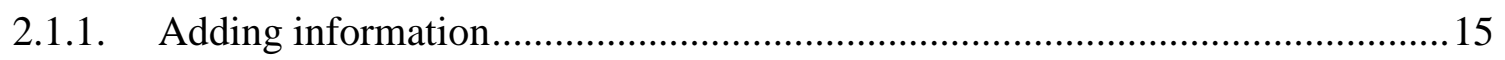

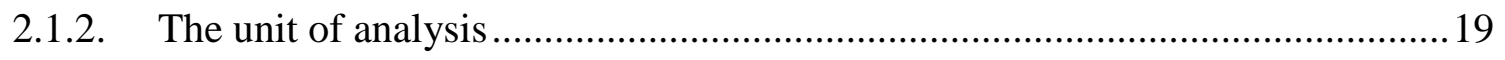

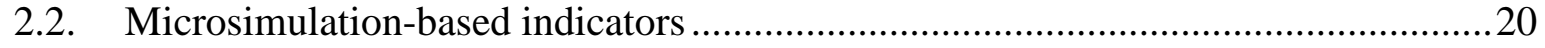

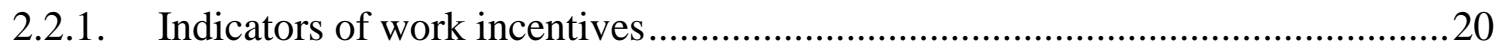

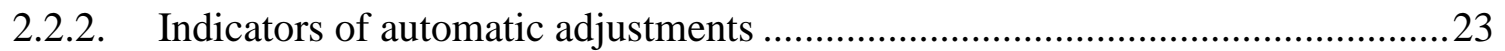

2.2.3. Indicators of household composition effects ................................................26

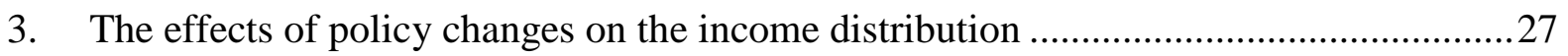

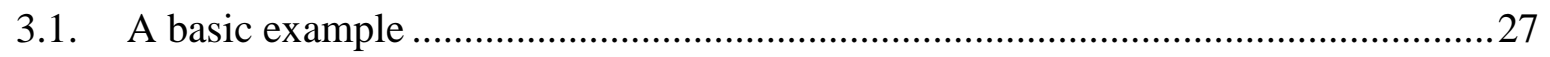

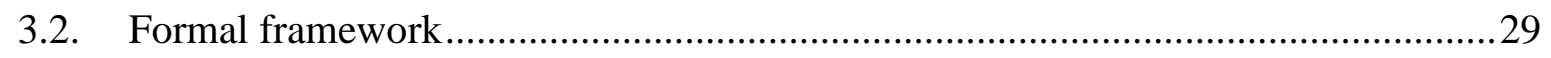

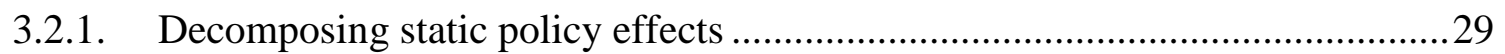

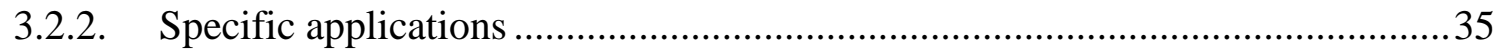

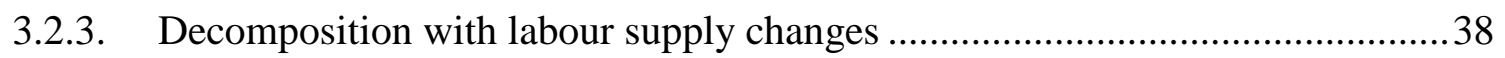

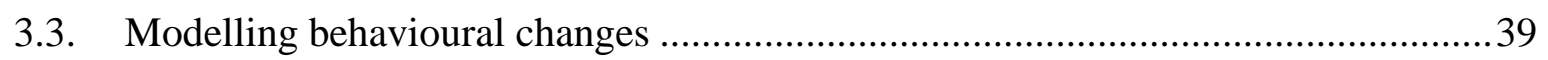

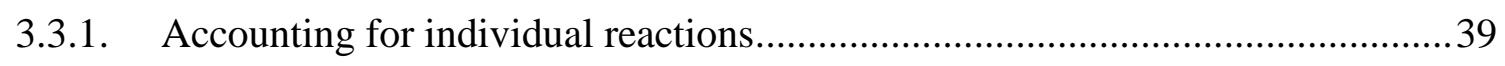

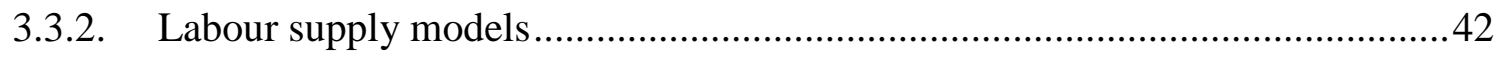

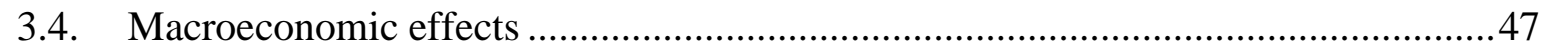

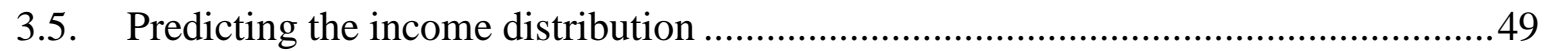

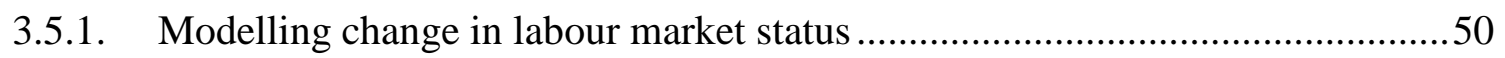

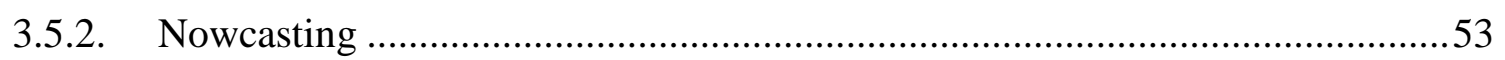

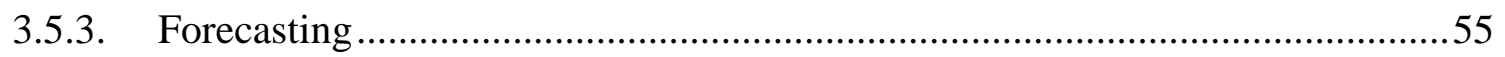

3.6. Cross country comparisons using microsimulation ............................................57

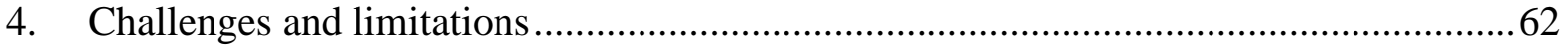

4.1. Reconciling simulated income with recorded income and macro statistics.............62

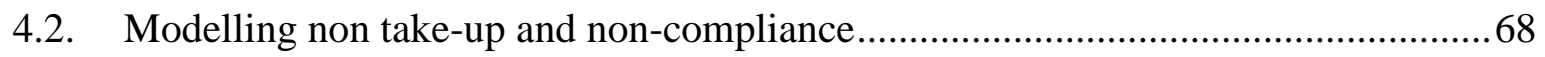


4.3. Assessing the reliability of microsimulation estimates .74

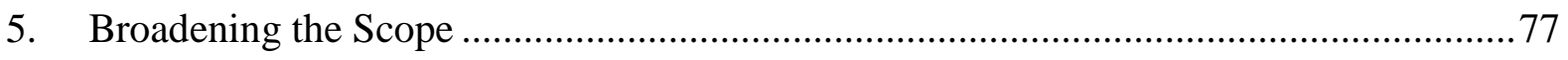

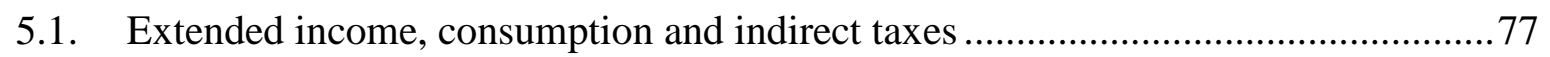

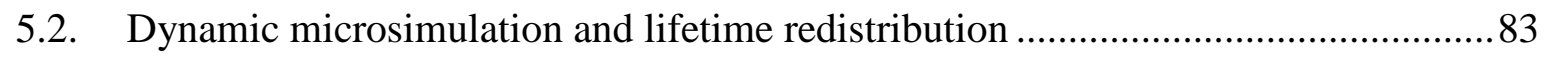

5.3. Crossing boundaries: sub- and supra- national modelling ...................................... 86

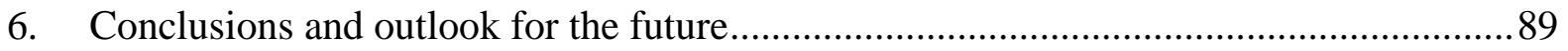

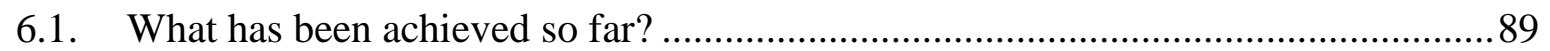

6.2. Data and methodological developments ......................................................... 92

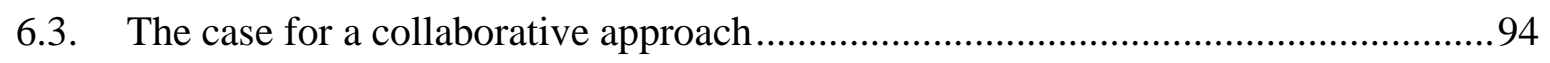

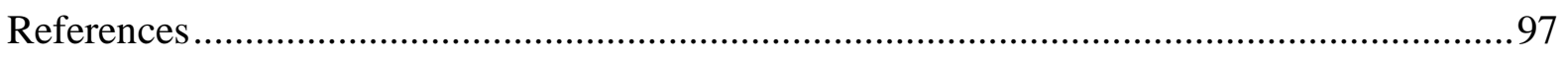

Appendix A: Increasing UK Child Benefit in 2001 and 2013: the net effects .....................114

Appendix B: Comparison of simulated estimates of income tax with administrative statistics,

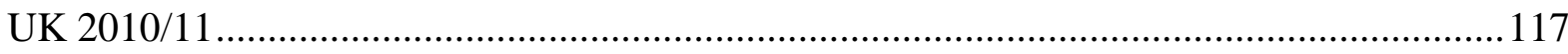




\section{Introduction and overview}

\subsection{What is microsimulation?}

Microsimulation methods are increasingly used to evaluate the effects of policies on the income distribution. Microsimulation is a term used to describe a wide variety of modelling techniques that all operate at the level of individual units (such as persons, firms or vehicles) to which a set of rules is applied to simulate changes in state or behaviour. These rules may be deterministic or stochastic, with the result being an estimate of the outcomes of applying these rules, possibly over many steps and taking account of many interactions. These estimates are also at the micro-level, allowing analysis of the distribution of the outcomes and changes to them, as well as the calculation of any relevant aggregate. ${ }^{1}$

Microsimulation models in the social sciences were pioneered in the 1950 s by Guy Orcutt and his colleagues as a new approach to analysing the impact of social and economic policies which took account of the characteristics and behaviour of the micro-level units under investigation (Orcutt, 1957; Orcutt et al., 1961). Microsimulation is commonly applied to many areas of public policy-relevance such as, for example, transportation, the location planning for public services and commercial developments, and demand for health care and long-term care. ${ }^{2}$ The microsimulation approaches considered here are those that primarily address questions related to the impact of tax-benefit policies on income distribution. Models simulating the effects of social and fiscal policies on household income were first developed in the 1980s when the essential inputs - micro-data from household surveys and accessible computing power - began to be made available.

\footnotetext{
1 Adapted from the definition provided by the International Microsimulation Association (http://microsimulation.org/). Broadly speaking, microsimulation modelling could also cover agent-based simulation (ABS), though they have remained very distinct fields in the literature with microsimulation methods drawing heavily on micro-data (Spielauer, 2011).

${ }^{2}$ There are extensive literatures covering each area. See for example Dowling et al. (2004), Waddell et al. (2003) and Gupta and Harding (2007).
} 
These early tax-benefit microsimulation models were arithmetic, re-calculating the components of household disposable income (usually cash benefits, direct taxes and social contributions) for each household in a representative micro-dataset under different sets of policy rules. They could answer "what if" questions about the effects of specific policy reforms on each household's income and hence on the overall income distribution, and on the aggregate public budget. Some early studies include Atkinson et al. (1983) and Betson et al. (1982). They could also readily be used to calculate indicators of work incentives on the intensive margin (Atkinson and Sutherland, 1989; Bourguignon et al., 1993). Since then this "static" modelling approach has not only proliferated but also been refined in a number of directions with developments in data availability, methodology, speed and capacity of accessible computing power and the demands made by policy making and policy analysis each playing a role.

Microsimulation models are often categorised as "static", "dynamic" or "behavioural" (see for example, Harding 1996a). The first type applies purely deterministic policy rules on micro-data in combination with data adjustments such as re-weighting. The characteristics of the micro units stay constant. Dynamic models, on the other hand, "age" the micro units through time, changing their characteristics in response to natural processes and the probabilities of relevant events and transitions ( $\mathrm{Li}$ and O'Donoghue, 2013). Behavioural models use micro-econometric models of individual preferences to estimate the effects of policy changes on behaviour, often in terms of labour supply. In practice the distinction between modelling approaches is no longer necessarily useful as much modern microsimulation analysis combines elements of each type, according to the question being addressed. For example, labour supply models require the calculation of budget sets (household income under alternative labour supply scenarios) for individuals and these are usually generated by static tax-benefit models. Behavioural reactions, as well as static 
calculations, are relevant in dynamic micro-simulations. In seeking to simulate the effects of policy changes in a variety of economic environments, so-called static models may borrow elements of dynamic model methodology and in seeking to simplify the dynamic modelling process, the reverse can also be true (Caldwell, 1990). Dynamic models in practice mainly address questions about the effects of policies that take time to evolve such as pensions (e.g. Borella and Coda Moscarola, 2010; Dekkers et al., 2010; Flood, 2007) and long term care reform (e.g. Hancock, 2000; Hancock et al., 2013), often focusing on the cost, gainers and losers, as well as questions about intra-personal redistribution over the lifecycle (Harding, 1993).

Without tax-benefit microsimulation modelling, and before it was widespread, analysis of the effects of taxes and benefits on household income, and calculation of work incentive indicators, was limited to "model family" calculations for stylised households, sometimes referred to as "tax-benefit models". These calculations, still carried out by the OECD for the purpose of making cross-country comparisons (OECD, 2012), although useful for understanding the net effects of policies in particular standardised cases, are not informative about the impact on the income distribution.

The aim of this chapter is to provide an overview of microsimulation approaches to explore the effects of policy on the income distribution, and highlight some particular state-of-the-art or innovative studies that have been carried out. The main emphasis is on static modelling methods, though we also consider extensions accounting for behavioural reactions (section 3.3) and highlight the main modelling features of dynamic modelling (section 5.2), referring to the existing reviews. We have not attempted a comprehensive review of the models themselves. Their proliferation would make such a task not only daunting, but quickly out-ofdate. There are already a number of reviews and collections describing both models and analysis using them, a selection of which we summarise below. 


\subsection{Microsimulation in the economic literature}

There are several distinct motivations for using a microsimulation model to simulate the impact of a given policy on the income distribution. Microsimulation can be used to quantify the role of existing policies on income inequality or poverty in a given context. More importantly, it is a tool to aid the design of new policies with particular objectives and to evaluate actual or proposed reforms in dimensions that were not taken into account in the original design. Moreover, it can also be used to show how alternative approaches could result in better outcomes in some respect. From a practical policy perspective, one of the main uses of microsimulation modelling for the design of policy by policymakers is to assess the approximate budgetary cost of a new policy given its objectives, e.g. the desire to reduce the poverty gap or to increase work incentives for particular groups. Such analysis rarely sees the light of day except in its final form: as a costed reform proposal.

Evidence from microsimulation modelling is also used to inform academic economic debates about the impact of policy reforms and the optimal design of policy (Blundell, 2012). In general terms, a microsimulation approach allows the research to conduct a "controlled experiment" by changing the parameters of interest while holding everything else constant and avoiding endogeneity problems in identifying the direct effects of the policy under analysis (Bourguignon and Spadaro, 2006). The use of tax-benefit microsimulation models to calculate counterfactual states and scenarios underpins much micro-economic analysis of the causal impact of fiscal policy reforms. A prime example is the use of the Institute of Fiscal Studies tax-benefit microsimulation model, TAXBEN for the UK, to provide empirical evidence for the arguments about tax design put forward in the authoritative Mirrlees Review (2010). Moreover, the counterfactuals shed light on the potential ingredients of optimal tax analysis which cannot be derived in a quasi-experimental setting. This is demonstrated by the 
developments of the computational optimal income taxation theory, applied by Aaberge and Colombino (2013) to Norway and Blundell and Shepard (2012) to the UK.

Microsimulation modelling is increasingly recognised as part of the policy evaluation literature, where it is one of the key ingredients of a careful, evidence-based evaluation of the design of tax-benefit reforms. While this literature in general has been more focused on expost analysis, Keane (2010) and Blundell (2012), among others, have underlined the need to consider both ex-ante and ex-post approaches to study the effects of policy changes. In this context, tax-benefit microsimulation models can offer insights in two ways. First, they are the unique tool to conduct ex-ante analysis through the simulation of the counterfactual scenarios reflecting alternative policy regimes. Such counterfactuals are needed both for the "morningafter" evaluation of tax-benefit reforms and for more complex structural models which reveal individual behavioural changes based on simulated budget constraints and an estimated model of individual and family choices (see section 3.3). Second, by developing a counterfactual scenario, tax-benefit microsimulation models enable the researcher to disentangle ex-post what would have happened without a given policy. Although ex-post analysis is typically conducted by means of quasi-experimental approaches, based on difference-in-difference, matching and selection estimators, the cross-fertilisation between ex-ante and ex-post approaches has contributed to the increasing credibility of analysis based on detailed microsimulation models, making them a core part of the causal policy evaluation literature. A prime example is the quasi-experimental analysis used to validate structural models of labour supply which use microsimulation models to derive the budget sets faced by individuals (see, among others, Blundell, 2006).

Furthermore, microsimulation features in the strand of literature that involves micro-macro linkage, aiming to measure the effects of macro-economic changes (including macroeconomic policy) on the income distribution. More specifically, the linkage of 
microsimulation models to macro-economic models allows one to consider the interactions of macroeconomic policies or shocks with the tax-benefit systems (see section 3.4). Ignoring the tax-benefit policy effects on income distribution can be justifiable in some circumstances, for example when analysing their impact in developing countries because they may be very limited in size and reform to social expenditures or macro-economic shocks could be much more relevant for re-distribution, but it is more problematic in the context of mature welfare states (Bourguignon and Bussolo, 2013).

The literature on microsimulation has expanded enormously in the last twenty years along with the spread and development of this methodology. An attempt to cover all relevant publications would be a daunting task and, therefore, we aim to provide some of the most important methodological references with relevant illustrations in the rest of this chapter. For further and broader material, we refer the reader to a number of reviews and workshop and conference volumes which provide good surveys, both of applications of models and of models themselves, and reflect well how the state-of-art modelling has evolved since the beginning of the 1990s: Harding (1996b), Gupta and Kapur (2000), Mitton et al. (2000), Gupta and Harding (2007), Harding and Gupta (2007), Lelkes and Sutherland (2009), Zaidi et al. (2009), Dekkers et al. (2014), O’Donoghue (2014). ${ }^{3}$ For surveys of models themselves, see Merz (1991), Sutherland (1995), Klevmarken (1997), Gupta and Kapur (2000), O’Donoghue (2001), Zaidi and Rake (2001), Gupta and Harding (2007), Urzúa (2012), Li and O'Donoghue (2013). In addition, there are several books focusing on specific models, as such providing excellent examples of opening the 'black box' often associated with complex economic models. For example, Harding (1993) describes the details of her dynamic cohort microsimulation model used to evaluate lifetime income distribution and redistribution for Australia, Redmond et al. (1998) provide an extensive discussion of inner workings of

\footnotetext{
${ }^{3}$ For older conference volumes and reviews, see literature references given in these collections.
} 
POLIMOD, a static tax-benefit model for the UK, and Bargain (2007) offers a collection of applications using EUROMOD, the EU tax-benefit model. Furthermore, the microsimulation community established the International Microsimulation Association (IMA) in 2005 and since 2007 it has been possible to follow the latest developments in the field with the International Journal of Microsimulation, a refereed online journal published under the auspices of the IMA. ${ }^{4}$

\subsection{Summary of chapter}

The remainder of this chapter is structured as follows. Before getting into the ways in which microsimulation can be used to understand the effects of policy changes, section 2 describes how it can also be useful in improving the existing information available for the analysis of income distribution and re-distribution. Simulated estimates of tax liability and benefit entitlement can be used alongside the values recorded in survey and administrative microdatasets, to understand and improve on the deficiencies in the latter (e.g. to impute gross income from net if the former is not available or measured satisfactorily in the source data). Furthermore, indicators that cannot be collected in surveys or through administrative processes but are of value in understanding the relationships between policy and income distribution, such as indicators of work incentives, can be calculated using microsimulation models.

Throughout the chapter we provide some empirical illustrations drawing mainly on analysis using the EU-wide tax-benefit model EUROMOD (Sutherland and Figari, 2013). Covering 27 countries and made generally accessible this is now one of the most widely used models. We have chosen to highlight EUROMOD at least partly because it is generally available to

\footnotetext{
${ }^{4}$ See http://www.microsimulation.org/ijm/
} 
use, and readers can relatively easily reproduce, update and extend the examples of analysis included in this chapter. More information about EUROMOD is provided in Box 1.

The primary motivation for building a tax-benefit microsimulation model is to be able to analyse the effects of policy changes on income distribution. Section 3 starts with a description of the basic process and explains the need to carry out micro-level calculations in order to capture the effects due to the complexity of tax-benefit systems. However, in any microsimulation analysis there are choices over which dimensions to focus on and which to hold constant. Most studies do not set out their specific choices in formal terms. Section 3.2 provides a formal framework applicable to most tax-benefit microsimulation analysis. The following four sub-sections focus on some of the major and commonly-applied extensions to the basic approach. Section 3.3 discusses how individual behavioural responses to policy changes are estimated and focuses particularly on labour supply responses. This is followed in section 3.4 by a review of the ways changes in income distribution can be linked to macroeconomic processes. Section 3.5 covers the use of microsimulation, in conjunction with macro-level statistics or forecasts, to provide estimates of income distribution for periods beyond those covered by the latest micro-data. These projections might be for the current situation ("nowcasting") or sometime in the future (forecasting). Finally, section 3.6 focuses on the ways in which microsimulation can be used to inform cross-country comparisons of the effects of policies. 


\section{Box 1: EUROMOD - a tax-benefit microsimulation model}

EUROMOD is the tax-benefit microsimulation model of the European Union. It simulates individual and household tax liabilities and cash benefit entitlements according to the policy rules in place, and reforms to them, in each member state. It has two main distinguishing features. First, it covers many countries within the same framework enabling a wide range of applications and comparability of results. Generally, EUROMOD is much more flexible than national microsimulation models in order to ensure consistency of results and transferability of tax-benefit system components across countries. Secondly, it is intended to be openly accessible: use is not restricted to the owners of the model. These special features justify our use of EUROMOD analysis to provide many of our empirical illustrations. The calculations carried out by EUROMOD for any one country are in other respects quite typical of all tax-benefit microsimulation models, at least for developed countries. The description below is therefore generally applicable.

EUROMOD combines information on policy rules with detailed and nationally representative micro-data on individual and household circumstances drawn from household income surveys and other data sources. The rules for each policy instrument are applied arithmetically to the characteristics of each individual, resulting in the amount of tax liability or benefit entitlement. For example, in the case of the simplest universal child benefit, the number of children within the eligible age range in the family is counted and the benefit amount per child is multiplied by this number to give the family's entitlement. Further issues complicate the calculation: "child" and "family" need to be defined and the interaction of the child benefit amount with the rest of the tax-benefit system needs to be accounted for. This illustrative calculation is taken further in Appendix A by considering the effects of a change in policy. The two alternative child benefit entitlements and resulting measures of household disposable income can be compared.

The results of the calculations for each household are stored at the micro level and can be analysed with any statistical software. At their simplest they may be weighted to population level and the weighted change in income can be added up to provide an estimate of the budgetary effect of the policy change, or it can be analysed in relation to any characteristics provided in the data: for example to show the proportion of households gaining and losing by income quantile, region or household type. The micro-outputs from alternative policy or labour market scenarios can also be used as the basis for calculating indicators of work incentives or for modeling changes in labour supply or other behavior.

EUROMOD aims to simulate as much as possible of the tax and benefit components of household disposable income and generally, the following instruments are simulated: income taxes, social insurance contributions, family benefits, housing benefits, social 
assistance and other income-related benefits. Instruments which are not simulated are taken directly from the data. These include most contributory benefits and pensions (due to the lack of information on previous employment and contribution history) and disability benefits (because of the need to know the nature and severity of the disability, which is also not present in the data).

EUROMOD input data for most countries are derived from the European Union Statistics on Income and Living Conditions (EU-SILC). In common with most sources of micro-data used as input into microsimulation models, the EU-SILC was not designed for this purpose (Figari et al., 2007). A significant amount of preparation of the data, including imputing necessary information that is missing, needs to be done. For example, if gross income values are not directly recorded during the data collection operations and are imputed in an unsatisfactory way, a net-to-gross procedure is applied to the net income variables in order to derive the gross values used in the policy simulation.

EUROMOD includes some simple adjustments for the non take-up of some benefits and evasion of taxes in some countries. In common with other adjustments and assumptions (e.g. the updating of non-simulated incomes to a more recent point in time than the data income reference point) these can be changed or "switched off" by the user, depending on the analysis being done.

Baseline systems in EUROMOD have been validated and tested at micro level (i.e. case-bycase validation) and macro level. For each system simulated in EUROMOD Country Reports are available on the EUROMOD web pages with background information on the tax-benefit system(s), a detailed description of all tax-benefit components simulated, a general overview of the input data and an extended summary of the validation process.

For more information about EUROMOD and its applications, see the official website (https://www.iser.essex.ac.uk/euromod) and Sutherland and Figari (2013). 
Of course, there are many remaining challenges to providing estimates of the effects of policy and policy changes that can be used with confidence within policy analysis, and Section 4 considers three major ones. First, section 4.1 considers the issues about reconciling the simulated income distribution and that measured using the original micro-data (from surveys particularly, but also administrative sources). A major difference between the two distributions can undermine confidence in microsimulation results but has a number of interrelated causes, some of which can point to problems in survey data (e.g. income underreporting), and can be mitigated using information from simulations, and others which cannot (e.g. small and unrepresentative samples of high income earners). Simulations can overestimate income if the non-take-up of benefits is not accounted for and also distorted if there is tax evasion. These issues, and how they may be accounted for in microsimulation models, are discussed in section 4.2. Finally it is important that the reliability of microsimulation estimates is possible to ascertain. This applies both in terms of how well point estimates match up to information from other sources ("validation") and the need for statistical reliability indicators that can be applied to microsimulation estimates. Section 4.3 considers these issues.

While the main focus of this chapter is the contribution to policy analysis of (direct) tax and (cash) benefit microsimulation of household incomes at the national level at a given point in time, section 5 considers a somewhat broader scope, in some dimensions. Section 5.1 discusses a broadening of the outcome income measure to include the effect of non-cash benefits and, particularly, indirect taxes. Section 5.2 reviews the main features of dynamic microsimulation models, used in analysing the long-term redistributive effects of policies and the incidence of tax-benefit systems over the lifetime rather than cross-sectionally at a point in time. Section 5.3 discusses the use of microsimulation to explore the effects of policies at a 
lower level than that of the nation (e.g. Spanish regions or US states) and at a higher level (e.g. the European Union, or world regions such as southern Africa).

The final section concludes by first summarising our view of the achievements of microsimulation for policy analysis to date, and then by exploring the outlook for the future along two dimensions: the need for data improvements and methodological developments; and the need to consider ways to organise development, maintenance and access to microsimulation models for policy analysis purposes.

\section{What does microsimulation add to analysis of the income distribution and re-distribution?}

\subsection{Enriching existing micro-data}

While the most obvious application of the microsimulation method is assessing the effects of tax-benefit policy changes on income distribution, it can be also useful for analysing the existing income distribution and redistribution. Compared to research on income distribution utilising only survey or administrative data directly, fiscal microsimulation can complement and improve such analysis by (i) adding further information, (ii) checking the consistency of the collected data, and (iii) allowing for greater flexibility with respect to the unit of analysis.

\subsubsection{Adding information}

Simulations allow data to be generated which may be difficult or too expensive to collect directly or accurately from individuals. A common use of microsimulation in the processing of income survey data is deriving gross incomes from the net values that are collected, or vice versa. Compared to other methods such as statistical imputation, this takes into account the full details of the tax-benefit rules that are applicable for a given individual or household. Hence it provides more accurate results, but may also require more effort to develop and keep 
up-to-date. Specific microsimulation routines are often built for this purpose. Among others see Betti et al. (2011) on the Siena Microsimulation Model which is used for conversions between net and gross income variables for several countries in the European Union Statistics on Income and Living Conditions (EU-SILC) survey and Jenkins (2011) on the derivations of net income variables for the British Household Panel Survey (BHPS).

Such gross-to-net conversion routines naturally follow the logic of full-scale tax-benefit models, though may still have notable differences. For example, tax-benefit models typically deal with the final tax liability (i.e. aiming to account for all tax concessions and considering the total taxable income) while taxes withheld on specific income sources are often more relevant for gross/net adjustments in a survey. For net-to-gross conversions, there are two microsimulation-related approaches. One is to apply inverted statutory tax rules and the other to use gross-to-net routines in an iterative procedure to search for the corresponding gross value for a given net income, as suggested in Immervoll and O'Donoghue (2001). The first approach can be more straightforward if tax rules are relatively simple and analytical inversion is feasible, while the second approach allows the use of already existing tax-benefit models. The latter approach has also been used in the Siena model and related applications, e.g. Rodrigues (2007).

If a tax-benefit model is applied to income data which contain imputed gross values, it is important to ensure that the net-to-gross conversion is consistent with the tax-benefit model calculations as otherwise simulated net incomes will not match the observed values. This source of bias is easy to overlook and consistency often difficult to establish as the documentation of net-to-gross derivations carried out by survey data providers often lacks sufficient details for tax-benefit modelling purposes. 
Microsimulation methods can be also used to obtain more detailed tax information compared to what is usually available in the surveys (if any at all). For example, the Current Population Survey (CPS), one of the main household surveys in the US, provides such information through the Annual Social and Economic Supplement (ASEC) which includes simulated direct taxes and imputed employer's contributions for health insurance (Cleveland, 2005). Alternatively, surveys could be combined with detailed tax information from administrative records, though in practice this is still underdeveloped due to limitations on access to administrative records. Furthermore, microsimulation models can extend the scope of income information by simulating employer social insurance contributions and indirect taxes which are usually not captured in income (and expenditure) surveys, even though their economic incidence is typically considered to be borne by individuals (Fullerton and Metcalf, 2002) and hence relevant for welfare analysis.

Although benefit information tends to be more detailed in income surveys, there are applications where microsimulation methods can still provide further insights. Specifically, microsimulation allows the assessment of the intended effect of transfers (by calculating benefit eligibility) and contrast it with reported outcome (i.e. observed benefit receipt), which is influenced by individual compliance behaviour (see more in section 4.2) and the effectiveness of benefit administrations, among other factors.

Overall, it is of course possible to carry out analysis of the redistributive effect of taxes and benefits only using survey information directly. For example, Mahler and Jesuit (2006) and Wang et al. (2012) use household survey data from the Luxembourg Income Study (LIS) to analyse redistributive effects in the OECD countries and Fuest et al. (2010) and Atta-Darkua and Barnard (2010) use the SILC data for EU countries. However, microsimulation methods can often add to the scope and detail of the analysis, e.g. Immervoll et al. (2006a), Paulus et al. (2009), Jara and Tumino (2013) use tax and benefit data simulated with EUROMOD for 
EU countries, and Kim and Lambert (2009) analyse redistribution in the US on the basis of the CPS/ASEC. Wagstaff et al. (1999) specifically analyse the progressivity of personal income taxes in the OECD countries using also the LIS data, while Verbist and Figari (2014) carry out similar analysis for EU countries relying on EUROMOD simulations, allowing them to extend the analysis with social insurance contributions as well. Piketty and Saez (2007) use the TAXSIM ${ }^{5}$ model to compute US federal individual income taxes and analyse their progressivity. Furthermore, Verbist (2007) employs EUROMOD to consider the distribution and redistributive effects of replacement incomes taking into account interactions with taxes and social contributions, and Hungerford (2010) uses simulations to examine certain federal tax provisions and transfer programs in the US. Decoster and Van Camp (2001), O’Donoghue et al. (2004) and Decoster et al. (2010) are examples of studies simulating and analysing the effects of indirect taxes across the distribution of income.

Microsimulation can help to detect inconsistencies and potential measurement errors in the existing data. An obvious example is cross-checking whether gross and net income values (if both are reported) correspond to each other (see section 2.1.1). As benefit income tends to be underreported in survey data (Lynn et al., 2012; Meyer et al. 2009), use of simulated benefits has the potential to improve the accuracy of income information (see more in section 4.1). However, it needs to be born in mind that the quality of input data is also critical for the simulated results themselves and there could be other reasons for discrepancies between observed and simulated income apart from underreporting (see Figari et al., 2012a).

\footnotetext{
5 TAXSIM is the NBER microsimulation model that calculates US federal and states income taxes (http://www.nber.org/taxsim/). It covers the federal tax system from 1960 and the state systems from 1977 up to the current year. Model calculations are done in the TAXSIM server on the basis of survey data provided by the users in the required format containing different sources of income, deductions and personal characteristics used to calculate tax liabilities. The program, written in FORTRAN, reads the input data sent by the user through a web application, calculates tax liabilities and loads the results on the user's computer. Recent applications are based on the March Current Population Survey, the Survey of Consumer Finance, the Consumer Expenditure Survey and the Panel Study of Income Dynamics, and a library of scripts used to derive the input data from different sources is made available by previous users. See Feenberg and Coutts (1993) for more information.
} 


\subsubsection{The unit of analysis}

Microsimulation can also offer some flexibility in the choice of unit of analysis. In any analysis of distribution, the unit of measurement is an important issue. Income is often measured at the household level, aggregating all sources across all individuals. Income surveys may not facilitate analysis at a lower level (e.g. aggregating within the narrow family or the fiscal unit) because some or all income variables are provided only at the household level. This is the case, for example, for the micro-data provided by Eurostat from the European Statistics on Income and Living Conditions (EU-SILC). However, considering the effect of policy on the incomes of sub-units within households may be relevant in a number of ways. The assumption of complete within-household sharing of resources deserves to be questioned, and its implications made clear. For example, assessments of poverty risk among pension recipients might look quite different if it were not assumed that they shared this income with co-resident younger generations, and vice versa. Furthermore, it may be particularly relevant to consider the effects of policy in terms of the particular unit of assessment, rather than the household as a whole. Minimum income schemes use a variety of units over which to assess income and eligibility and these are often narrower than the survey household. A flexible microsimulation model is able to operate using a range of units of analysis as well as units of assessment and aggregation, since they are able to assign income components, or shares of them, to the relevant recipient units within the household. Examples of microsimulation studies that consider units of analysis apart from the household are Decoster and Van Camp (2000) in relation to tax incidence at the household or fiscal unit level, Figari et al. (2011a) who analyse income within couples, and Bennett and Sutherland (2011) who consider the implications of means-testing at family-unit level for receipt of benefit income by individuals. 


\subsection{Microsimulation-based indicators}

The microsimulation method is also used to construct various indicators to measure the extent to which household disposable income reacts to changes in gross earnings or individual or household characteristics through interactions with the tax-benefit system. The two main groups of such indicators reflect individual work incentives and automatic adjustment mechanisms built into fiscal systems. This subsection gives an overview of these indicators and provides some examples, while a more formal presentation can be found in section 3.2.

\subsubsection{Indicators of work incentives}

Marginal effective tax rates and participation tax rates are indicators of work incentives for the intensive (i.e. work effort) and the extensive labour supply margin (i.e. decision to work), respectively. Marginal effective tax rates (METR) reflect the financial incentive for a working person to increase his work contribution marginally either through longer hours or higher productivity (increasing the hourly wage rate). They show the proportion of additional earnings which is taxed away, taking into account not only the personal income tax but also social contributions as well as interactions with benefits, e.g. withdrawal of means-tested benefits as private income increases. As such, METRs indicate more accurately the actual tax burden on additional income compared to statutory marginal income tax rates. Given that taxes and benefits form a complex non-linear system, it is usually not feasible to obtain METRs in the form of analytical derivatives of the overall tax-benefit function. Instead, METRs are estimated empirically by incrementing gross earnings of an employed person by a small margin (e.g. $1 \%$ to 5\%) and re-calculating disposable income, see Immervoll (2004), Adam et al. (2006b), Jara and Tumino (2013). Figure 1 provides an example from the last of these showing the extent to which average METRs and their distributions vary across the 
European Union. ${ }^{6}$ The scope of these calculations is usually limited to direct taxes and (cash) benefits and current work incentives, though there are also extensions accounting for consumption taxes and taking a life-cycle labour supply perspective, see Kotlikoff and Rapson (2007). Graphically, METRs can be illustrated with a budget constraint chart which plots net income against gross earnings (or hours worked), see e.g. Adam et al. (2006b) and Morawski and Myck (2010), as the slope of this line corresponds to $1-M E T R$, i.e. the proportion of additional gross earnings retained by the individual.

Figure 1. Marginal effective tax rates across the EU, 2007 (\%)

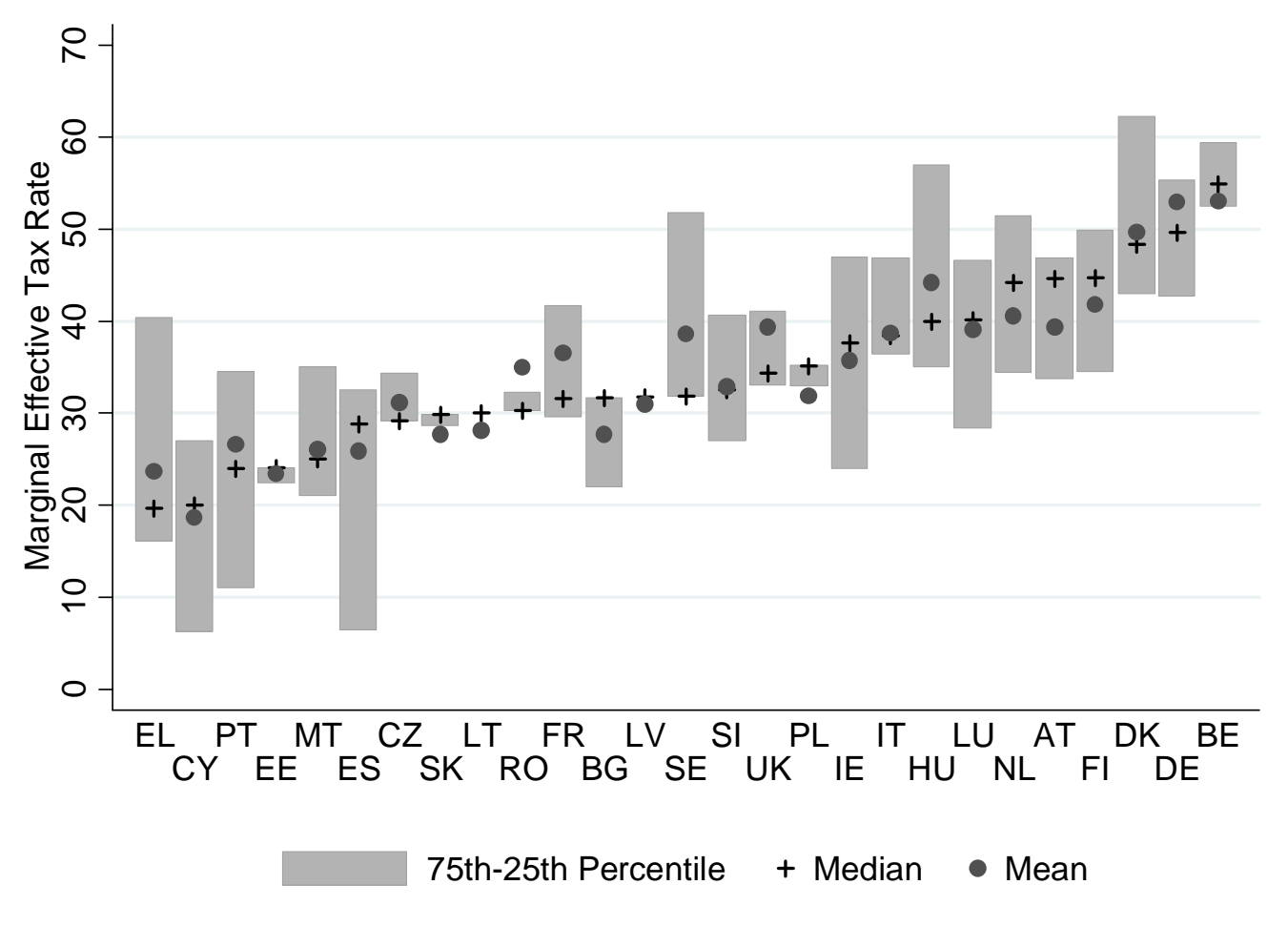

Notes: Countries are ranked by median METR. Source: Jara and Tumino (2013) using EUROMOD.

Participation tax rates (PTR) are conceptually very similar, indicating the effective tax rate on the extensive margin, i.e. the proportion of earnings paid as taxes and lost due to benefit

\footnotetext{
${ }^{6}$ In Figure 1 and elsewhere we use the official country acronyms for the EU countries. These are (using the official country ordering): Belgium (BE), Bulgaria (BG), Czech Republic (CZ), Denmark (DK), Germany (DE), Estonia (EE), Ireland (IE), Greece (EL), Spain (ES), France (FR), Italy (IT), Cyprus (CY), Latvia (LV), Lithuania (LT), Luxembourg (LU), Hungary (HU), Malta (MT), Netherlands (NL), Austria (AT), Poland (PL), Portugal (PT), Romania (RO), Slovenia (SI), Slovakia (SK), Finland (FI), Sweden (SE), United Kingdom (UK).
} 
withdrawal if a person moves from inactivity or unemployment to work. METRs and PTRs are typically between $0 \%$ and $100 \%$, with higher rates implying weaker incentives to work (more). Because of non-linearities and complex interactions in the tax-benefit systems, however, individuals facing greater than $100 \%$ (or negative) tax rates may be also found. These often expose unintended effects built into the tax-benefit system. More generally, relatively high values indicate situations which can constrain labour supply and trap people at certain income/employment levels. Marginal effective tax rates and participation tax rates are hence useful indicators to assess whether the tax-benefit system may limit employment for certain individuals. These are also central parameters in assessing optimal tax design, see Immervoll et al. (2007) and Brewer et al. (2010) for empirical applications. Figure 1 illustrates how in many countries there is a considerable spread in the value of the METRs even before considering the extremes of the distributions. This demonstrates how an analysis using work incentive indicators based on calculations for average or representative cases may be quite misleading.

Replacement rates (RR) complement participation tax rates, showing the level of out-of-work income relative to in-work disposable income, see e.g. Immervoll and O’Donoghue (2004). High replacement rates also reflect low financial incentives to become (or remain) employed. Compared to METRs and PTRs, negative values are even more exceptional (though not ruled out altogether). RRs are often calculated separately for short-term and long-term unemployed to reflect differences in the level of unemployment benefits depending on unemployment duration. As work incentive indicators, PTRs and RRs are calculated for non-working persons for whom potential employment income is not observed and, hence, the latter must be either predicted or assumed. ${ }^{7}$

\footnotetext{
${ }^{7}$ For example, OECD calculates these indicators assuming various income levels in the range of 33-150\% of average (gross) production worker (APW) salary, see e.g. Carone et al. (2004).
} 
Although PTRs and RRs both describe work incentives on the extensive margin they have a different focus and characteristics (Adam et al., 2006a). For instance, if taxes and benefits are changed so that net income increases by the same amount for the out-of-work and in-work situation (e.g. corresponding to a lump-sum transfer), then the replacement rate would increase while the participation rate would remain unchanged. This is because the tax burden on additional income does not change while, in relative terms, working becomes less attractive. On the other hand, RRs remain constant if out-of-work and in-work net income increase by the same proportion (but for PTRs this is not the case).

While these three indicators are used to measure work incentives for a particular individual by changing individual gross earnings (and labour market status), the effect on disposable income is assessed at the household level as this is usually considered to be the more relevant unit of assessment for benefits and unit of aggregation when measuring living standards. ${ }^{8}$ Each measure can be also decomposed to show the effect of specific tax-benefit instruments, for example, income taxes, social insurance contributions and benefits.

\subsubsection{Indicators of automatic adjustments}

Another closely related group of indicators characterise how tax-benefit systems act as automatic stabilizers to income or unemployment shocks, i.e. the extent to which (aggregate) household income or tax revenue fluctuations are moderated without direct government action. These focus on exogenous shocks rather than individual incentives to alter labour supply. Apart from this, calculations are technically very similar to the previous group, with the main differences to do with the interpretation. ${ }^{9}$

\footnotetext{
${ }^{8}$ In principle other units of aggregation within the household could be specified.

${ }^{9}$ One technical nuance concerns the treatment of multi-person households. While work incentives are typically estimated for each household member separately, holding earnings of other household members constant, in the case of automatic stabilizers changes are simulated for all of the relevant population at once.
} 
Such estimates based on micro-data go back at least to Pechman (1973) who simulated income tax revenues in the US for 1954-1971 and showed how much tax liabilities change compared to changes in income (at the aggregate level), characterised as built-in flexibility. While this is very similar to marginal effective tax rates, the interpretation is different and focussed on the macro-level and government revenue side rather than at the individual. A closely related measure captures the elasticity of tax liability with respect to changes in incomes, i.e. percentage increase in taxes for a one percent change in income, though as Auerbach and Feenberg (2000) point out, this mainly reflects the progressivity of taxes as it does not capture whether the tax burden is high or low.

More recently, Auerbach and Feenberg (2000) estimate the aggregate change in taxes when increasing all (taxable) income (and deductions) for each individual by $1 \%$ to measure the responsiveness of tax revenues to income changes for the US. They find that over the period 1962-1995 income taxes offset between $18 \%$ and $28 \%$ of variation in before-tax income (at the aggregate level). Similarly, Mabbett and Schelke (2007) simulate a 10\% increase in individual earnings for $14 \mathrm{EU}$ countries and estimate both the responsiveness (i.e. elasticity) of various tax-benefit instruments and the overall stabilization effect of the system. The latter varies according to their estimates from $31 \%$ in Spain to $57 \%$ in Denmark.

Dolls et al. (2012) model a negative income shock where household gross incomes fall by $5 \%$ and an unemployment shock (with household income at the aggregate level decreasing also by 5\%), covering both the US and a large number of the EU countries. While the proportional income shock is distribution-neutral, the unemployment shock is asymmetric as not all households are affected. They find that tax-benefit systems absorb a greater proportion of income variation in the EU compared to the US - respectively, $38 \%$ vs. $32 \%$ of the income shock and $47 \%$ and $34 \%$ of the unemployment shock (see Figure 2), largely explained by the higher coverage and generosity of unemployment benefits in Europe. Automatic stabilisers in 
the case of an unemployment shock are basically replacement rates for a transition from employment to non-work at the aggregate level. Rather than work incentives (as discussed in the previous section), they reflect how much the tax-benefit system absorbs (market) income losses due to becoming unemployed or exiting the labour market altogether.

Figure 2. Share of income compensated by the tax benefit system in case of an unemployment shock

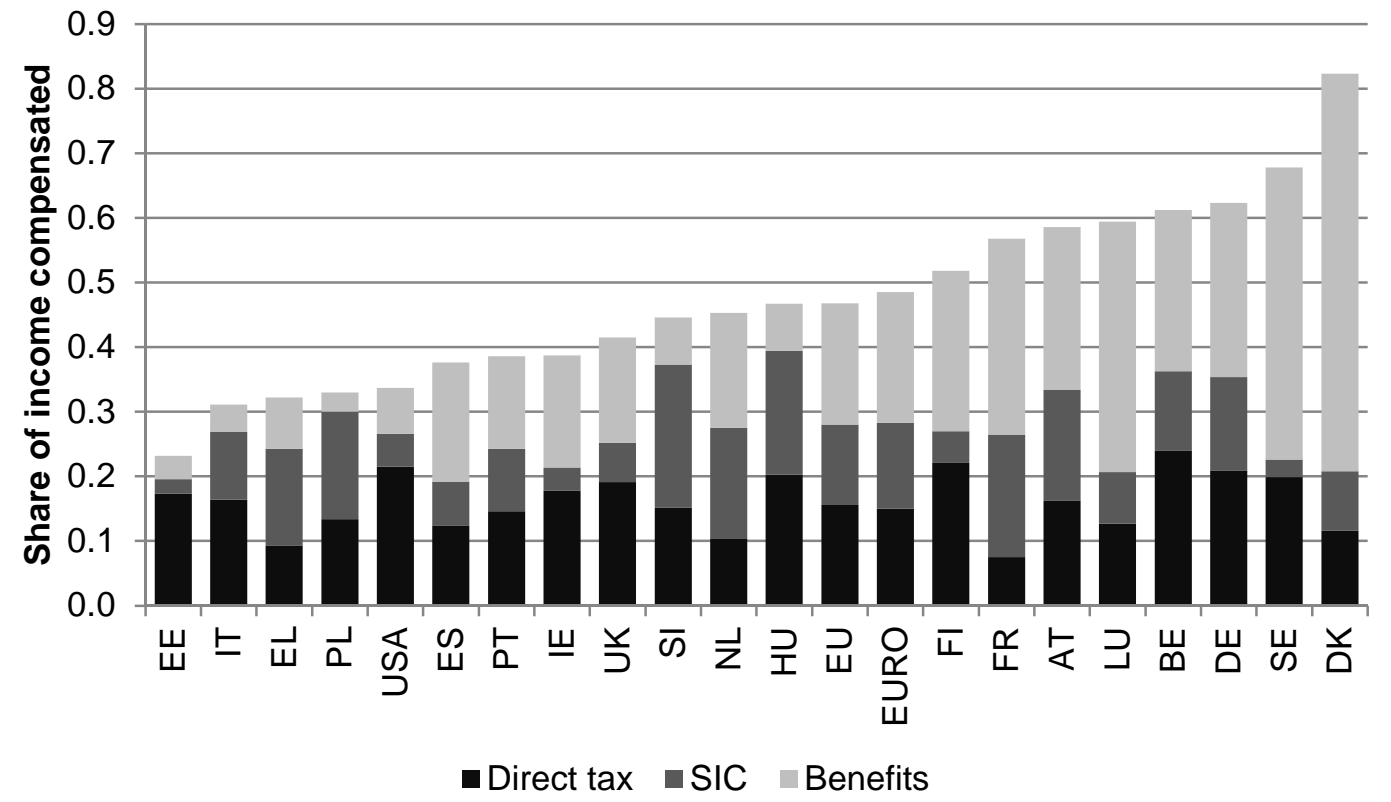

Notes: The unemployment shock corresponds to an increase in the unemployment rate such that the total household income decreases by 5\%. Countries are ranked by the share of income compensated. EU and EURO are population-weighted average of $19 \mathrm{EU}$ and 13 Eurozone countries, respectively, included here. Estonia joined the Euro-area later and is here excluded from that group. Source: Dolls et al. (2012) using EUROMOD and TAXSIM.

Instead of focussing on aggregate stabilization, Fernández Salgado et al. (2014) analyse the distribution of replacement rates when simulating the unemployment shock in six EU countries due to the Great Recession. They distinguish between short- and long-term unemployment and their findings confirm higher replacement rates in the short term and point to serious challenges for minimum income schemes to cope with the consequences of 
this crisis in the longer term. They also highlight the important role of incomes of other household members in boosting replacement rates.

2.2.3. Indicators of household composition effects

Another type of indicator based on microsimulation captures the effect of changes in household socio-demographic characteristics in order to identify the marginal effect of the tax-benefit system due to particular household configurations. For example, Figari et al. (2011b) apply this approach to calculate "child contingent" incomes estimated as the change in household disposable income for families with children as if they did not have children. They argue that 'child-contingent' incomes, capturing not only transfers net of taxes but also tax concessions, account more precisely for the full, net support provided through tax-benefit systems to families with children, compared to considering simply (gross) benefit payments labelled explicitly for children or families, as is typically the case using the information available directly in the survey data. As shown in Figure 3 the net value can be greater than the gross if there are tax concessions or child supplements in benefits labelled for other purposes, and the gross value can be greater than net if the benefits are taxed or reduced because of other interactions. 
Figure 3. Total net child-contingent payments vs gross family/parental benefits per child as a percentage of per capita disposable income

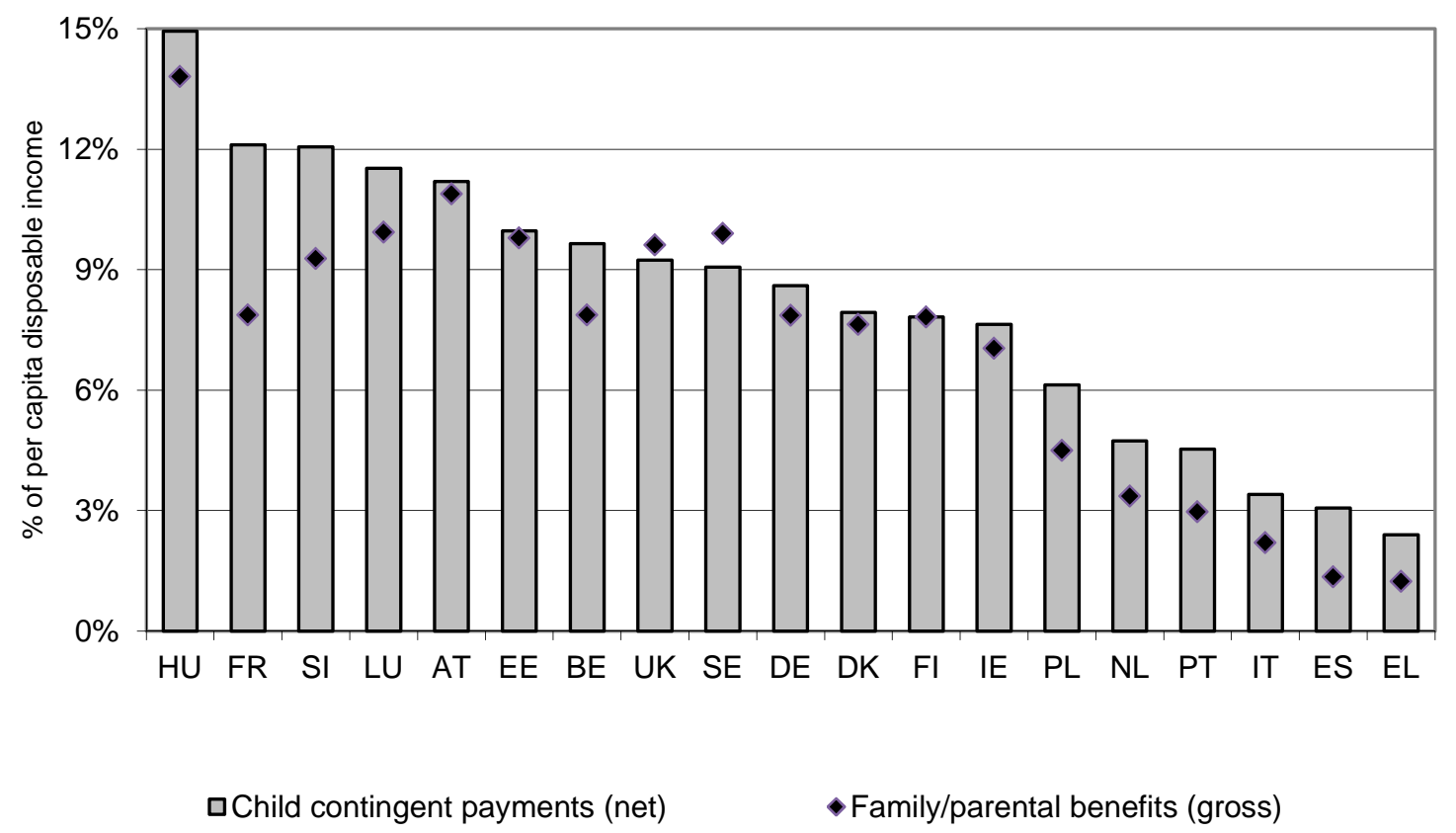

Notes: Countries are ranked by total net child-contingent payments. Source: Figari et al. (2011b) using EUROMOD.

\section{The effects of policy changes on the income distribution}

\subsection{A basic example}

The simplest use of a tax-benefit microsimulation model involves calculating the effects of a policy change on household income, without changing any of the characteristics of the household members. A simple example might be an increase in the amount of an existing universal child benefit. The model would take account of the increase in payment per eligible child, any clawback through the system of means-tested benefits (if the child benefit is included in the income assessment for these benefits), any clawback if the benefit is taxed or included in the base for contributions and any other relevant interaction with the rest of the tax-benefit system. Even a simple reform involves quite complicated arithmetic and ignoring the interactions would give misleading results. This is illustrated in Appendix A with a 
concrete example, comparing the effects of doubling the UK child benefit at two points in time: 2001 and 2013. While the structure of child benefit itself has remained the same, the net effect of changes to it is quite different because of changes to the interactions with the rest of the tax-benefit system. The interactions matter and need to be accounted for in understanding the effects of policy changes and in designing policy reforms.

The financing of such a reform would also need to be considered. For example, if the net cost were met by a percentage point increase in all rates of income tax, this increase might also have knock-on effects (e.g. if the assessment of any means-tested benefits depended on after tax income) and then iterations of the model would be needed to find a revenue-neutral solution to the tax rate increase. The "revenue neutral" package could then be evaluated relative to the pre-reform situation, in terms of its effect on the income distribution and an analysis of gainers and losers.

Of course, in the new situation some people affected will wish to change their behaviour in response to the change, in some way and at some point in time. One might expect labour supply and fertility to be affected and, depending on the specifics of the system and the change in it, so might other dimensions of behaviour. As Bourguignon and Spadaro (2006) point out, it is important to be clear about when these second order effects can, and cannot, be neglected. We return to this issue in section 3.3 below.

In any case, it is clear that an "overnight" or "morning after" analysis, as the pure arithmetic effect is often called, is of value in its own right as the immediate effect might be relevant to a particular research question. Moreover, the mechanics of the way in which policy reforms impact on incomes are relevant for improving design and it will often be important to identify how much of the overall effect on income can be attributed to the direct effect. 


\subsection{Formal framework}

3.2.1. Decomposing static policy effects

Tax-benefit models provide information on the distribution of household disposable income and its components under various policy scenarios, allowing the effects of policies to be inferred from a comparison of different scenarios. As such, the application of the microsimulation method starts from defining an appropriate baseline and a counterfactual scenario. The latter corresponds to the state after policy changes (i.e. how the world would look after implementing new policies) in forward-looking analysis or the state before policy changes (i.e. how the world would have looked without new policies or what would happen if policy changes where rolled back) in the case of backward-looking analysis.

Drawing on Bargain and Callan (2010) and Bargain (2012a), we provide a formal framework for decomposing changes in household income to separate the effects of policy changes. ${ }^{10}$ Mathematical formulation helps to avoid ambiguities about how exactly a counterfactual scenario is defined, which often arise in empirical microsimulation applications relying only on textual descriptions. Furthermore, full decomposition (rather than focusing only on the role of policy changes) has clear advantages by drawing attention to the fact that the (marginal) contribution of a given component is evaluated conditional on the values of other components and, hence, the overall change in income can be decomposed in multiple ways. Decomposing all components (at once) also helps to ensure that these are consistently derived. Apart from small technical modifications, ${ }^{11}$ we follow closely Bargain and Callan's original approach but broaden its scope by showing that a wider range of applications can be interpreted within the same framework.

\footnotetext{
${ }^{10}$ There is a notable strand in the economic literature focusing on the decomposition of income distributions, reviewed recently in Fortin et al. (2011). This, however, is primarily concerned with wage distributions, ignoring the role of tax-benefit policies.

${ }^{11}$ We carry out decomposition in steps starting from the policy effects - our key interest - and other effects, then introducing further splits. Such nesting helps to ensure consistency between the various components and across different combinations. We also distinguish socio-demographic characteristics $(c)$ from original incomes $(x)$.
} 
Let us denote household socio-demographic (and labour market) characteristics with (a vector) $c$ and household original income ${ }^{12}$ (i.e. income before adding cash benefits and deducting direct taxes) with $x$. The net transfer via the tax-benefit system $k$ (i.e. total cash benefit entitlement less total direct tax liability) for a household with characteristics $c$ and income $x$ is denoted as a function $f_{k}\left(c, x, m_{k}\right)$, where, following Bargain and Callan (2010), we distinguish between the structure of the tax-benefit system $f_{k}$ and various monetary parameters $m_{k}$ it takes as arguments (e.g. tax brackets, benefit amounts). $f_{k}\left(c, x, m_{k}\right)$ is positive if public pensions and cash benefits received by a given household exceed direct taxes for which the household is liable, and negative if the opposite holds. Household disposable income $y$ is then

$$
y_{k}\left(c, x, m_{k}\right)=x+f_{k}\left(c, x, m_{k}\right)
$$

In the simplest case, where original income and household characteristics (can be assumed to) remain constant, the effect of policy changes $(A \rightarrow B)$ on disposable income is

$$
\Delta y=y_{B}\left(c, x, m_{B}\right)-y_{A}\left(c, x, m_{A}\right)
$$

This corresponds to how the effects of proposed or hypothetical tax-benefit reforms are studied typically, i.e. 'morning-after' changes, with the policy rules before and after referring (implicitly) to the same time period. There are numerous examples of such exercises, e.g. Callan and Sutherland (1997), Matsaganis et al. (2006), Matsaganis and Flevotomou (2008), Paulus and Peichl (2009), Figari (2010).

Next, let us consider the case of analysing the effect of policy changes over time. Accounting explicitly for the time span over which policy changes are considered introduces additional complexities for defining an alternative scenario. It is important to ensure that the baseline and the counterfactual refer to the same time period and if there is a time gap between the

\footnotetext{
${ }^{12}$ This includes market incomes from employment, self-employment, property and investments and other nonpublic income sources such as private pensions and transfers between households. It is also known as "pre-tax and pre-transfer income" in the literature.
} 
existing policies and the counterfactual then one or the other must be adjusted to reflect that. For example, when analysing the effect of policy change in $t+1$ it may not be sufficient to assume that the alternative would have been simply period $t$ policies continuing (in nominal terms) in period $t+1$, even though this is often implicitly done. One should consider how existing policies in nominal terms would have evolved otherwise, given the legal rules or usual practice of indexation of policy parameters, or should have evolved. The importance of the time factor becomes even more obvious when considering policy changes over a longer period. We will return later to the question of what is an appropriate basis for indexing monetary parameters in the counterfactual scenario, while for now we simply denote such a factor as $p$.

First, the total change in disposable income for a given household can be decomposed to show first order policy effects (or mechanical effects) conditional on household characteristics and original incomes in the end-period $B$ (denoting the start-period with $A$ ):

$$
\begin{aligned}
& \Delta y=y_{B}\left(c_{B}, x_{B}, m_{B}\right)-y_{A}\left(c_{A}, x_{A}, m_{A}\right) \quad \text { (total change) } \\
& =y_{B}\left(c_{B}, x_{B}, m_{B}\right)-y_{A}\left(c_{B}, x_{B}, p m_{A}\right) \quad \text { (policy effect) } \\
& +y_{A}\left(c_{B}, x_{B}, p m_{A}\right)-y_{A}\left(c_{A}, x_{A}, m_{A}\right) \quad \text { (other effect) } \\
& =\Delta y_{I}^{P}+\Delta y_{I}^{O}
\end{aligned}
$$

Here we are implicitly assuming that we are dealing with panel data, where characteristics and original income for the same household are observed in several periods. The total change for the same household cannot be observed with multiple waves of cross-sectional datasets, however, as explained further below, the same decomposition approach can be also applied at the group-level (e.g. the bottom decile group) or to statistics summarising the whole income distribution (such as various inequality indices). Importantly, household characteristics are only required at a single point in time to calculate the policy effect (in absolute terms). 
Noting the symmetry of the decomposition, the other effect can be decomposed further into two sub-components separating the impact of change in household characteristics and nominal levels. The effect due to changes in characteristics can be measured either in endperiod income levels:

$$
\begin{aligned}
& \Delta y_{I}^{O}=y_{A}\left(c_{B}, x_{B}, p m_{A}\right)-y_{A}\left(c_{A}, p x_{A}, p m_{A}\right) \quad \text { (change in characteristics) } \\
& +y_{A}\left(c_{A}, p x_{A}, p m_{A}\right)-y_{A}\left(c_{A}, x_{A}, m_{A}\right) \quad \text { (change in nominal levels) }
\end{aligned}
$$

or start-period incomes

$$
\begin{array}{rlr}
\Delta y_{I}^{O} & =y_{A}\left(c_{B}, x_{B}, p m_{A}\right)-y_{A}\left(c_{B}, p^{-1} x_{B}, m_{A}\right) & \text { (change in nominal levels) } \\
& +y_{A}\left(c_{B}, p^{-1} x_{B}, m_{A}\right)-y_{A}\left(c_{A}, x_{A}, m_{A}\right) & \text { (change in characteristics) }
\end{array}
$$

The term capturing the effect of 'change in nominal levels' measures how household disposable income is affected if original income and all money-metric policy parameters change in the same proportion. As Bargain and Callan (2010) pointed out, tax-benefit systems are typically homogenous of degree one, meaning that in such a case household disposable income would also change by the same factor:

$$
p y(c, x, m)=y(c, p x, p m)
$$

They illustrate this with a hypothetical example involving a basic income and a flat tax and find empirical support for Ireland and France. ${ }^{13}$

In principle, the term reflecting the impact of changes in characteristics could be split further distinguishing between changes in socio-demographic (and labour market) characteristics $c$ and movements in original incomes $x$. Again, there would be two possible combinations which can be obtained by introducing a new term, e.g. either $y_{A}\left(c_{B}, p x_{A}, p m_{A}\right)$ or $y_{A}\left(c_{A}, x_{B}, p m_{A}\right)$ with equation 4.

\footnotetext{
${ }^{13}$ Bargain and Callan (2010) refer to the personal income tax in Germany as one of the few examples for which this property does not hold, due to its unique quadratic functional form.
} 
Secondly, the change in disposable income can be decomposed to assess policy effects conditional on household characteristics and original incomes in the start-period $A$ :

$$
\begin{array}{rrr}
\Delta y & =y_{B}\left(c_{B}, x_{B}, m_{B}\right)-y_{B}\left(c_{A}, x_{A}, p^{-1} m_{B}\right) & \text { (other effect) } \\
& +y_{B}\left(c_{A}, x_{A}, p^{-1} m_{B}\right)-y_{A}\left(c_{A}, x_{A}, m_{A}\right) & \text { (policy effect) } \\
& = & \Delta y_{I I}^{O}+\Delta y_{I I}^{P}
\end{array}
$$

The other effect can be now decomposed again such that the effects due to changes in characteristics are measured in end-period incomes:

$$
\begin{array}{rlr}
\Delta y_{I I}^{O} & =y_{B}\left(c_{B}, x_{B}, m_{B}\right)-y_{B}\left(c_{A}, p x_{A}, m_{B}\right) & \\
& +y_{B}\left(c_{A}, p x_{A}, m_{B}\right)-y_{B}\left(c_{A}, x_{A}, p^{-1} m_{B}\right) & \text { (change in characteristics) }
\end{array}
$$

or start-period incomes

$$
\begin{aligned}
\Delta y_{I I}^{O} & =y_{B}\left(c_{B}, x_{B}, m_{B}\right)-y_{B}\left(c_{B}, p^{-1} x_{B}, p^{-1} m_{B}\right) & \text { (change in nominal levels) } \\
& +y_{B}\left(c_{B}, p^{-1} x_{B}, p^{-1} m_{B}\right)-y_{B}\left(c_{A}, x_{A}, p^{-1} m_{B}\right) & \text { (change in characteristics) }
\end{aligned}
$$

Altogether there are four ways to decompose the overall change in income, given the initial split into the (direct) policy effect and the other effect.

Until now, we have focused on a single household though it is straightforward to derive the aggregate change in disposable income by summing income differences (and its subcomponents) across all households:

$$
\Delta Y=\sum_{i} \Delta y^{i}
$$

Decomposition can be also applied to any distributional statistic $D$ calculated for a specific sub-group, e.g. average income among households with elderly, or summarising the whole income distribution, $(\boldsymbol{y})$, e.g. the Gini coefficient or the head-count poverty ratio. For example, equation 3 would then become (indicating vectors in bold):

$$
\begin{array}{rlll}
\Delta D(\mathbf{y}) & =D\left[y_{B}\left(\boldsymbol{c}_{\boldsymbol{B}}, \boldsymbol{x}_{\boldsymbol{B}}, \boldsymbol{m}_{\boldsymbol{B}}\right)\right]-D\left[y_{A}\left(\boldsymbol{c}_{\boldsymbol{A}}, \boldsymbol{x}_{\boldsymbol{A}}, \boldsymbol{m}_{\boldsymbol{A}}\right)\right] & & \text { (total change) } \\
& =D\left[y_{B}\left(\boldsymbol{c}_{\boldsymbol{B}}, \boldsymbol{x}_{\boldsymbol{B}}, \boldsymbol{m}_{\boldsymbol{B}}\right)\right]-D\left[y_{A}\left(\boldsymbol{c}_{\boldsymbol{B}}, \boldsymbol{x}_{\boldsymbol{B}}, \boldsymbol{p} \boldsymbol{m}_{\boldsymbol{A}}\right)\right] & \text { (policy effect) } \\
& +D\left[y_{A}\left(\boldsymbol{c}_{\boldsymbol{B}}, \boldsymbol{x}_{\boldsymbol{B}}, \boldsymbol{p} \boldsymbol{m}_{\boldsymbol{A}}\right)\right]-D\left[y_{A}\left(\boldsymbol{c}_{\boldsymbol{A}}, \boldsymbol{x}_{\boldsymbol{A}}, \boldsymbol{m}_{\boldsymbol{A}}\right)\right] & \text { (other effect) }
\end{array}
$$


In the case of scale-invariant distributional measures (see Cowell, 2000) and linearly homogenous tax-benefit systems, the decomposition of other effects (equations 4-5, 8-9) simplifies because the effect of a change in nominal levels becomes (approximately) zero at the population level. ${ }^{14}$ Furthermore, equation 4 is now equivalent to 5 and equation 8 is equivalent to equation 9, reducing the overall number of combinations from four to two.

We now return to what would be an appropriate basis for choosing the indexation factor $p$. Bargain and Callan (2010) have argued for using the growth of average original incomes, i.e. $p=\bar{x}_{B} / \bar{x}_{A}$, to obtain a 'distributionally neutral' benchmark. This would broadly ensure that aggregate disposable income rises (or falls) in proportion to an increase (or a decrease) in aggregate original incomes, i.e. the overall tax burden and expenditure level remain constant in relative terms. ${ }^{15}$ Nevertheless, disposable income for a given household could still grow at a higher (or lower) rate than their original income if the latter grows less (or more) than on average. However, there are alternatives ways of choosing $p$, depending on the chosen conception of "neutrality". For example basing it on a consumer price index would be appropriate if the point was to ensure a constant absolute standard of living (on average). Clarke and Leicester (2004) contrast price-indexation with indexation based on the nominal GDP, and show that the choice matters for results. There is no clear consensus in the literature on decomposition regarding the most appropriate choice of index.

Finally, there is the issue of how to deal with path dependency and multiple combinations for decomposition. Can some combinations be preferred over others or different combinations somehow be brought together? In some cases, one might be limited to specific combinations by data constraints. The prime example here is ex ante analysis of (implemented) policy

\footnotetext{
${ }^{14}$ Notice also that with each sub-component aggregated separately (rather than aggregating the differences between various components), it is possible to carry out such exercise on two waves of cross-sectional data without necessarily using panel data.

${ }^{15}$ This holds for linearly homogenous tax-benefit systems, while non-linear elements make this an approximation. Nevertheless, as demonstrated in Callan et al. (2007) for Ireland, the bias would typically be small.
} 
changes before micro-data of actual post-reform incomes become available (e.g. Avram et al., 2013). Relying on estimates for $p$, one could already quantify the effect of policy changes (with equation 7), while both start- and end-year dataset are needed to assess other effects. As there are no clear arguments for preferring one particular combination over another, all variants should be covered. Bargain and Callan (2010) adopt the Shorrocks-Shapley approach (Shorrocks, 2013) to summarise various combinations, essentially averaging the effect of a given component across all combinations. In this way, results conditional on household characteristics in each period are given equal weights.

Other examples where such decomposition has been used explicitly include Bargain (2012b), Bargain et al. (2013b) and Creedy and Herault (2011). In addition, there is a large literature which has carried out similar assessments within less formal frameworks (for example, see Clark and Leicester, 2004; Thoresen 2004).

\subsubsection{Specific applications}

Actual vs. counterfactual indexation of policy parameters

Any system which is not fully indexed with respect to growth in (average) private incomes or prices would result in the erosion of the relative value of benefit payments and increased tax burden through so-called bracket creep (or fiscal drag). Furthermore, it is essential to acknowledge that keeping a tax-benefit system unchanged also impacts household incomes (unless the distribution of household original income is also constant over time). Let us consider the change in household disposable income in such a case using our notation from above:

$$
\Delta y=y\left(c, x_{B}, m\right)-y\left(c, x_{A}, m\right)
$$

Following the decomposition framework in the more general case above, equation 12 can be split again into three terms: the policy effect, changes in original incomes and the change in 
nominal levels (i.e. change in disposable income if both original incomes and policy parameters were scaled up by the same factor). The policy effect would now reflect the outcome of keeping policy parameters constant in nominal terms and can be calculated as $y\left(c, x_{B}, m\right)-y\left(c, x_{B}, p m\right)$ or $y\left(c, x_{A}, p^{-1} m\right)-y\left(c, x_{A}, m\right)$. In a typical case, $p$ is positive, reflecting growth in private incomes (or consumer prices), and, hence, the policy effect would be negative (i.e. income reducing). This is because a positive $p$ implies higher benefit amounts and tax bands in the counterfactual scenario and translates into higher disposable incomes (for the same original incomes) compared to disposable incomes under tax-benefit rules when these are kept nominally constant. This has been studied for example by Immervoll (2005), Immervoll et al. (2006) and Sutherland et al. (2008). It is also important to realise that if $p$ is negative, i.e. average original incomes (or prices) fall, and a tax-benefit systems is kept nominally constant then households' tax burdens fall in relative terms.

\section{Policy swaps}

An analogous type of exercise to that comparing the effects of policies across time in one country involves assessing the effects of policies from one country $(A)$ when simulated in another $(B)$, the so-called policy swaps. The starting point is again equation 3 with the aim being instead of comparing the effects of two different national policy regimes on the same population and distribution of original incomes, comparing the effects of a particular set of 'borrowed' policies, on different populations and income distributions. Some studies focus on the effects of several alternative systems in one particular country (one-way swaps), others carry out two-way swaps sometimes involving more than two countries in a series of swaps. Section 3.6 discusses some examples of such studies. Instead of growth in income over time and the relative movement in tax-and benefit parameters, the nature of $p$ has to do with difference in nominal levels of original income across countries. Often there are additional complexities involved in maintaining correspondence with original policies, especially if 
more than one pair-wise comparison is made. Attempts so far have aimed to keep the values of parameters fixed in relative terms, for example, in connection to average income or in order to maintain budget neutrality.

\section{Microsimulation-based indicators}

The same framework can be used to describe microsimulation-based indicators, designed to capture some inherent characteristics of a given tax-benefit system, which are not directly observable. The nature of these was already explained in section 2.2 , while here we formalise the key definitions. Overall, these indicators show how household disposable income reacts to changes in people's gross earnings and circumstances (for a given tax-benefit system):

$$
\Delta y=y\left(c_{B}, x_{B}, m\right)-y\left(c_{A}, x_{A}, m\right)
$$

Using our notation, we can express marginal effective tax rates (METR) as follows:

$$
\operatorname{METR}=1-[y(c, x+d, m)-y(c, x, m)] / d
$$

where the change in household disposable income is divided by the margin $(d)$ used to increment gross earnings $(x)$ of a given household member, yielding a relative measure. This is further deducted from one to show the part of additional earnings which is taxed away.

In the case of participation tax rates (PTR), both earnings $(x)$ and other household characteristics $(c)$ are adjusted to reflect the change in labour market status, i.e. from inactivity or unemployment $(A)$ to work $(B)$ :

$$
\operatorname{PTR}=1-\left[y\left(c_{B}, x_{B}, m\right)-y\left(c_{A}, x_{A}, m\right)\right] /\left(x_{B}-x_{A}\right)
$$

The relative income change is again deducted from one to reflect the effective tax rate at this margin. (Note that this could be further simplified as $x_{A}=0$.) Replacement rates (RR) are calculated simply as the ratio of out-of-work disposable income $(A)$ to in-work disposable income $(B)$ : 


$$
R R=y\left(c_{A}, x_{A}, m\right) / y\left(c_{B}, x_{B}, m\right)
$$

Finally, indicators based on counterfactuals reflecting only changes in household sociodemographic characteristics (c) can be calculated as $\Delta y=y\left(c_{A}, x, m\right)-y\left(c_{B}, x, m\right)$. For example, 'child contingent' incomes would show the change in household disposable income for families with children $(A)$ compared to if they did not have children $(B)$.

\subsubsection{Decomposition with labour supply changes}

So far we have focused on the static effects of policy changes, whereby potential behavioural reactions have been absorbed by the component capturing changes in household characteristics more generally. Following Bargain (2012a) we now extend the previous case and explicitly account for behavioural changes in the form of labour supply adjustments due to policy changes. For this purpose, we slightly change the notation from $x_{k}$ to $x_{k}^{l}$, which refers to original incomes by population with characteristics $c_{k}$ based on labour supply choices made under the policy system $l$. (As such, the meaning of $x_{k}^{k}$ is exactly the same as $x_{k}$ before and, hence, will be shortened to the latter.) This allows the term 'changes in characteristics' to be split into further two components - labour supply adjustments following changes in policy rules $(A \rightarrow B)$ and other effects due to changes in the population structure $c$ (which are assumed to be exogenous to tax-benefit policy changes, at least in the short and the medium term). We can now express the overall change in household disposable income as a sum of four components: direct (or mechanical) policy effect, labour supply reactions, change in nominal levels and change in characteristics.

Decomposing equation 4 and combining it with equation 3, we can separate the behavioural effects comparing disposable income with labour supply under the initial and the new policy rules, expressed in terms of initial policy rules $\left(y_{A}, p m_{A}\right)$ and either start-period household characteristics $c_{A}$ : 


$$
\begin{array}{rlc}
\Delta y & =y_{B}\left(c_{B}, x_{B}, m_{B}\right)-y_{A}\left(c_{B}, x_{B}, p m_{A}\right) & \text { (direct policy effect) } \\
& +y_{A}\left(c_{B}, x_{B}, p m_{A}\right)-y_{A}\left(c_{A}, p x_{A}^{B}, p m_{A}\right) & \text { (change in characteristics) } \\
& +y_{A}\left(c_{A}, p x_{A}^{B}, p m_{A}\right)-y_{A}\left(c_{A}, p x_{A}, p m_{A}\right) & \text { (behavioural effects) } \\
& +y_{A}\left(c_{A}, p x_{A}, p m_{A}\right)-y_{A}\left(c_{A}, x_{A}, m_{A}\right) & \text { (change in nominal levels) }
\end{array}
$$

or end-period household characteristics $c_{B}$

$$
\begin{aligned}
& \Delta \mathrm{y}=y_{B}\left(c_{B}, x_{B}, m_{B}\right)-y_{A}\left(c_{B}, x_{B}, p m_{A}\right) \quad \text { (direct policy effect) } \\
& +y_{A}\left(c_{B}, x_{B}, p m_{A}\right)-y_{A}\left(c_{B}, x_{B}^{A}, p m_{A}\right) \quad \text { (behavioural effects) } \\
& +y_{A}\left(c_{B}, x_{B}^{A}, p m_{A}\right)-y_{A}\left(c_{A}, p x_{A}, p m_{A}\right) \quad \text { (change in characteristics) } \\
& +y_{A}\left(c_{A}, p x_{A}, p m_{A}\right)-y_{A}\left(c_{A}, x_{A}, m_{A}\right) \quad \text { (change in nominal levels) }
\end{aligned}
$$

Decomposing equation 8 instead and combining it with equation 7, allows the behavioural effects to be expressed in terms of new policy rules $\left(y_{B}, m_{B}\right)$ and, again, start-period household characteristics $c_{A}$ :

$$
\begin{array}{rlc}
\Delta y & =y_{B}\left(c_{B}, x_{B}, m_{B}\right)-y_{B}\left(c_{A}, p x_{A}^{B}, m_{B}\right) & \text { (change in characteristics) } \\
& +y_{B}\left(c_{A}, p x_{A}^{B}, m_{B}\right)-y_{B}\left(c_{A}, p x_{A}, m_{B}\right) & \text { (behavioural effects) } \\
& +y_{B}\left(c_{A}, p x_{A}, m_{B}\right)-y_{B}\left(c_{A}, x_{A}, p^{-1} m_{B}\right) & \text { (change in nominal levels) } \\
& +y_{B}\left(c_{A}, x_{A}, p^{-1} m_{B}\right)-y_{A}\left(c_{A}, x_{A}, m_{A}\right) & \text { (direct policy effect) }
\end{array}
$$

or end-period household characteristics $C_{B}:{ }^{16}$

$$
\begin{array}{rlc}
\Delta y & =y_{B}\left(c_{B}, x_{B}, m_{B}\right)-y_{B}\left(c_{B}, x_{B}^{A}, m_{B}\right) & \text { (behavioural effects) } \\
& +y_{B}\left(c_{B}, x_{B}^{A}, m_{B}\right)-y_{B}\left(c_{A}, p x_{A}, m_{B}\right) & \text { (change in characteristics) } \\
& +y_{B}\left(c_{A}, p x_{A}, m_{B}\right)-y_{B}\left(c_{A}, x_{A}, p^{-1} m_{B}\right) & \text { (change in nominal levels) } \\
& +y_{B}\left(c_{A}, x_{A}, p^{-1} m_{B}\right)-y_{A}\left(c_{A}, x_{A}, m_{A}\right) & \text { (direct policy effect) }
\end{array}
$$

Modelling behaviour and in particular labour supply is discussed in more detail in the next section.

\subsection{Modelling behavioural changes}

\subsubsection{Accounting for individual reactions}

The impact of policies on individual behaviour, through incentives and constraints, is at the core of economics and behavioural microsimulation models are valuable tools to provide

\footnotetext{
${ }^{16}$ We skip decompositions based on equation 5 and equation 9 as the terms for 'behavioural effects' and 'change in characteristics' are simply scaled down by $p$ (if the homogeneity property holds), compared to equation 4 and 8 , respectively.
} 
insights into the potential behavioural reactions to changes in the tax-benefit system and, consequently, on their effect on economic efficiency, income distribution and individual welfare (Creedy and Duncan, 2002). Nevertheless, it is important to be clear when the second order effects can, and cannot, be neglected. To capture the individual welfare effect of reforms, it is not always necessary to quantify behavioural responses, on the assumption that the effects of the policy changes are marginal to the budget constraint (Bourguignon and Spadaro, 2006).

Of course it is not possible to judge a priori whether the behavioural response is large or ignorable. Judgements must necessarily be made on an ad hoc basis, using available evidence and related to the context of the analysis and how results are to be interpreted. If behaviour is known to be constrained (e.g. in the case of labour supply adjustments at times of high unemployment) then behavioural responses might be ignored and the results of the analysis treated purely as changes in income (rather than welfare). If static indicators of work incentives such as marginal effective tax rates and participation tax rates change very little as a result of a policy change then one can assume that labour supply responses driven by substitution effects will be small. If the change in income with and without modelled behavioural response is expected to be rather similar, then given the error in the modelling of behaviour and in the static microsimulation estimates themselves, going to the trouble of modelling responses may not be worthwhile (Pudney and Sutherland, 1996).

Moreover, being clear about the relevant time period is important. From a policy-making viewpoint it is the effect on the income distribution and on the public budget in the year of the reform that often matters. Most tax and benefit policy changes are made year to year and are fine-tuned the following year if necessary. On the one hand, behaviour takes time to adapt to changing policies, partly because of constraints, adjustment costs and lack of information or understanding. This applies most obviously to fertility but also to labour supply in systems 
where full information about the policy rules is not available until the end of the year (after labour supply decisions have already been acted on). On the other hand, changes in behaviour may also happen in anticipation of the policy being implemented, with short-term responses larger than long-terms effects. This may apply particularly to tax planning behaviour and is well-illustrated by the case of an announcement in the UK in 2009 of a large increase in the top rate of tax on high incomes in 2010/11. Major forestalling of income by those who would pay the additional tax and were in a position to manipulate the timing of their income resulted in an unexpected increase in tax revenue in $2009 / 10$ and a corresponding reduction in the following year (HMRC, 2012).

In some situations the "morning after" effect is the most relevant when considering shortterm policy adjustments and equilibrium (or partial equilibrium) considerations are not particularly relevant. Furthermore, if indicative results are needed quickly because reform is imperative, then in the absence of an already-estimated and tested behavioural model, static results with the appropriate "health warnings" are still more informative than nothing at all.

Nevertheless, it is widely recognised that, depending on the policy change being analysed, ignoring behavioural reactions can lead to misleading estimates of the impact of the policy reform on the income distribution and the macro-economic consequences (Bourguignon and Spadaro, 2006), as is also illustrated by the tax planning example.

At the other extreme, modelling behavioural responses in the case of very large changes to policy poses challenges for the empirical basis of behavioural modelling. For example, replacing an existing tax-benefit system with a combination of a basic income and a flat tax such that no income fell below the poverty threshold would presumably result in large changes in many dimensions of behaviour which are unlikely to be correctly captured by the labour supply models that are used traditionally. 
Despite the long tradition in modelling behaviour in economics, the behavioural reactions to changes in the tax system that are most commonly analysed are related to labour supply (starting from the seminal contributions of Aaberge et al. 1995 and van Soest 1995) and programme participation (Keane and Moffitt, 1998), feeding into a growing literature, which is characterised by an increasing level of econometric sophistication. The same level of development does not yet apply to other research areas where microsimulation models have been used, e.g. to investigate the potential effects of tax policies on consumption (Creedy, 1999b; Decoster et al., 2010), saving (Feldstein and Feenberg, 1983; Boadway and Wildasin, 1995) and housing (King, 1983), at least partly due to a lack of suitable data.

\subsubsection{Labour supply models}

There is a general consensus in the literature about using (static) discrete choice models to simulate the individual labour supply reactions to changes in the tax-benefit system. ${ }^{17}$ Such models are structural because they provide direct estimations of preferences over income and hours of work, through the specification of the functional form of the utility function. Discrete choice models belong to the family of random utility maximisation models (McFadden, 1974) which allow the utility function to have a random component (usually following the extreme value distribution), affecting the optimal alternative in terms of utility level associated with each choice.

The discrete choice character of the models is due to the assumption that utility-maximising individuals and couples choose from a relatively small number of working hour combinations which form the personal choice set. Each point in the choice set corresponds to a certain disposable income given the gross earnings of each individual (derived using the observed or predicted wage), other incomes and the tax-benefit system rules simulated by means of a taxbenefit microsimulation model taking into account the socio-demographic characteristics of

\footnotetext{
${ }^{17}$ See Creedy and Kalb (2005) for an extensive review of modelling strategies.
} 
the family. The nonlinear and nonconvex budget sets determined by complex tax-benefit systems provide a primary source of identification of the model itself. Most of the discrete choice models based on the van Soest (1995) approach assume that the same choice sets are defined and available for each individual and that an individual has the same gross hourly wage for each such alternative. Ilmakunnas and Pudney (1990) is one of the few exceptions in the literature, allowing the hourly wage to be different according to the number of hours offered by each individual. A more flexible specification is provided by Aaberge et al. (1995) that defines the alternatives faced by the individuals in terms of a set of a wage rate, hours of work and other job related characteristics. The wage rate can differ for the same individual across alternatives, the hours of work are sampled from the observed distribution and the availability of jobs of different types can depend on individual and institutional characteristics.

Regardless of the econometric specification, the sample is usually restricted to individuals who are considered "labour supply flexible" in order to exclude individuals whose labour choices are affected by factors that are not or cannot be controlled for in the labour supply model. Examples of these factors include disability status, educational choices or early retirement but also self-employment status. This represents a limit in the use of the estimated labour supply responses to analyse changes in the overall income distribution because, for the individuals not covered by the labour supply models, the behaviour is assumed to be inelastic. In most applications, working age individuals within the family are allowed to vary their labour supply independently of each other while the utility maximisation takes place at the family level considering the income of both partners subject to a pooled income constraint, in line with the unitary model of household behaviour. Blundell et al. (2007) is an example of structural model of labour supply in a collective setting but excluding the effects of taxes. 
Figure 4 depicts the main components of a standard labour supply model which uses a static tax-benefit algorithm to generate input for the labour supply estimation and to evaluate the labour supply reactions to policy reforms.

Figure 4: Behavioural tax-benefit model and underlying data

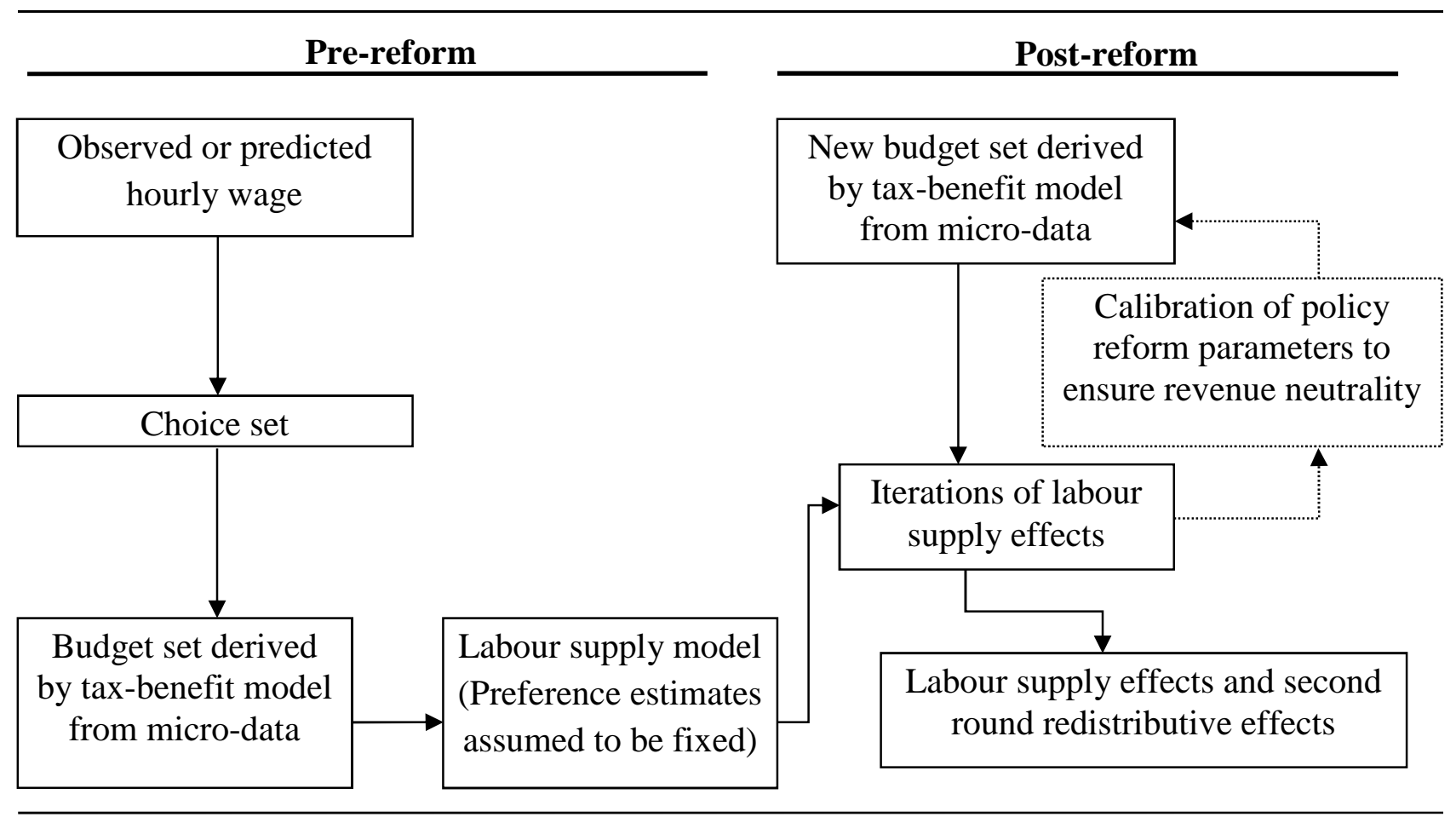

In the pre-reform scenario (left panel of Figure 4), the labour supply model is estimated on the budget set providing a direct estimate of the preferences over income and hours. In the post-reform scenario (right panel of Figure 4) a new budget set for each family is derived by the tax-benefit model applying the new tax-benefit rules following the simulated reform. Assuming that individual random preference heterogeneity as well as observable preferences do not vary over time, labour supply estimates from the pre-reform scenario are used to predict the labour supply effects and the second round redistributive effects (i.e. when labour supply reactions are taken into account) of the simulated policy reforms. Such effects might come out of an iterative procedure calibrating the policy parameters to ensure revenue 
neutrality once the labour supply reactions and their effects on tax revenue and benefit expenditure are taken into account.

Applications of discrete choice behavioural models are too numerous to be surveyed in this context. Along with many applications focussed on the potential effects of specific taxbenefit policies (among others, see Brewer et al. (2009) for a review of analysis of the effects of in-work benefits across countries), labour supply models based on microsimulation models provide labour supply elasticities that can be used in other tax policy research (e.g. Immervoll et al., 2007). Using EUROMOD and TAXSIM, Bargain et al. (2014) provide the first largescale international comparison of labour supply elasticities including $17 \mathrm{EU}$ countries and the US. The use of a harmonised approach provides results that are more robust to possible measurement differences that would otherwise arise from the use of different data, microsimulation models and methodological choices. Figure 5 shows the estimated ownwage elasticities for single individuals and individuals in couples, which suggest substantial scope for the potential impact of tax-benefit reforms on labour supply and hence income distribution, though the differences across countries are found to be smaller with respect to those in previous studies. Bargain et al. (2014) also show the extent to which labour supply elasticities vary with income level which has important implications for the analysis of the equity-efficiency trade off inherent in tax-benefit reforms. To this aim, labour supply models can be used to implement a computational approach to the optimal taxation problem, allowing the empirical identification of the optimal income tax rules according to various social welfare criteria under the constraint of revenue neutrality (Aaberge and Colombino, 2013). 


\section{Figure 5. Europe and US: own-wage elasticities}
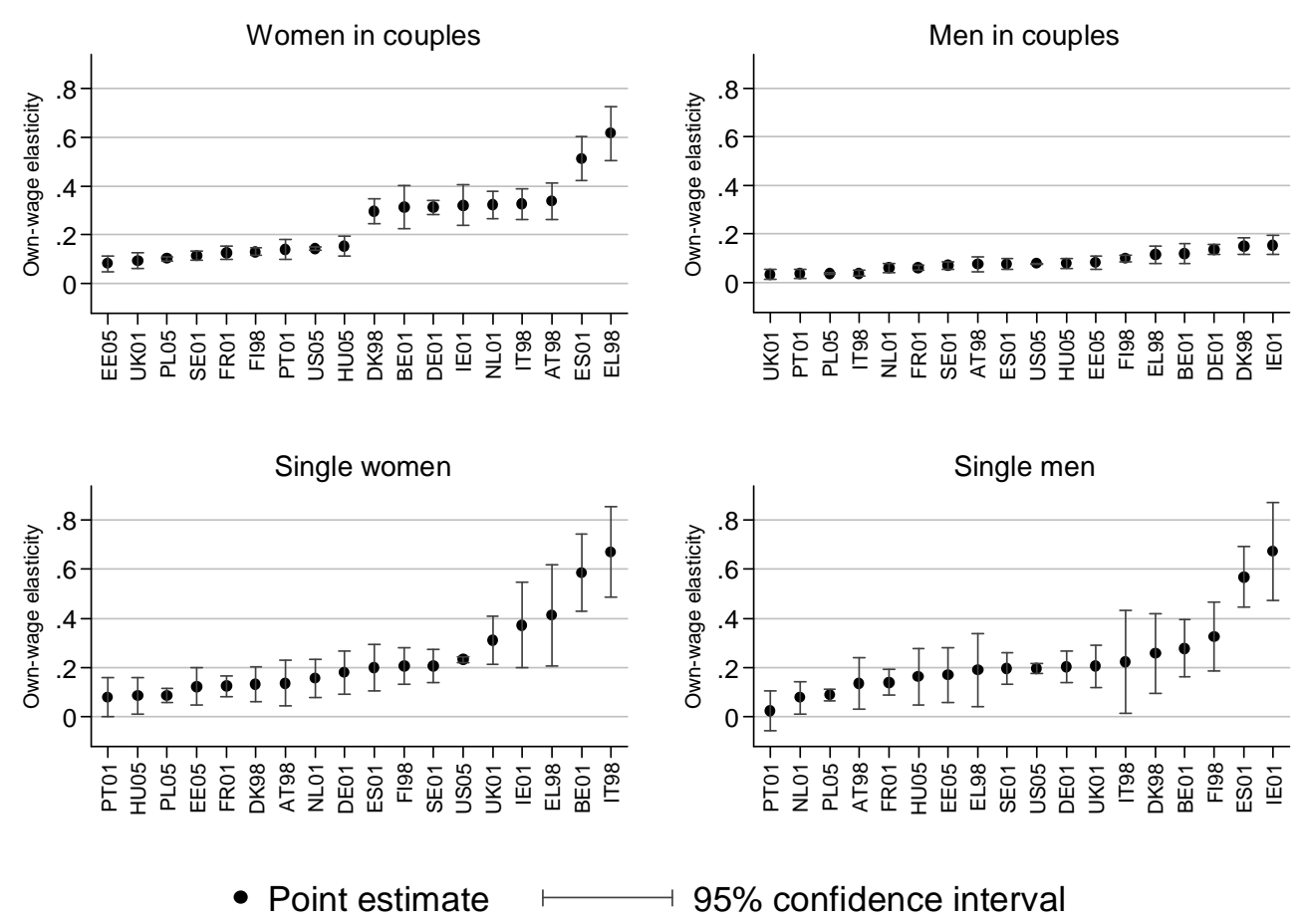

Source: Bargain et al. (2014) using EUROMOD and TAXSIM.

The rapid dissemination of labour supply models, no longer restricted to the academic sphere and increasingly used to inform the policy debate, has been accompanied by a continuing refinement of the econometric specifications. Nevertheless, further improvements are still necessary to model the labour market equilibrium that can emerge as a consequence of a policy simulation (Colombino, 2013), to take into account demand side constraints (Peichl and Siegloch, 2012) and to exploit the longitudinal dimension of micro-data, where this is available, in order to avoid labour supply estimates being potentially biased by individual unobserved characteristics and to consider the state dependence in the labour supply behaviour (Haan, 2010). 


\subsection{Macroeconomic effects}

In a basic application of a static microsimulation model labour market conditions and levels of market income are taken from the underlying data without further adjustments. However, these conditions may change due to policy, economic and institutional changes and in order to assess the social consequences of macroeconomic changes, it is important to consider the interactions of the tax-benefit system with new conditions in the labour market and with other macroeconomic effects in general. On the one hand, micro-oriented policies can have a second round effect due to micro-macro feedbacks: for example, a generous income support scheme can have effects on labour market and saving behaviours. On the other hand, macro oriented policies or exogenous shocks have a redistributive impact which needs to be assessed if the potential implications for the political economy of the reforms is to be understood (Bourguignon and Bussolo, 2013).

As in the case of a policy change, the microsimulation approach can offer insights in two ways. First, it can provide, in a timely fashion, an ex-ante assessment of how individuals are affected by the macroeconomic changes, either actual or hypothetical. Second, it can be used to develop a counterfactual scenario to disentangle ex-post what would have happened without a given component of the macroeconomic shock. However, in order to capture the consequences of a macroeconomic shock on income distribution, a partial equilibrium setting at micro level can be too limited. The need to capture the interactions of the tax-benefit system with population heterogeneity observed at micro level and the macro changes in the fundamentals of an economy due to policy reforms or exogenous shocks is necessary. ${ }^{18}$

In the last decade, the growing literature has explored different ways to link micro and macro models (often belonging to the family of Computational General Equilibrium (CGE) models)

\footnotetext{
${ }^{18}$ This is less relevant in developing countries where the effects of social expenditures are more relevant in shaping the income distribution than tax-benefit systems but it cannot be ignored in mature welfare states and in emerging countries due to the increasing use of conditional cash transfer programs.
} 
yet the construction of a comprehensive, policy-oriented micro-macro economic model still faces many challenging issues. While it is nowadays quite common to see disaggregated information from micro level data used in a macro model (i.e. using the parameters of behavioural models or the effective tax rates simulated by micro-simulation models in CGE models), it is rarer to see a fully developed microsimulation model being integrated with a macro model. See Bourguignon and Bussolo (2013) for an excellent review of the different approaches.

The simplest and widely implemented way to combine micro and macro models is the topdown approach. Robilliard et al. (2008) provide an example of combining in a sequential way a microsimulation model with a standard multi-sector CGE model, not only focussing on the labour markets but also on the expenditure side taking into account the heterogeneity of consumption behaviour of individuals. First, the macro model predicts the linkage variables, i.e. new vectors of prices, wages and aggregate employment variables which are the consequences of a macroeconomic shock or a new policy. Second, the microsimulation model generates new individual earnings and employment status variables consistent with the aggregates from the macro model and hence simulates a new income distribution. In such a top-down approach, the potential macro feedback effects of the new situation faced by the individual are not taken into account specifically but only through the representative households embedded in the macro model. Since it depends on the aggregation of behaviour at the individual level, this approach can only provide the first-round effects of the exogenous (policy) change. Bourguignon et al. (2005) extend the top-down approach by including in the microsimulation model the behavioural reactions of individuals to the price changes predicted by the macro model.

In contrast, in the bottom-up approach, the individual behavioural changes due to a policy reform are simulated at micro level and then aggregated to feed into the macro model as an 
exogenous variation in order to analyse the overall effect on the economy. Any feedback effect from the macro model back into the microeconomic behaviour is ignored in this setting (Brown et al., 2009).

A more complete recursive approach is given by the combination of the two approaches through a series of iterations until effectively no further adjustments are observed, in order to take into account the feedbacks that would otherwise be ignored and to arrive at a fully integrated macro-micro model. In the macro part of such a model the household sector is not given by a few representative households but by the micro level sample of households, representative of the whole population. Aaberge et al. (2007) is an example of the integration between a labour supply microsimulation model and a CGE model in order to assess the fiscal sustainability of the ageing population in Norway. Peichl (2009) uses the same approach to evaluate a flat tax reform in Germany.

Considering the efforts needed to develop a fully integrated model, the choice of the appropriate approach depends on the research or policy question at hand, and more parsimonious models can do the job in many circumstances. Notwithstanding, a fully integrated micro-macro model as suggested by Orcutt et al. (1976) would be an incredibly powerful tool to build counterfactuals taking into account feedback effects between micro and macro level and to disentangle the effect of a given macro change on individual resources and hence on the income distribution.

\subsection{Predicting the income distribution}

Using microsimulation to predict the income distribution is an area of work that is fuelled by the need of policy-makers to have more up-to-date estimates of poverty and inequality and the effects of policy than can be supplied directly from micro-data that are usually 2 to 3 years out of date. 
This need is particularly acute if indicators of income distribution are to be taken into account in assessments of economic and social conditions alongside aggregate economic indicators, which are generally available in a more timely way (Atkinson and Marlier, 2010; Stiglitz, 2012). Furthermore, the practice of setting targets for the future achievement of social goals is becoming more widespread. In relation to poverty and income distribution this applies particularly in the European Union through the Europe 2020 target for risk of poverty and social exclusion, ${ }^{19}$ and in the developing world through the UN Millennium Development Goal for eradication of hunger and extreme poverty. ${ }^{20}$ Predictions of the current situation (known as "nowcasts") are valuable indicators to measure the direction and extent of movement towards the associated targets, along with predictions for the target date at some future point (i.e. forecasts).

The approaches to predicting the income distribution depend also on the time framework of the analysis. Methods for "nowcasting" and forecasting are distinct in the sense that the latter must rely on assumptions or other forecasts about the economic and demographic situation as well as the evolution of policies, rather than recent indicators, data and known policy parameters. However the choice of techniques is common to both and before discussing the two time frameworks in turn, the next sub-section considers a key issue: how to model changes in labour market status.

\subsubsection{Modelling change in labour market status}

In order to capture the effects of (exogenous) changes in economic status on the income distribution, two techniques can be implemented at micro level. One approach is to re-weight the data (Merz, 1986; Gomulka, 1992; Creedy, 2004) while another approach is to model transitions from one status to another at individual level (Fernández Salgado et al., 2014).

\footnotetext{
${ }^{19} \mathrm{http}: / /$ ec.europa.eu/europe2020/targets/eu-targets

${ }^{20} \mathrm{http}$ ///www.un.org/millenniumgoals/
} 
Re-weighting is commonly used because it is relatively straightforward to carry out, and to test the effects of alternative specifications. For example, to model an increase in unemployment rate (Immervoll et al., 2006b), the survey weights of households containing unemployed people at the time the survey was collected must be increased and the weights of other similar households reduced, in order to keep demographic characteristics and household structures constant in other relevant dimensions. Following this approach, Dolls et al. (2012) simulate a hypothetical unemployment shock in 19 European countries and the US in order to analyze the effectiveness of the tax and transfer systems to act as an automatic stabilizer in an economic crisis.

However, the main disadvantage of the re-weighting approach, especially in the context of a rapidly changing labour market, is that it assigns the characteristics of the "old" unemployed (in the original data) to the "new" unemployed (corresponding to the current period). To the extent that the unemployed in the data were long-term unemployed this will under-estimate the number of new unemployed in receipt of unemployment insurance benefits, which are time-limited in most countries, and over-estimate the extent to which incomes are lowered by unemployment. Furthermore, the unemployment shock may have affected certain industries and occupations more than others.

Another drawback of re-weighting is that it can result in very high weights for some observations which can distort the results of simulations affecting dimensions not controlled for. In addition, while the implications of alternative formulations for the empirical results are straightforward to explore, it is far less straightforward to assess the statistical properties and reliability of the weights themselves, given that for any one set of weights satisfying the calibration constraints, there are also others (Gomulka, 1992). 
Moreover, re-weighting does not permit account to be taken of the interactions between changes in the individual status and different tax-benefit instruments, for example to analyse to what extent the welfare system counterbalances income losses specifically for those who became unemployed rather than at the aggregate level. This is possible with the second approach which involves explicit modelling of transitions at the individual level, making use of external information about the changes occurring in a given dimension. In principle, the full range of relevant characteristics of the people affected can be taken into account. An explicit simulation allows for the detailed effects of tax and benefit policy to be captured for those making the transition. In other words, it gives the possibility to produce quasi 'panel data' tracking the same individual before and after a given change, disentangling what would have happened without the change and highlighting the interactions of the tax-benefit system with the individual socio-demographic characteristics.

Following this approach, Fernández Salgado et al. (2014) simulate the individual transitions from employment to unemployment at the onset of the Great Recession in six European countries. As a consequence of the macroeconomic shock, household incomes of individuals who lose their job are predicted, considering the direct cushioning effect of the tax-benefit systems and the way they depend on the market income of other household members and personal/household characteristics. The comparison between incomes before and after the shock provides a way to stress-test the tax-benefit systems assessing the relative and absolute welfare state resilience.

To date there have been few systematic comparisons of re-weighting versus the explicit simulation of individual transitions. Hérault (2010) provides a comparison of results using the two methods on South African data and concludes that "the reweighting approach can constitute a good alternative when data or time constraints do not allow the use of the 
behavioural approach and when the production of individual level transition matrices in and out of employment is not essential" (p. 41).

\subsubsection{Nowcasting}

Tax-benefit microsimulation models have for many years been used to simulate the effects of the most recent policies so that ex ante analysis of policy reforms can take the current situation as the starting point. In doing this, it is necessary to update the input micro-data to reflect current economic and social conditions. This might be done with varying degrees of sophistication depending on the question at hand and the amount of change in relevant dimensions between the reference period of the micro-data and the reference year of the policy. Usually, information in the data on original income is updated using appropriate indexes. In addition, the sample might be re-weighted to account for certain demographic and economic changes (see section 3.5.1). The simulated distribution of household disposable income, based on adjusted population characteristics, updated original income and simulated taxes and benefits using current rules, is then assumed to be a reasonable representation of the current income distribution. $^{21}$

However, in times of rapid change two factors suggest that this approach may not be adequate. First, simple re-weighting cannot generally capture major changes accurately and income growth may vary greatly around the mean, requiring a disaggregated approach. Most obviously this applies in the case of an economic downturn and a sudden increase in unemployment with its asymmetric effects, or an upturn and an increase in employment, when, as is typically the case, the impact is uneven across the population. Secondly, it is at times of rapid change or economic crisis that policy-makers particularly need to know about very recent movements in the income distribution and the current situation rather than those a few years previously. The same applies in times of growth if policy-makers are concerned

\footnotetext{
${ }^{21}$ See for example Redmond et al. (1998) and Callan et al. (1999).
} 
about some sections of the population being left behind. Furthermore, in times of crisis fiscal stimulus or fiscal consolidation policies may play a particularly important role in re-shaping the income distribution. A microsimulation approach has particular advantages because it captures the specific impact of the components of these policy packages that have a direct effect on household incomes, as well as their interactions with changing market incomes. In times of rapid growth, fiscal drag will typically have distributional consequences (see section 3.2.2), which will be important for policy-makers to anticipate if they wish to prevent relative poverty from rising (Sutherland et al., 2008).

Borrowing the term "nowcasting" from macroeconomics (see, for example, Banbura et al., 2011) the use of an extended and refined set of microsimulation methods in combination with timely macro-economic statistics is able to provide estimates of the current income distribution using micro-data on household income which are typically 2 or more years out of date. These methods include: (a) updating market incomes from the income data year to current (or latest), using published indexes with as much disaggregation as these statistics allow; and from the latest to "now" according to macro-level forecasts or assumptions; (b) simulating policy changes between the income data year to those prevailing currently; (c) data adjustments to account for important dimensions of actual labour market change between the data year and the most recently available information; (d) data adjustments to account for actual and projected demographic and other compositional changes (e.g. household composition) between the data year and "now". 22

An early attempt to use these methods to update poverty statistics for the $\mathrm{UK}$ is provided by de Vos and Zaidi (1996). More recently, these methods have been used to nowcast the policy effects of the crisis in Ireland (Keane et al., 2013); to examine the distributional effects of the

\footnotetext{
${ }^{22}$ Some studies also make specific data adjustments that are relevant to the effect of policies in the projection period, such as increasing the pension age (Brewer et al., 2011).
} 
crisis in Greece (Matsaganis and Leventi, 2013) and to nowcast the income distribution in Ireland (Nolan et al., 2013), the UK (Brewer et al., 2013) and Italy (Brandolini et al., 2013). They have also been used for 8 European Union countries to nowcast risk of poverty using EUROMOD (Navicke et al., 2013). ${ }^{23}$

A key issue for all the studies that aim to nowcast the income distribution in (or on the way out of) the Great Recession, using pre-recession data, is to capture labour market changes sufficiently precisely. The same would apply during a period of increasing employment rates. Most of the studies cited above use re-weighting to adjust for both demographic and labour market changes. The study by Navicke et al. (2013) is an exception and, holding demographic factors constant, used explicit simulation of labour market transitions to capture the very specific and varied incidence of unemployment across the eight countries considered in the relevant period. The method is based on that used by Figari et al. (2011c) using Labour Force Survey (LFS) statistics to establish the required number of transitions of each type according to personal characteristics. The microsimulation model, in this case EUROMOD, then selects from the available pool of people with these characteristics in the input database and changes their status accordingly. Incomes are simulated, taking account of the new status, for example by calculating eligibility and entitlement to unemployment benefits for those making the transition from employment to unemployment.

\subsubsection{Forecasting}

While nowcasts can make use of very recent indicators of economic and labour market conditions, and typically project forward by only a few years, allowing slowly-changing

\footnotetext{
${ }^{23}$ In the US, where there is also an interest in predicting current indicators, child poverty has been nowcast using a simple econometric model based on state level current and lagged economic indicators and benefit receipt statistics (Isaacs and Healy, 2012). This is a feasible approach, rather than using microsimulation, because in the US the poverty threshold is not a function of the income distribution, as it is in the EU, and because welfare benefit receipt is in itself a good predictor of poverty, which is not the case in the EU or elsewhere in the OECD.
} 
factors such as demographic composition to stay the same, forecasts generally project further in time and must rely on assumptions and predictions from other models. In this sense they are usually better seen as drawing out the implications for the income distribution of a particular economic/demographic scenario. For example, Marx et al. (2012) explore the implications of meeting the Europe 2020 targets for employment for indicators of risk of poverty and social exclusion, finding that the composition of any new employment is a key factor. World Bank (2013) uses a similar approach to exploring the implications of meeting both the education and employment targets for the poverty indicators in the countries of Eastern Europe. In both cases there is no tax-benefit microsimulation and it is assumed that tax-benefit effects are as in the underlying micro-data. This is justified on the grounds that future policy reforms are difficult to predict. However, this approach neglects any interactions between socio-demographic and labour market characteristics and the tax-benefit system. Microsimulation can take account of these and, even assuming a constant tax-benefit policy structure and a constant relationship between income levels and tax-benefit parameters, would allow the automatic effects of policies on changing market incomes to be captured.

Nevertheless, as explained in section 3.2.2 above, it is important to be aware that assumptions about the indexation of current policies can have a major effect on distributional outcomes (Sutherland et al., 2008). In some situations enough is known about the probable evolution of policies to include in the predictions the discretionary tax-benefit reform effects, as well as the automatic effects driven by changes in the circumstances of households. In the UK not only are policy reforms often announced several years in advance, but also there is detailed information available about indexation assumptions that are built into official public finance forecasts (HM Treasury, 2013; Table A1), as well as regular and detailed growth and inflation forecasts (OBR, 2013; Table 2.1) that can together be used as baseline assumptions 
in defining policies in the forecast year. Brewer et al. (2011) have forecast child poverty in 2020 using a combination of these types of assumptions, re-weighting and tax-benefit microsimulation. Such an approach not only provides a prediction (in this case that, given the assumptions, the UK will not meet its target for child poverty reduction in 2020) and allows the drivers of the prediction to be identified (through sensitivity analysis) but also allows a "what would it take?" analysis to suggest what combinations of reforms and other changes would be needed to meet the target.

\subsection{Cross country comparisons using microsimulation}

Cross-country comparisons of the effects of policies naturally add value to what can be said about a single country because the broader perspective helps to provide a sense of scale and proportion. They provide the basis for assessing the robustness of results and to generalise conclusions. In addition, considering several countries within the same analysis provides a kind of "laboratory" in which to analyse the effects of similar policies in different contexts or different policies with common objectives (Sutherland, 2014). Comparisons can take several forms. At their simplest the effects of different policies or policy reforms in different countries can be analysed side-by side. Bargain and Callan's (2010) decomposition analysis for France and Ireland is one example of this approach. Another is Avram et al. (2013) who analyse the distributional effects of fiscal consolidation measures within a given period in nine countries.

A second approach is to contrast the effects of a common, hypothetical policy reform in several countries, highlighting the relevance of the interactions of a specific policy design with population characteristics and economic conditions. Often the "reform policy" is designed to highlight features of the existing national system that it replaces or supplements. Examples include Atkinson et al. (2002) and Mantovani et al. (2007) for minimum 
guaranteed pensions, Levy et al. (2007a) for universal child benefits, Callan and Sutherland (1997) for basic income, Bargain and Orsini (2007) and Figari (2010) for in-work benefits, Matsaganis and Flevotomou (2008) for universal housing transfers, Figari et al. (2012b) for the taxation of imputed rent, and Paulus and Peichl (2009) for flat taxes. This type of analysis is usually complicated by the need for the reform policy to be scaled somehow if it is to have an equivalent effect in countries with different levels of income, and because of the need to consider how the reform policies should be integrated with existing national policies. Given that the starting points are different (e.g. the tax systems may treat pensions differently) the net effects will differ too.

A third approach, which was introduced in section 3.2.2 above, is to swap existing policies across countries in order to explore how their effects differ across different populations and economic circumstances. Examples of this kind of "policy learning" experiment include a comparison of the effectiveness of benefits for the unemployed in Belgium and the Netherlands (De Lathouwer, 1996) and many studies of the effectiveness of public support for children and their families: Atkinson et al. (1988) for France and the UK; Levy et al. (2007b) for Austria, Spain and the UK; Levy et al. (2009) for Poland, France, Austria and the UK; Salanauskaite and Verbist (2013) for Lithuania, Estonia, Hungary, Slovenia and the Czech Republic; and Popova (2014) who compares Russia with four EU countries.

Policy swap analysis can in principle be done using a set of national microsimulation models, side by side. But Callan and Sutherland (1997) found that the task of making models produce comparable results was formidable, even for just two (arguably) relatively similar countries (Ireland and the UK). This justified the construction of EUROMOD as a multi-country model which now covers all EU Member States (see Box 1). 
Indeed, with some exceptions, many of the studies referred to above make use of EUROMOD. As intended, this greatly facilitates cross-country comparability (particularly of the concepts used), the implementation of common reforms using common code and the mechanics of carrying out policy swaps (transferring coded policies from country A to country B). EUROMOD is designed to be as flexible as possible, allowing a huge range of assumptions to be made about cross-country equivalence of different aspects of policy simulation. One example is the treatment of non take-up of benefits (see section 4.2) another is the default indexation of policies each year (see section 3.2.2). Thus policy swapping is not a mechanical procedure. Each exercise has its own motivation and corresponding decisions to be made about which aspects of policy (and assumptions driving its impact) are to be "borrowed" from elsewhere and which to be retained from the existing local situation.

Here, we give two empirical examples. The first is an example of side-by-side cross-country analysis using EUROMOD from Avram et al. (2013). This compares the distributional effects of the fiscal consolidation measures taken in nine European countries in the period up to 2012 from the start of the financial and economic crisis. ${ }^{24}$ Figure 6 shows the percentage change in average household income due to the measures across the (simulated) 2012 income distribution. The measures include different mixes of increases in income tax and social contributions and cuts in public pensions, other cash benefits and public sector pay.

\footnotetext{
${ }^{24}$ These matter, not only for their immediate effect on income inequality but also because they may have consequences for the political acceptability of the measures (Perotti, 1996) and for the macro-economic recovery (Paulus et al., 2013).
} 
Figure 6. Percentage change in household disposable income due to fiscal consolidation measures 2008-12 by household income decile group
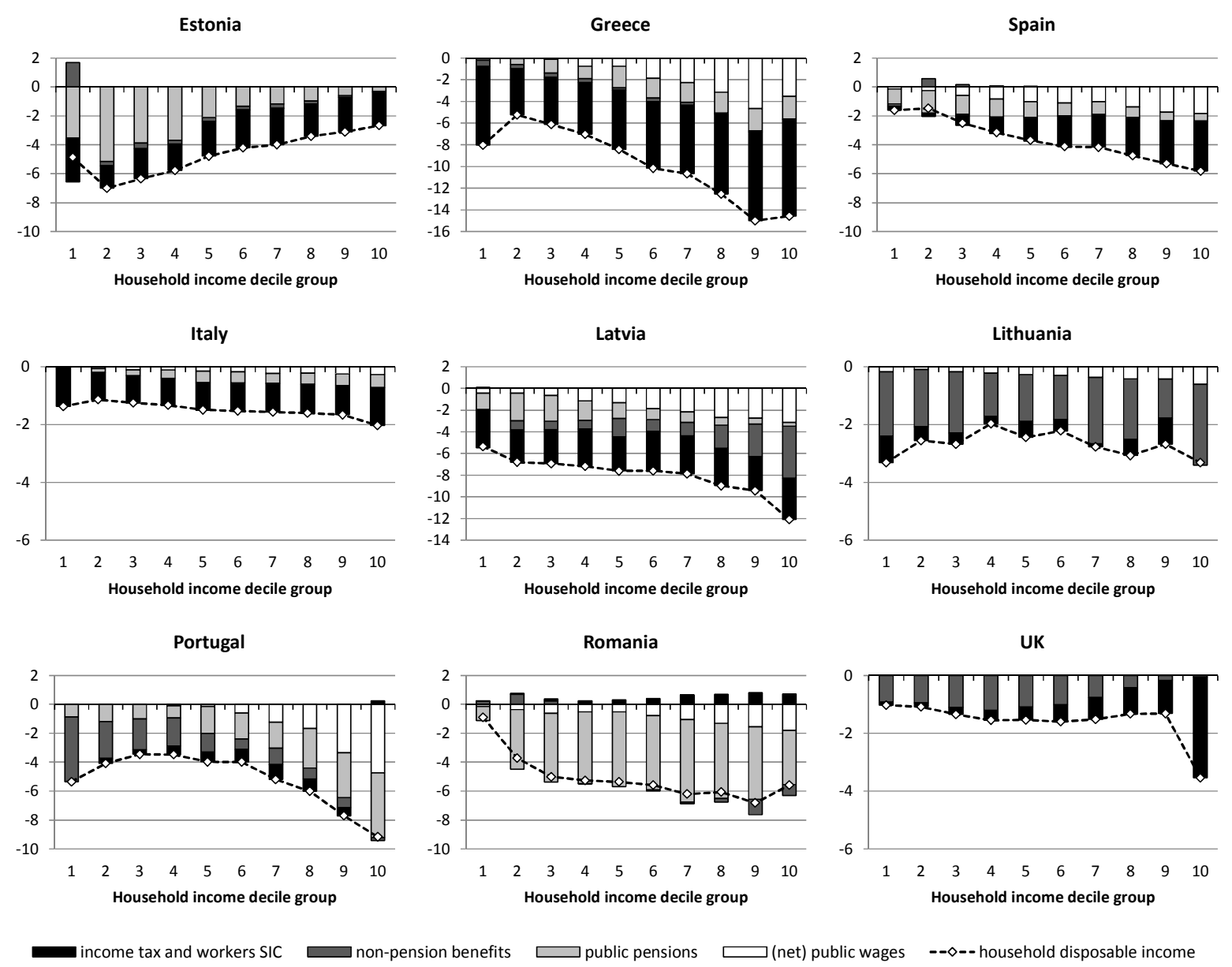

Notes: Deciles are based on equivalised household disposable income in 2012 in the absence of fiscal consolidation measures and are constructed using the modified OECD equivalence scale to adjust incomes for household size. The lowest income group is labelled "1" and the highest "10". The charts are drawn to different scales, but the interval between gridlines on each of them is the same. Source: Avram et al. (2013) using EUROMOD.

Four things are striking about this figure and serve to demonstrate the added value of crosscountry comparisons of this type, relative to single country studies. First, the scale of the effect varies greatly across the countries (noting that the country charts are drawn to different scales but the grid interval is uniformly 2 percentage points), ranging from a drop in income on average from in $1.6 \%$ Italy to $11.6 \%$ in Greece. Secondly the choices made by governments about which instruments to use differ across countries. Thirdly the incidence of the particular changes is not necessarily as one might expect a priori. For example, increases 
in income tax have a roughly proportional effect in many countries and are concentrated on higher income households only in Spain and the UK as might be expected a priori. Cuts in (contributory parental) benefits in Latvia particularly target the better off. Finally, the overall distributional effects range from broadly progressive in Greece, Spain, Latvia and the UK to broadly regressive in Estonia.

The second example is of a policy swap, showing what would happen to child poverty in Poland under a range of child and family tax-benefit arrangements compared with the actual 2005 system including a reform introduced in 2007 and the revenue-neutral alternatives offered by scaled down versions of the Austrian, French and UK systems of child and family support (Levy et al., 2009). As Figure 7 shows, any of the alternative policy systems would have reduced child poverty by more than the actual 2007 reform (costing the same). The French and UK systems would perform especially well from this perspective.

As well as EUROMOD there have been other multi-country initiatives to construct and use microsimulation models. These include a Latin American project that built separate models using a range of software and approaches for Brazil, Chile, Guatemala, Mexico and Uruguay (Urzúa, 2012). A WIDER project has constructed models that are available in simplified form on the web for ten African countries. ${ }^{25}$ To our knowledge neither set of models has been used for cross-country comparisons of the effects of common reforms or for policy swap exercises. In contrast there is an ongoing collaboration among some of the Balkan countries to make use of the EUROMOD platform to build models with the explicit intention that they will be used for comparisons. The Serbian model SRMOD is the first completed step in this process (Ranđelović and Rakić, 2013) followed by the Macedonian model, MAKMOD (Mojsoska Blazevski et al., 2013). Similarly, the South African model SAMOD, again using the EUROMOD platform, (Wilkinson, 2009) has been joined by a sister model for Namibia (NA-

\footnotetext{
${ }^{25} \mathrm{http}: / /$ african-models.wider.unu.edu/
} 
MOD), with the aim, among other things, of modelling "borrowed" policies that have been successful in a South African context (Wright et al., 2014).

\section{Figure 7. Child poverty in Poland under alternative tax-benefit strategies}

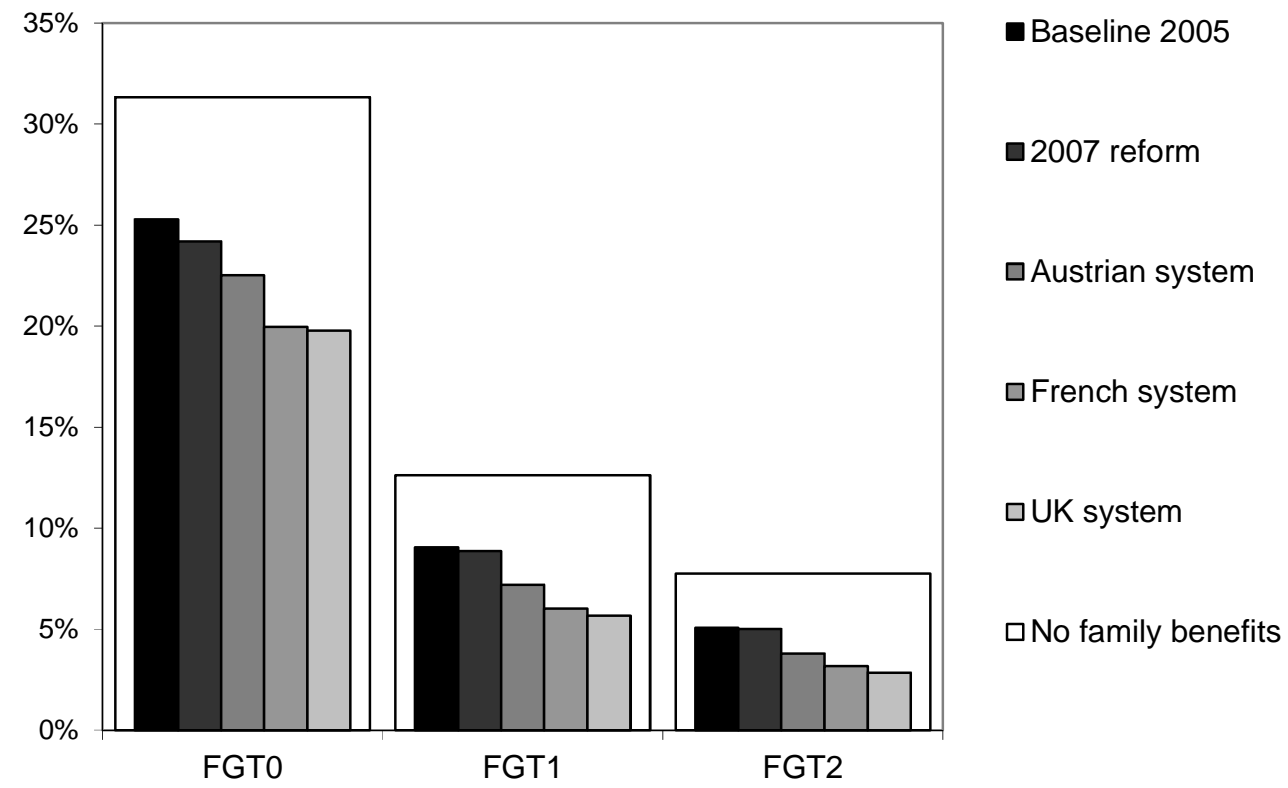

Notes: Poverty is measured using FGT indexes and 60\% of median household disposable income as the poverty threshold. Source: Levy et al. (2009) using EUROMOD.

\section{Challenges and limitations}

\subsection{Reconciling simulated income with recorded income and macro statistics}

A common problem when using micro-data from surveys for the analysis of policies and income distribution is that aggregate values (e.g. of gross earnings or income taxes) do not match estimates from National Accounts or other sources of macro-economic statistics. This problem also applies to microsimulation studies based on survey data, with one exception. Tax-benefit model calculations of benefit entitlements may match administrative totals better 
than information on recorded receipt in the data, if there is a problem of under-reporting of these sources of income in the survey.

Chapter 12 considers the reconciliation of household surveys and national accounts. Here, we focus on a somewhat different issue, also related to the plausibility and usability of empirical findings. This is that the simulated income distribution is not identical to the income distribution that is measured using the underlying survey (or register) micro-data directly. Typically measures of income inequality in microsimulated estimates, using the same microdata and the relevant policy year, are lower. Adjustments in the simulations for the non takeup of benefits and for tax evasion go some way to reducing the discrepancy and these issues are discussed in section 4.2. However, they appear not to be the full explanation and it is clear that the contributory factors differ across countries. Indeed, in some countries for particular datasets and policy years the differences are small: for example, Figari et al. (2012a) show this to be the case for four EU countries using data from the EU Statistics on Income and Living Conditions (EU-SILC) and EUROMOD. However this is by no means always or often the case and reconciling simulated with recorded estimates is an important component of both the process of building a tax-benefit model and validating the content of micro-data from surveys.

As alluded to above, there is evidence that some surveys under-report recipients of some major cash benefits, when compared with administrative statistics. ${ }^{26}$ If the reason for this is failure to report these sources of income by recipients then simulated benefits may perform better, generally leading to higher incomes at the bottom of the distribution and suggesting that the survey over-estimates income inequality. An illustration from the UK is provided in Box 2.

\footnotetext{
${ }^{26}$ For the UK see http://statistics.dwp.gov.uk/asd/frs/2008 09/frs_2008 09 report.pdf, Table M.6. The increasingly used practice of linking surveys to administrative sources of income data should reduce the prevalence of this problem.
} 


\section{Box 2: Benefit recipients in the UK: comparing microsimulation estimates with survey responses and administrative statistics}

The UK Family Resources Survey (FRS) data which is used as input by all the main UK taxbenefit models under-estimates recipiency of some benefits by as much as $30 \%$ in the case of Pension Credit, as shown in the table below.* Simulations using the UK component of EUROMOD based on the same data halve the amount of the discrepancy for Pension Credit. The simulations take account of non take-up by applying official estimates for each benefit and client group. Simulations are also closer to the administrative data values in the case of Housing Benefit (where the shortfall is $2 \%$ compared with $19 \%$ in the data) but in the case of Working Tax Credit the simulated shortfall is larger. The entitlement here mainly depends on being in low paid work over the year allowing families to meet the eligibility criteria for Working Tax Credit for short periods which is not captured by the simulations based on current income and circumstances. For the other two payments shown in the table, EUROMOD over- rather than under- estimates recipiency. The over-estimation of Child Tax Credit recipients is to some extent explained by the administrative statistics not containing some long-term recipients of Income Support, whose child payments are still waiting to be migrated to the tax credit system. Most simulated and non-simulated benefits are included in the means-test for the Council Tax Benefit: its overestimation is expected to the extent that some non-simulated benefits are under-reported and tax credits are under-simulated.

Clearly, simulating receipt is not a solution in itself and a comprehensive reconciliation needs other benefit-specific factors to be taken into account.

Numbers of recipients of selected UK benefits in 2009/10: estimates from Family Resources Survey (FRS), EUROMOD and administrative statistics (thousands)

\begin{tabular}{lccccc}
\hline & FRS & EUROMOD & $\begin{array}{c}\text { Administrative } \\
\text { statistics }\end{array}$ & $\begin{array}{c}\text { Ratio } \\
\text { FRS/external }\end{array}$ & $\begin{array}{c}\text { Ratio } \\
\text { EUROMOD/external }\end{array}$ \\
\hline $\begin{array}{l}\text { Working Tax } \\
\text { Credit }\end{array}$ & 1,800 & 1,615 & 2,240 & 0.80 & 0.72 \\
$\begin{array}{l}\text { Child Tax } \\
\text { Credit }\end{array}$ & 3,700 & 4,951 & 4,090 & 0.90 & 1.16 \\
$\begin{array}{l}\text { Pension } \\
\begin{array}{l}\text { Credit } \\
\text { Housing }\end{array}\end{array}$ & 1,800 & 2,337 & 2,580 & 0.70 & 0.85 \\
$\begin{array}{l}\text { benefit } \\
\text { Council tax }\end{array}$ & 3,700 & 4,474 & 4,550 & 0.81 & 0.98 \\
benefit & 5,100 & 6,331 & 5,570 & 0.92 & 1.14
\end{tabular}

Source: EUROMOD version F6.20 with adjustments for non-take-up, using Family Resources Survey 2009/10 updated to $2010 / 11$ incomes.

* After adjusting the administrative statistics for recipients not living in UK private households in the case of Pension Credit. 
Shortfalls in reported receipt of means-tested welfare benefits compared with administrative information are also found in US surveys, on a larger scale (Meyer et al., 2009). Wheaton (2007) uses microsimulation to calculate entitlement and then to calibrate the numbers of recipients so that they match administrative statistics. The result is a large increase in the estimated extent of poverty reduction due to the programs in question.

However, as illustrated in Box 2, under-reporting of benefit income may not be the only source of the problem. If part of the reason for the shortfall in the survey is that benefit recipients are more likely to be non-respondents, then microsimulation of eligibility and entitlement is unlikely to solve the problem on its own and benefit recipiency estimates will still not match administrative information. In this case re-calculation of the survey weights including controls for characteristics that are correlated with benefit receipt and also underrepresented in the survey may in principle provide a solution, if such characteristics can be identified and external information is available to control the process. This is not often the case.

There are many possible reasons for discrepancies in each simulated income component. Here we discuss income tax as an important example. First, survey estimates of income tax may not relate to the current year or may include only withholding taxes. Second, survey gross incomes (and hence taxes) may have been imputed from net income (see also section 2.1) but their quality and consistency with calculations in the tax-benefit model is usually difficult to establish due to detailed documentation not being made available. We might also expect some discrepancies when compared with fiscal data. Such comparisons necessarily take national specifics into account, including the nature of the tax structure and administration as well as the questions asked in the survey. The nature of the comparison and the conclusions that are drawn also depend on whether fiscal data are available at micro-level and whether they can be matched to the survey. In addition the fiscal data themselves may 
not provide a fully reliable benchmark, especially if they are based on samples of administrative data or if the administrative process that generates them is not comprehensive or consistent. We provide a case study in Appendix B based on a published table of fiscal statistics, for the UK.

Microsimulation estimates of income taxes may be over- or under- estimated relative to what is shown by fiscal data. For example, income tax may be under-estimated because the market incomes that make up the tax base are under-reported or the survey does not adequately represent high income taxpayers. In this case estimates of income distribution are sometimes adjusted by inflating incomes at the top of the distribution, informed by fiscal data. This is the case for the official estimates of poverty and income distribution produced by the UK Department of Work and Pensions (DWP, 2013) though the same adjustment is not (to our knowledge) applied in UK tax-benefit models. In contrast, the French model TAXIPP merges micro-data and statistics from many sources for its input database. ${ }^{27}$ This includes information on top incomes specifically to capture correctly the very top of the distribution and particularly the taxes paid by that section of the population (Bozio et al., 2012).

Income tax may be over-estimated because of tax evasion that has not been modelled (see section 4.2). It may be over-estimated because it is not possible to model or measure the size of some tax reliefs and common avoidance measures. It may also be under- or over-estimated in line with other simulated income components which are taxable. Combinations of these factors may occur and indeed it is possible for the simulated tax aggregate to match well that from fiscal data but for the distribution of tax paid to be very different - see Appendix B for an example of this. In addition, estimates of gross income and tax liability from fiscal data themselves may be subject to error, due to tax evasion.

\footnotetext{
${ }^{27}$ http://www.ipp.eu/en/tools/taxipp-micro-simulation/
} 
Time periods for income assessments are also important. In surveys that collect current income (as in the UK) which is mainly from a reference time period of a month, the simulation of income tax must assume that the same monthly income was received all year and will not identify cases with tax liability for part of the year. However, the survey response for those with part year incomes will, at least in principle, indicate the correspondingly lower or higher tax payments, already adjusted for part-year incomes. The UK is unusual in collecting short-period current income. Most income surveys ask about annual income (in the previous year) which is the appropriate reference time period for the calculation of tax liabilities. However, it must also be used to simulate the income assessment of social assistance and other means-tested benefits for which the relevant period is generally much shorter than one year. This leads to fewer households being simulated to receive these benefits than shown in the data.

Generally, simulations are only as good as the underlying micro-data and, in the cases where they are necessary, as good as the imputations and adjustments that must be carried out in the absence of all the necessary information. This in turn depends on the specifics of the national benefit and tax systems as well as the quality of the data. In some circumstances it might be appropriate to calibrate and re-weight to try and adjust the baseline simulated distribution of income and its components to match that given by the data directly. Generally, however, such an approach will distort the estimates of change due to a policy reform. A better approach is to try and understand the source of each problem and to make adjustments that can be applied in a consistent way, and with transparent assumptions, across policy scenarios. This highlights the importance not only of validation and adjustment but also of documenting the process so that users of the models and readers of model applications can make their own assessment, based on the research questions at hand. 


\subsection{Modelling non take-up and non-compliance}

One particular challenge arises with benefit non take-up and tax non-compliance. ${ }^{28}$ This is because there is no natural data source with explicit information about these phenomena and modelling each is highly context-specific. Accounting for take-up and non-compliance behaviour in tax-benefit models is important as it affects estimates of fiscal aggregates (i.e. total benefit expenditures and tax revenues) but even more importantly as it can affect various parts of the income distribution in a different way. Furthermore, take-up and compliance behaviour are likely to be affected by tax-benefit policy reforms and, hence, are themselves endogenous factors in the analysis. Even if microsimulation models commonly assume full take-up and compliance this has an important implication for cross-national comparisons as results are unlikely to be consistent, as long as the prevalence and patterns of non take-up and non-compliance vary across countries.

Benefit non take-up refers to the situation where those eligible for a given benefit do not successfully claim it for various reasons. This could be simply due to people not being aware of their entitlement (or even the existence of a particular form of public support), being put off by a complex or time-consuming claiming process, or related to social stigma, i.e. not wanting to appear vulnerable and dependent on others' support. In an economic context, these factors can be summarised as implied costs related to take-up (Hernandez et al., 2007). Another likely key determinant is the size of the entitlement (Blundell et al., 1988), both in absolute terms and relative to other income sources and wealth of the claimant. Benefit takeup tends to be higher for universal benefits as the claiming process is simpler and the associated social stigma lower. Arguably, people are most likely to claim contributory benefits (e.g. for old age and maternity) as these are directly linked to their own previous contributions and, hence, entitlement is perceived to be more justified, while take-up of

\footnotetext{
${ }^{28}$ Benefit take-up is also referred to as welfare participation, especially in the studies on the US.
} 
means-tested benefits tends to be lower. Therefore, assuming full take-up can distort comparisons between various benefits and make some benefits seem more effective than in fact they are. It also matters how extensive and long-established the benefit scheme is, as this contributes to the spread of knowledge among the population. A related phenomenon is benefit leakage, meaning that a benefit is received by those who should not be eligible. This could either indicate an unintentional error on behalf of the benefit administrator or claimant, or benefit fraud.

Studies estimating the scale and determinants of benefit take-up require information on eligibility for a given benefit and actual benefit awards. As benefit eligibility is not directly observed (for a wider population) it must be inferred from relevant individual and household characteristics on the basis of benefit rules - and as such constitutes a microsimulation exercise in itself. Depending on the nature of the rules, especially when income means-testing is involved, there can be complex interactions with other tax-benefit instruments as well as with tax compliance. It is difficult to over-emphasise the importance of data quality in this context, and most precise estimates can presumably be obtained with administrative data providing information as close as possible to that used by the welfare agencies, as well as actual benefit receipt (e.g. Bargain et al. 2012). For this to cover all potentially eligible people and not just claimants, it implies that agencies rely (mainly) on information from existing registries (e.g. tax records) rather than data collection from the claimants. Even then it can still leave some scope for simulation error if the claiming process involves e.g. discretion on behalf of officials awarding benefits. For example, local social welfare offices are in some countries given a considerable level of discretion in deciding who is in greater need and, hence, more qualified for public support. On the other hand, there could be also errors made by the program administrators in the assessment of the eligibility, resulting in an incorrect approval or rejection of the claim. 
This type of administrative data, if it exists, is usually not accessible and most empirical studies have relied on survey data instead. There are however additional challenges with survey data due to potential measurement error in the observed benefit receipts and relevant other characteristics affecting the eligibility and the entitlement calculation - see also section 4.1. For example, survey respondents may have simply forgotten the receipt of a particular benefit, associated it with an incorrect period or benefit type, or intentionally left it unreported (e.g. because of social stigma). There is often also a time delay between becoming entitled and receiving a first payment. Therefore a careful assessment and cleaning of benefit data is usually required (e.g. Hancock and Barker 2005; Matsaganis et al., 2010). Similarly, individual and household characteristics relevant for determining benefit eligibility and entitlement might be reported with error, especially other income sources and/or assets in the case of means-tested benefits. There have been only a few attempts to model the various errors explicitly (Duclos, 1995 and 1997; Hernandez and Pudney, 2007; Zantomio et al., 2010).

The modelling of benefit take-up becomes even more complicated when considering the receipt of multiple benefits (e.g. Dorsett and Heady, 1991; Hancock et al., 2004), interactions with labour supply (e.g. Moffitt, 1983; Keane and Moffitt, 1998; Bingley and Walker, 1997 and 2001) or dynamics in the take-up behaviour (e.g. Blank and Ruggles, 1996; Anderson and Meyer, 1997). Analyses combining several of these aspects are rare, e.g. Chan (2013), and avoiding behavioural responses in other dimensions, such as labour supply, is one reason why many of the recent advances in take-up modelling have concentrated on take-up among the retired or others unable to work (e.g. Hernandez and Pudney, 2007; Pudney et al., 2006; Zantomio et al., 2010). Much of the applied research that has been done is for the UK and US (see above), but, among others, there are also studies for Canada (Whelan, 2010), Finland (Bargain et al., 2012), Germany (Riphahn, 2001; Bruckmeier and Wiemers, 2012), Greece 
and Spain (Matsaganis et al., 2010). ${ }^{29}$ For recent reviews, see Hernanz et al. (2004) and Currie (2004).

Despite general progress with modelling take-up, it remains a challenge to deal with in microsimulation models due to the data requirements and complexities involved. Ideally, taxbenefit models should treat take-up endogenously in simulations, as policy reforms can change take-up behaviour (e.g. Zantomio et al., 2010). Such attempts remain scarce; see e.g. Pudney et al. (2006). A second best approach is to predict the probability of take-up conditional on personal characteristics which are not affected by policy changes and hence remain constant in policy simulations. To predict take-up on the basis of previously estimated statistical models the same explanatory variables need to be present in the data used for the tax-benefit model. Furthermore, take-up is highly circumstantial and a prediction model developed for one benefit in one country is unlikely to perform satisfactorily for other benefits or countries. A simpler approach used commonly to account for incomplete benefit take-up in tax-benefit models is to assign take-up randomly among the group of eligible units for a given benefit such that the aggregate take-up rate matches that in official statistics or previous studies (e.g. Redmond et al., 1998; Sutherland et al., 2008; Hancock and Pudney, 2014). This is obviously a rather crude approach as some people are more likely to claim than others and, hence, it may not be sufficient to align aggregate benefit expenditure with official statistics, particularly if take-up is correlated with the level of entitlement. Another option is to link benefit entitlement to the observed receipt which, however, seriously limits the scope for simulations.

Tax non-compliance (or tax evasion) is the other side of the coin and refers to intentional effort to lower tax liability in unlawful ways. In the context of tax-benefit models, this

\footnotetext{
${ }^{29}$ A number of US studies have focused on non-cash programs such as Food Stamps (e.g. Daponte et al., 1999; Haider et al., 2003) or The Special Supplemental Nutrition Program for Women, Infants, and Children (e.g. Bitler et al., 2003).
} 
concerns primarily income tax and payroll tax evasion, in the form of under-reporting taxable income or over-reporting (income tax) deductions. Compared to benefit non take-up, this is an even more challenging issue for several reasons. First, while take-up is binary by nature (i.e. an eligible person either claims or not), tax compliance is often partial. Second, there is no single data source which would allow the precise measurement of tax evasion - while tax records contain income reported to the tax authority, "true" income remains unobserved. Third, evading taxes may also affect how related incomes are reported to surveys. These constraints point towards the need to combine and utilise multiple data sources to study tax evasion and help to explain why hard empirical evidence at the individual level is very scarce.

Studies estimating the extent and determinants of tax non-compliance by individuals have mainly relied on audited tax records (e.g. Clotfelter, 1983; Feinstein, 1991; Erard, 1993 and 1997; Erard and Ho, 2001; Martinez-Vazquez and Rider, 2005). Although tax audits are designed to detect tax non-compliance, these are typically not carried out randomly and target those more likely to evade on the basis of initial screening. Repeated and extensive random tax audits, from which insights into tax evasion can be inferred for a broader population, have been primarily carried out in the US. However, even audits are unable to detect all noncompliance, especially income under-reporting where cash transactions are involved, and usually have very limited information on individual characteristics.

Surveys offer a much richer set of information on individuals but usually lack a good measure of non-compliance. Some surveys include explicit questions on compliance (e.g. Forest and Sheffrin, 2002) but given its sensitivity the reliability of such self-reported data is unclear (Elffers et al., 1992). On the other hand, studies such as Pissarides and Weber (1989), Lyssioutou et al. (2004) and Hurst et al. (2014) have relied on indirect methods, employing 
econometric models which contrast surveyed income and consumption. These, however, are inevitably cruder and allow for a less detailed analysis of compliance.

Finally, laboratory experiments are common in tax compliance research, see e.g. Alm et al., (1992, 2009, 2012); Laury and Wallace (2005). While experiments allow one potential determinant to be isolated from the rest and for clearer conclusions to be drawn about causality, it is unclear how well conditions in the laboratory reflect the actual behaviour, not least as the subjects are typically students without substantial experience of paying taxes.

Overall, there is substantial evidence on factors influencing people's decision to evade taxes. There are also studies showing that tax non-compliance is more prevalent for income sources which are less easily tracked by the tax authority, see Klepper and Nagin (1989) and Kleven et al. (2011). For example, the extent of under-reporting income from self-employment is notably higher compared to wages and salaries as the latter are usually subject to third party reporting (i.e. by employers), which reduces opportunities for evasion (though does not necessarily eliminate these). Fewer studies have focused on the distributional implications of tax non-compliance (e.g. Johns and Slemrod, 2010; Doerrenberg and Duncan, 2013), some in combination with microsimulation modelling (Benedek and Lelkes, 2011; Leventi et al., 2013). For reviews of theoretical and empirical literature on tax evasion, see Andreoni et al. (1998), Slemrod (2007) and Alm (2012).

However, given the highly specific datasets that are often involved in the study of tax compliance, it is not straightforward to utilise previous findings in tax-benefit models nor is it easy to provide own estimates with the type of data commonly used for microsimulation. This helps to explain why attempts to account for tax non-compliance in tax-benefit models seem to remain very limited (e.g. Ceriani et al., 2013, Matsaganis and Leventi, 2013). On the other hand, this may partly also reflect the fact that microsimulation studies lack details on 
such adjustments. Therefore, the first step towards improving the modelling of tax noncompliance (as well as benefit take-up) is increasing transparency about how this is handled (if at all) in existing models and studies.

\subsection{Assessing the reliability of microsimulation estimates}

The overall credibility of a microsimulation model in simulating the effects of a given taxbenefit policy encompasses different aspects, some of which are interrelated, and include the application of "sound principles of inference in the estimation, testing and validation" (Klevmarken, 2002).

First, the reliability of a microsimulation model is closely tied to its validation and transparency which is indicated by the extent to which the internal features of the model and the validation of the results against external statistics are documented. Unfortunately, a high level of transparency does not characterise many of the microsimulation models used in the academic and policy literature, which tend to be "black boxes". Good practice is to provide a detailed description of all tax-benefit components simulated, including details of assumptions used as well as information about the input data and related transformations or imputations. Documented validation of the output against external statistics on benefit recipients and taxpayers and total expenditure/revenue is also an important component of the informed use of microsimulation models.

Nevertheless, such validation is not a comprehensive assessment for three reasons. First, as illustrated in section 4.1 above, microsimulation estimates and the information available in official statistics may not be comparable conceptually. Secondly, in some countries limited external information is available and in all it is rarely available without a time delay. Thirdly, while it is possible to validate results for existing and past systems it is usually not possible to 
find independent estimates of the effects of policy reforms. A correct baseline does not ensure that the model or its input data can correctly estimate the effect of a reform.

Second, as mentioned by Wolf (2004), a persistent failure of most microsimulation applications is the lack of recognition of the degree of statistical uncertainty associated with the results, some inherent in the sampling process that underlies the input micro-data and some propagated from simulation errors and estimated parameters. The accuracy of the underlying data, the correct and detailed representation of the tax-benefit rules and the actual implementation of the policy parameters in the simulation code determine the point-estimate of the simulated policy. Nevertheless, the correct interpretation of the results should take into account their statistical inference - an aspect often neglected in the microsimulation literature - which also depends on the nature of the model and whether it is purely deterministic or also involves probabilistic or econometric specifications.

To start with, simulations are subject to the same degree of sampling error, measurement error, and misreporting as any other analysis based on survey data. On the one hand, as discussed in section 4.1, simulations can improve the accuracy of results by simulating the exact rules rather than relying on observed values which might be misreported. On the other hand, the simulation process can introduce other sources of errors due to, for example, approximations in the simulation of tax benefit rules, adjustments for non-compliance or nontake up, uprating of monetary parameters and socio-demographic characteristics to the simulation year or ignoring behavioural responses or market adjustments.

In the case of simulation of the first-order effects of policy changes, Goedemé et al. (2013) argue that the lack of attention to the statistical significance of the results is undesirable and unjustified due to the availability of standard routines embedded in most standard statistical software. Moreover, when comparing the statistics related to different scenarios, they show 
the importance of taking into account not only the sampling variance of the separate point estimates but also the covariance between simulated and baseline statistics which are based on the same underlying sample. This can lead to a generally high degree of precision of estimates of the effects of a reform on a particular statistic of interest.

The situation is much less straightforward in the case of more complex simulations involving, for example, revenue-neutral reforms or behavioural reactions which add additional sources of uncertainty due to the use of estimated wage rates to construct the budget set and the preference parameters estimated using econometric models. Despite the growing literature on estimation of labour supply effects of policy changes (see section 3.3), there are only a few examples of studies focussing on the analytical properties of the sampling distribution of the microsimulation outcomes which are affected by simulation uncertainty and estimation uncertainty. The former stems from the simulated choice set that can be different from the one that an agent would choose in reality. The estimation variability comes from the sampling variability of the estimated parameters of the labour supply model (Aaberge et al., 2000). Pudney and Sutherland (1994) derived the asymptotic sampling properties of the most important statistics usually reported in microsimulation studies taking into account the additional uncertainty introduced by the imposition of revenue neutrality in the construction of the confidence intervals. Pudney and Sutherland (1996) augmented the previous analysis deriving analytically the asymptotically-valid confidence intervals of a number of statistics of interest allowing for errors associated with sampling variability, econometric estimation of parameters of a multinomial logit model of female labour supply and stochastic simulation in the calculations. They concluded that the sampling error is the largest source of uncertainty but parameter estimation errors may add additional uncertainty which undermines the practical use of such behavioural models. 
The complexity of the analytical solution associated with very detailed microsimulation model, rather complex policy simulation and sophisticated econometric models has lead to the use of more tractable empirical approaches. Creedy et al. (2007) opted for a simulation approach to approximate the sampling distribution of statistics of interest based on the sampling distribution of the estimated parameters. The approach relies on a number of draws from the parameter distribution of the underlying behavioural model. Moreover, they suggest a simpler and more practical approach in which the functional form of the sampling distribution is assumed to be normal, requiring a small number of draws from the parameter distribution and leading to generally accurate results.

Furthermore, to avoid having to assume the normal distribution for stochastic terms, and exploiting the increasingly available computer power, assessing the statistical reliability of the estimates now commonly relies on re-sampling methods such as the bootstrap which allows one to obtain a set of replicated econometric estimates used in one or more simulation runs, whose variance is used to capture the variability of the statistics of interest. Although the additional uncertainty added by behavioural modelling is not found to be critical for most analysis (e.g. Bargain et al., 2014) there are reasons for concerns when the estimates refer to specific small demographic groups and further developments in this research area are needed.

\section{Broadening the Scope}

\subsection{Extended income, consumption and indirect taxes}

Although disposable income is the most used indicator of living standard, it is widely recognised that economic well-being is a multidimensional concept (see Chapter 3 on Inequality, income and well-being by Fleurbaey et al.). The economic value of the consumption of goods and services, including inter-household transfers, in-kind benefits and 
homeowners' imputed rent related to the main accommodation, is often considered a better indicator than income to measure individual well-being on both theoretical and pragmatic grounds (Meyer and Sullivan, 2011). The exclusion of consumption expenditure and noncash income from empirical studies of the redistributive effect of the tax-benefit systems might also hamper cross-country comparison given the different degree of monetisation of the economy across countries. Moreover, the distributional impact of policy changes may be rather different if non-cash incomes and indirect taxes are included with important implications for the design of policies aiming to fight poverty and social exclusion, since such an omission may lead to imperfect targeting and misallocation of resources. Notwithstanding their importance, most microsimulation models do not include either in-kind benefits or indirect taxes, mainly due to data limitations.

In-kind benefits, such as services related to child and elderly care, education, health and public housing, represent, in European countries, about half of welfare state support and contribute to reducing the inequality otherwise observed in the cash income distribution. The economic value of public in-kind benefits can be imputed at individual or household level on the basis of per capita spending considering the average cost of public services (such as providing care and education services), the gain from paying below-market rent or no rent at all for public housing or the risk-related insurance value approach that considers public health care services equivalent to purchasing an insurance policy with the same cost for individuals who have the same socio-demographic characteristics. See Aaberge et al. (2010a) and Paulus et al. (2010) for empirical evidence across European countries and for methodological insights on the derivation of needs-adjusted equivalence scales which are more appropriate for extended income. However, survey data usually do not include enough information to simulate changes in the value of the benefit due to policy reforms, nor take into account the 
real utilisation by the individual, the quality of the public service, or the discretion in the provision usually applied by local authorities (Aaberge et al., 2010b).

A more comprehensive measure of individual command over resources should include the income value of home ownership as well. This is because the consumption opportunities of homeowners (or individuals living in reduced or free rent housing) differ from those of other individuals due to the imputed rent that represents what they would pay if they lived in accommodation rented at market prices. The inclusion of imputed rent in microsimulation models is becoming more common due to the refinement of different methods to derive a measure of imputed rent (Frick et al., 2010) and also a renewed interest in property taxation. In a cross-country perspective, Figari et al. (2012b) analyse the extent to which including imputed rent in taxable income affects the short run distribution of income and work incentives, showing a small inequality-reducing effect together with a non trivial increase in tax revenue. This offers the opportunity to shift the fiscal burden away from labour and to increase the incentive to work for low income individuals.

Indirect taxes typically represent around $30 \%$ of government revenue. With only few exceptions, household income surveys used as input data for microsimulation models do not include detailed information on expenditures either, preventing micro-level analysis of the combined effect of direct and indirect taxation. The solution usually adopted to overcome this data limitation is to impute information on expenditures into income surveys (Sutherland et al., 2002). Decoster et al. $(2010,2011)$ provide a thoughtful discussion of the methodological challenges and a detailed explanation of the procedure implemented in the context of EUROMOD for a number of European countries. Detailed information on expenditure at household level is derived from national expenditure surveys where goods are usually aggregated according to the Classification of Individual Consumption by Purpose (COICOP), identifying, for example, aggregates such as food, private transport, durables. The value of 
each aggregate of expenditure is imputed into income surveys by means of parametric Engel curves based on disposable income and a set of common socio-economic characteristics present both in income and expenditure datasets. In order to prevent an unsatisfactory matching quality in the tails of the income-expenditure distributions, a two-step matching procedure can be implemented by first estimating the total expenditures and total durable expenditures upon disposable income and socio-demographic characteristics and then predicting the budget share of each COICOP category of goods. Moreover, the matching procedure takes into account the individual propensity for some activities, such as smoking, renting, using public transportation and education services, which are not consumed by a large majority of individuals. Individual indirect tax liability is then simulated according to the legislation in place in each country, considering a weighted average tax rate for each COICOP category of goods imputed in the data.

Most microsimulation models that include the simulation of indirect taxes rely on the assumption of fixed producer prices, with indirect taxes fully passed to the final price paid by the consumer. To relax such an assumption one should go beyond a partial equilibrium framework and link the micro-simulation models to macro models (see Section 3.4) in order to consider the producer as well as consumer response to specific reforms or economy-wide shocks. There is some variety in the ways in which the models deal with the estimation of changes in spending patterns due to the simulated reforms (Capéau et al., 2014). Some models simulate only a non-behavioural first round impact (i.e. quantities or expenditures are kept fixed at the initial level) while others estimate partial behavioural reactions taking into account the income effect on demand for goods and services by means of Engel curves (Decoster et al., 2010) or even full demand systems accounting for the real income effect and the relative price effects (Abramovksy et al., 2012). 
The inclusion of indirect taxes also raises the question of how to measure their incidence. Table 1 shows the incidence of indirect tax payments for three European countries expressed as a percentage of disposable income and as a percentage of expenditure, by decile of equivalised disposable income. In the first case (see the left panel of the table) the regressivity of indirect tax payments is clear: poorer individuals pay a larger proportion of their income in indirect taxes compared to richer individuals mainly due to a larger propensity to consume, or even dissaving reflected by the average expenditures exceeding incomes for the individuals at the bottom of the income distribution (Decoster et al., 2010). However, survey data might suffer from measurement error, in particular from income underrecording (Brewer and O'Dea, 2012), which could give a misleading snapshot of the incomeconsumption pattern at the bottom of the income distribution.

Table 1. Incidence of indirect tax payments

\begin{tabular}{lcccccc}
\hline \multirow{2}{*}{$\begin{array}{l}\text { Income } \\
\text { decile }\end{array}$} & \multicolumn{2}{c}{ As \% of disposable income } & \multicolumn{3}{c}{ As \% of expenditures } \\
\cline { 2 - 7 } & Belgium & Greece & UK & Belgium & Greece & UK \\
\hline 1 & 15.3 & 37.7 & 20.2 & 11.3 & 13.5 & 13.9 \\
2 & 12.0 & 23.4 & 13.5 & 11.8 & 13.9 & 14.0 \\
3 & 11.7 & 19.8 & 12.6 & 12.1 & 14.3 & 13.8 \\
4 & 11.6 & 18.4 & 12.4 & 12.5 & 14.2 & 13.8 \\
5 & 11.4 & 17.6 & 11.8 & 12.7 & 14.2 & 14.1 \\
6 & 11.0 & 16.0 & 11.6 & 12.8 & 14.1 & 14.3 \\
7 & 10.9 & 16.0 & 11.1 & 13.1 & 14.6 & 14.5 \\
8 & 10.8 & 14.9 & 10.7 & 13.3 & 14.2 & 14.7 \\
9 & 10.5 & 14.2 & 9.9 & 13.5 & 14.3 & 14.6 \\
10 & 9.9 & 11.9 & 8.2 & 13.9 & 14.1 & 14.4 \\
\hline Total & 11.1 & 16.0 & 10.8 & 12.9 & 14.2 & 14.3 \\
\hline
\end{tabular}

Notes: decile groups are formed by ranking individuals according to equivalised household disposable income using the modified OECD equivalence scale. Source: Figari and Paulus (2013) based on EUROMOD.

In the second case (i.e. the right panel of the table), indirect tax payments are progressive and poorer individuals pay a slightly smaller proportion of their total expenditure in VAT and excises compared to richer individuals. The main reason for this is that the goods that are exempt from VAT or subject to a lower rate (e.g. food, energy, domestic fuel, children's 
clothing) represent a much larger share of total spending of poorer individuals than of richer individuals (Figari and Paulus, 2013). The distributional pattern of the indirect taxes being regressive with respect to disposable income and proportional or progressive with respect to expenditure reinforces, on empirical grounds, the importance of the choice of the measurement stick that should be used as a benchmark in the welfare analysis (Decoster et al., 2010; Capéau et al., 2014).

The potential of microsimulation models that are capable of simulating direct and indirect taxes within the same framework is reinforced by the renewed interest in the tax shift from direct to indirect taxation in order to enhance the efficiency of the tax system (Decoster and van Camp, 2001; Decoster et al., 2010). In particular, microsimulation models have been used to assess the distributional consequences of a "fiscal devaluation", a revenue-neutral shift from payroll taxes toward value-added taxes that might induce a reduction in labour costs, an increase in net exports and a compression of imports, with an overall improvement in the trade balance (de Mooij and Keen, 2013; European Commission, 2013).

Two general considerations arise from the use of microsimulation models for the analysis of the redistributive effects of indirect taxes. On the one hand, the actual degree of regressivity of indirect taxes might be less than that observed if surveys tend to underreport income more than consumption at the bottom of the income distribution (Brewer and O'Dea, 2012; Meyer and Sullivan, 2011). On the other hand, a more systematic use of simulated income values as generated by a microsimulation model rather than as observed in the data can help in solving the underreporting of income values, closing the gap between reported income and consumption and providing a more robust indicator of living standards for those with a low level of resources. 


\subsection{Dynamic microsimulation and lifetime redistribution}

The importance of investigating the "long-range character" of public policies was already highlighted by Guy Orcutt in the 1950s (Orcutt, 1957) and pioneered through his work in the 1970s on DYNASIM, a dynamic microsimulation model of the US designed to analyse the long term consequences of retirement and ageing issues (Orcutt et al., 1976). A number of reviews survey the existing dynamic microsimulation models, the methodological challenges and the type of uses providing an overall picture of the evolution of the state of play and future research directions for interested readers (Harding, 1993, 1996b; Mitton et al., 2000; Gupta and Harding, 2007, Harding and Gupta, 2007; Li and O'Donoghue, 2013).

Dynamic microsimulation models extend the time frame of the analysis in order to address the long-term distributional consequences of policy changes, widening the perspective of the effects of the policies to encompass the individual lifetime and addressing questions about intra-personal redistribution over the lifecycle (Harding, 1993). Dynamic microsimulation models typically aim to capture two main factors that shape the income distribution in a longterm perspective. First, they cover the changing structure of the population due to evolving individual and household characteristics (such as age, education, household composition) and life events (such as marriage, household formation, birth, migration). Second, they capture the interaction of market mechanisms (e.g. labour market participation, earnings levels) and the tax-benefit system with such characteristics in each point in time.

In particular, they are useful tools to analyse: i) the performance of long-term policies such as pensions and other social insurance programmes such as health and long term care, ii) the consequences of different demographic scenarios, iii) the evolution of inter-temporal processes and behaviours such as wealth accumulation and intergenerational transfers, and iv) the geographical trend of social and economic activities if dynamic microsimulation models 
are supplemented with spatial information (Bourguignon and Bussolo, 2013; Li and O’Donoghue, 2013).

The methodological challenges behind a microsimulation model depend on the scope of the events taken into account and the methodology used to age the population of interest through the period of analysis. The ageing process can be either static or dynamic. With the static ageing method the individual observations are re-weighted to match existing or hypothetical projections of variables of interest. The approach is relatively straightforward but it can become unsatisfactory if the number of variables to be considered simultaneously is large or if one is interested in following individual transitions from one point in time to the next (see also section 3.5.1). The dynamic ageing method builds up a synthetic longitudinal dataset by simulating individual transition probabilities conditioned on past history and cohort constraints that take into account the evolution of the socio-demographic characteristics of interest through the time horizon of the analysis (Klevmarken, 2008). The major source of information for the estimation of the dynamic processes is derived from longitudinal data available in most developed countries although often the duration of the panel is not long enough to observe transitions for large samples of individuals, the main exceptions being the long panel data available in Australia, Germany, the UK and the US. Transitions can be estimated through reduced form models that incorporate deterministic and stochastic components or simulated taking into account behavioural reactions of individuals to other changes which occurred at the same time, based on individual preferences estimated through structural models that take into account the endogeneity of some individual transition probabilities (see section 3.3).

The ageing of individual and household characteristics can be implemented as a discrete or continuous process. The former is usually built around yearly time intervals; it is more straightforward but implies that some simulated events might not respect the real sequence. 
The latter is based on survival functions that consider the joint hazard of occurrence of the simulated events.

In principle, dynamic microsimulation models allow for analysis which is more in line with the theoretical arguments in favour of a lifetime approach to the analysis of the redistributive effects of tax-benefit systems as developed in the welfare economics literature (Creedy, 1999a). Nelissen (1998) is one of the few examples where the annual and lifetime redistributive effects of the social security system (here for the Netherlands) are analysed simultaneously, making use of the same microsimulation model that guarantees comparable simulations of the tax-benefit system in place over a long period of time. In line with other research (e.g. Harding, 1993), Nelissen (1998) finds that the lifetime redistributive effect is considerably smaller than the annual incidence with important policy implications due to the different incidence of various pension schemes on different generations.

Due to the complexity of the ageing process, early dynamic microsimulation models tended not to address the long term implications of policy and policy change on the income distribution as a whole (i.e. population-based models) but rather focussed on specific cohorts of population (cohort models). Nowadays such a distinction is less significant due to the improvements in the modelling set up as well as major improvements in available computing power. However, despite the improvements in dynamic microsimulation modelling, such models are often perceived as black-boxes making it difficult to understand and appreciate their properties. In particular, the lack of good economic theory and sound econometric inference methods are thought to contribute to a sceptical view of these models by the economics profession (Klevmarken, 2008).

Two particular research developments characterise the dynamic microsimulation field. First, this is an area where international collaborations are emerging in an attempt to reduce the 
efforts needed to build very complex models. The Life-Cycle Income Analysis Model (LIAM) stands out as a viable option to provide a general framework for the construction of new dynamic microsimulation models (O'Donoghue et al., 2009) and to be linked to EUROMOD (and other modular-based microsimulation models) in order to exploit the existing parameterisation of tax-benefit systems for the European countries (Liégeois and Dekkers, 2014). Second, most dynamic microsimulation models do not include macro feedback effects and do not have market clearing mechanisms that would require ambitious links to macro models (Bourguignon and Bussolo, 2013). However, due to the number and complexity of the interactions between many social and economic variables involved in the modelling, the integration between dynamic micro and macro models could introduce too much uncertainty in the results to make them useful in a policy context ( $\mathrm{Li}$ and O'Donoghue, 2013).

\subsection{Crossing boundaries: sub- and supra- national modelling}

The natural territorial scope for a microsimulation model is a country or nation. This is because in most countries some or all of the tax-benefit system is legislated and administered nationally, because the micro-data that are used as an input dataset are representative at national level, other data used to update, adjust and validate the model are usually made available at national level, and because the economy and society are usually assumed to exist and operate at this level. However, in some countries policies can vary across regions, sometimes following from (or accompanied by) major differences in politics, history and economic and social characteristics. In some cases the data that are especially suitable as the basis for micro-simulation modelling are only available for one region. For these reasons models may exist for single regions, or national models may be able to capture regional differences in policy. Examples of regional or sub-national models include Decancq et al. (2012) for Flanders (Belgium) and Azzolini et al. (2014) for Trentino (Italy): both are based 
on the EUROMOD framework and the latter exploits a rich dataset that combines administrative and survey data. Examples of national modelling exercises that capture extensive regional differences in policies include Cantó et al. (2014) for Spain.

If the micro-data are representative of each region, then the national model can operate as a federation of regional models, also capturing any national policy competencies. As well as simulating the appropriate policy rules regardless of location (many models for countries with regional policy variation simply opt to simulate policies from a single "representative" region), these federal models can identify the implied flows of resources (redistribution) between regions as well as within them, given budget constraints at either national or regional level. In the US, the most comprehensive in terms of policy coverage is the long-standing microsimulation model, TRIM3, which simulates welfare programs as well as taxes and regional variation in programs, making use of a common national input dataset: the Current Population Survey (CPS) Annual Social and Economic Supplement (ASEC). ${ }^{30}$ See, for example, Wheaton et al. (2011) who compare the effects of policies on poverty across three US states. For Canada, the microsimulation model SPSD/M has been linked to a regional input-output model in order to capture some of the indirect effects of national or provincial tax-benefit policy changes at the provincial level (Cameron and Ezzeddin, 2000).

In the European Union (EU) policies in the 28 Member States vary in structure and purpose to a much greater degree than across US states. Although the EU-SILC data is output harmonised by Eurostat it is far from ideal as an input database for a microsimulation model (Figari et al., 2007) and significant amounts of nationally-specific adjustments are needed to provide the input data for EUROMOD, the only EU-wide model (see Box 1). Indeed, although the supra-national administration of the EU has no relevant policy-making powers (at the time of writing), analysis which considers the EU (or the eurozone) as a whole is ${ }^{30}$ http://trim3.urban.org 
highly relevant to approaching the design of tax-benefit policy measures to encourage economic stabilisation and social cohesion. Analogously to regionalised national models, EUROMOD is able to draw out the implications of potential EU-level policy reforms for between- as well as within-country redistribution (Levy et al., 2013), policy harmonisation and stabilisation (Bargain et al., 2013a), as well as for the EU income distribution.

At the other extreme, microsimulation methods have been used to estimate income distribution and other indicators for small areas. This relies on spatial microsimulation techniques (Tanton and Edwards, 2013) or, more commonly, re-weighting national or regional micro-data so that key characteristics match those from census data for the small area (Tanton et al., 2011). The primary policy use of these models in the developed world generally is to predict the demand for services such as care facilities (for example, Lymer et al. (2009) for Australia and Wu and Birkin (2013) for the UK). In circumstances where the census data provide a good indication of income levels, such as in Australia, they have also been used to provide small area estimates of income distribution and its components (Tanton et al., 2009). Linkage of the census with household budget survey data in the UK has been used to estimate the small area effects of an increase in VAT (Anderson et al., 2014). A similar method known as "poverty mapping" has been applied to developing countries by Elbers et al. (2003) using household budget surveys and census micro-data in order to monitor the geographic concentration of poverty and to evaluate geographic targeting of the poor as a way of re-balancing growing welfare disparities between geographic areas. See, for Vietnam, Lanjouw et al. (2013). 


\section{Conclusions and outlook for the future}

\subsection{What has been achieved so far?}

Tax-benefit modelling is now in widespread use to provide evidence in the policy-making process. Tax-benefit models are used within governments to provide costings of policy reforms and impact assessments of distributional and incentive effects. They are used to assess progress towards meeting targets within relevant policy domains (and may be used to set feasible targets in the first place). They are used to explore the implications of alternative reform options. Other participants in the policy-making process (opposition political parties, special interest groups, NGOs, international organisations and civil society generally) may also put forward their own perspectives and alternative proposals on the basis of microsimulation analysis. All of them may draw on the growing body of microsimulationinformed economic analysis from academic research. Within academia, microsimulation is also now an accepted and recognised part of the toolbox in applied public economics, other branches of applied economics and other disciplines such as quantitative social policy, sociology and political science. Evidence for this is provided by the increasing frequency of publication of articles making use of microsimulation in mainstream journals, as is clear from the references included in this chapter, and reliance on microsimulation analysis in the economic debate as illustrated by the Mirrlees Review (2010).

Microsimulation modelling provides an opportunity for fruitful links between the policymaking and academic communities. There are many instances where methodological developments within academic policy-focussed research have provided new and more sophisticated tools that can be adopted for use by policy-making institutions. One example is the modelling of labour supply responses which is increasingly included in microsimulation models used by government agencies. There are also instances where innovation has taken 
place within government agencies in response to particular policy needs as well as instances of the analytical needs of policy-makers providing the impetus for academic developments. One example from the European Union is the adoption of social targets for Europe 2020 and the need to develop methods of forecasting micro-level indicators. Forging such links can bring additional benefit in the form of more open channels of communication with the official producers and providers of micro-data about the data requirements of microsimulation models and the potential benefits to policy-making.

In our view there are four major strands of technical/methodological achievement and ongoing progress in the use of tax-benefit microsimulation for the analysis of policy and income inequality. A formal framework for disentangling the effect of policies on income distribution is an important step towards helping to understand better how various studies have approached measuring these effects and their consistency. A coherent framework can no doubt greatly increase the clarity and transparency of microsimulation studies and facilitate links with other relevant methodological literature. The devil is in the details and microsimulation modelling offers these in abundance. ${ }^{31}$

Behavioural microsimulation is no longer limited to the academic sphere and it has an increasing impact on policy motivated analysis. Further developments of behavioural models in terms of policy scope (e.g. extending the economic modelling to cover areas such as housing, mobility and saving) and their robustness based on the comparison with ex-post evaluation studies may strengthen their role in the policy and economic debate. Moreover, the cross-fertilization between the analytical and the computational approach to the optimal taxation problem based on behavioural microsimulation models could reinforce the link between public finance theory and applied research.

\footnotetext{
${ }^{31}$ Furthermore, as Spielauer (2011, p. 18) has reflected: "If beauty is to be found in simplicity and mathematical elegance (a view not uncommon in mainstream economics), microsimulation models violate all rules of aesthetics."
} 
The analysis of tax-benefit policies with a clear impact on the labour market participation and the evaluation of the impact of macroeconomic shocks would clearly benefit from the availability of counterfactuals that consider feedback effects between micro and macro level. A fully integrated micro-macro model, although daunting in terms of time and resources required, is potentially an incredibly powerful tool to go beyond the partial equilibrium framework in which microsimulation models operate and to disentangle the effects of macro changes on individual resources, and also to extend the policy scope of the analysis through the linkage to e.g. environmental models. However, the practical, conceptual and methodological challenges are formidable. Even so, falling short of full model integration, improving methods of linking microsimulation analysis to macroeconomic data in various ways has been, and remains, an important part of the developing toolbox.

Cross country comparisons of the effects of policies, and especially policy swap analysis, inform our understanding of the variation in effects of policies in different economic and socio-demographic contexts and, at the same time, offer the opportunity for cross-country "policy learning". The development of EUROMOD, and other multi-country models, has facilitated carrying out this type of analysis while maintaining comparability of concepts and measurement and consistency in the operation of policy rules. There is potential to extend the approach to other global regions than the EU such as southern Africa, Latin America or the Balkan region (within each of which, arguably, policy learning is most relevant). There is also potential to extend beyond the EU to include all OECD countries to aid comparisons, for example, between the EU and the US.

There is room for improvement and for development in two key areas. The first relates to the data and methods that are available for input into and adoption by microsimulation models. Our understanding of how available micro-data may be improved and reconciled with other information, as well as the potential of new forms and sources of data which may improve the 
quality and scope of simulation or facilitate linkage with other models (macro, environmental etc) are areas for attention. In terms of methodological improvements, more attention is clearly needed to assess statistical significance and reliability of results obtained with microsimulation models drawing on various statistical methods.

The second area for improvement relates to the organisation of microsimulation activities. There is much the duplication of effort (with many models doing the same or similar things in some countries), combined with problems of lack of transparency (i.e. lack of documentation, results that are not reproducible by others). Furthermore, most existing models are not made available or accessible to the people who might make use of them. The final two sub-sections explore the outlook for microsimulation and policy analysis along these two dimensions.

\subsection{Data and methodological developments}

Microsimulation models require access to appropriate and good quality micro-datasets that are themselves well-documented and validated against independent information. The trend towards making more use of register (i.e. administrative) data to supply information on income receipt (and in some cases many other variables) is welcome in the sense that it reduces measurement problems and under-reporting and potentially frees up resources (e.g. survey interview time) for the collection of more or better quality data in other dimensions. At the same time, such linkage may introduce new problems. It may delay the timing of delivery of the micro-data if there are limits on the speed of obtaining and processing administrative information. Use of administrative information may raise new concerns about data confidentiality which may result in additional restrictions on the ways in which the datasets can be accessed and by whom. There seem to be trade-offs between using high precision data and widespread access. 
Technological developments may offer possible ways around these trade-offs if models and their micro-level data (both input and output) are housed on a suitably secure server and accessed remotely. This is a mode of working that was pioneered for income distribution analysis by $\operatorname{LIS}^{32}$ and, in spite of the additional complexities associated with microsimulation modelling, has also been successfully deployed in a few other cases. These include the WIDER African models referred to above, as well as two adaptations of national components of EUROMOD: Mefisto for Flanders (Decancq et al., 2012) and Soresi for Austria. ${ }^{33}$ In each of these cases the broad aim of the models is to provide access to modelling capacity by civil society, with the simulation and output options offered to users structured and restricted accordingly. More critically in this context, in each case the providers of the input micro-data have given permission for such access over the web. It remains to be seen whether it will be possible to make use of high-precision administrative data in this way. Even so, there would be other technical and pedagogical challenges to be overcome in offering to the public the full flexibility of a model like EUROMOD using remote access.

More generally there is potential to extend the policy scope and applicability of microsimulation models through the statistical linkage of data from different sources. Given the increasing complexity of tax-benefit systems that operate through direct and indirect taxes, wealth and property taxes, and cash and non-cash benefits, microsimulation models can help in understanding the overall effect on individual material well-being only if more comprehensive surveys become available, cross-links between various administrative datasets are utilised further or systematic and rigorous matching procedures are implemented and documented. A prime example is the analysis of the effects of indirect taxes where any conclusion about incidence and regressivity of taxes can be easily biased by the data

\footnotetext{
${ }^{32} \mathrm{http}$ ///www.lisdatacenter.org/

33 http://soresi.bmask.gv.at/Mefisto/\#
} 
inconsistency observed in particular at the tails of the income distribution, see Decoster et al. (2010) and Brewer and O'Dea (2012).

Finally, making progress on many of the technical challenges associated with microsimulation modelling, most notably the modelling of take-up and compliance behaviour, is also inhibited by lack of suitable data. For example, non-receipt of a benefit entitlement may be explained in many ways ranging from (among other causes) measurement error in the survey responses, lack of information about eligibility on the part of a nonclaimant or a decision not to claim due to the costs of claiming. It is likely that the relative importance of each factor varies with national context and specific benefit. Accurate modelling of the probability of taking up (i.e. receiving, given positive entitlement) a particular benefit in principle needs to take any one or many possible causes into account which typically would be demanding in terms of the data requirements. Modelling of tax noncompliance at the individual level is even more demanding given the concealed nature of such activities and a potentially wider range of possible factors and interactions at play. Progress in these areas can therefore be expected to be patchy and uneven, depending on the specific problems and the data possibilities.

\subsection{The case for a collaborative approach}

Few models are accessible beyond their producers. This leads to a proliferation of many similar models and the (largely wasteful) duplication of effort that this involves. It also limits access to models because building from scratch is time consuming and requires specialist skills; there are significant barriers to entry. Furthermore, the need to provide in the public domain documentation or validation of models that are essentially private to their producers is rarely acted upon. This lack of transparency inhibits proper evaluation of microsimulationbased studies and lack of access inhibits reproducibility of microsimulation analysis. 
Together these factors may reduce the chances of microsimulation-based studies being published in the best scientific journals. As Wolfson (2009, p. 29) says: “... microsimulation modelling still has not achieved the kind of scientific status it deserves. One reason is that many potential users are concerned about the 'black box' nature of microsimulation models. An important step, therefore, is for microsimulation modelling to become a 'glass box' activity, including for example public availability of the model and open source code."

Models are also expensive to maintain and keep up to date. If there were fewer, better models that were made generally accessible this would improve efficiency and quality. A collaborative approach would also bring the various types of use and user closer together and, with the appropriate level of (technical) model flexibility could also facilitate innovations such as model linkages. EUROMOD and TAXSIM provide two rather different examples of models which already take this approach. EUROMOD makes available both tax-benefit codes and input data to anyone with permission to access the original micro-data sources, while TAXSIM provides only the tax code that may be linked to input data of the user's own choosing. $^{34}$

Of course there are also good reasons why microsimulation models are developed as individually- or institutionally- private investments. In some cases the necessary micro-data cannot be made available more widely (e.g. in the case of government models, especially those using administrative data). In the academic sphere there are few incentives to share technical developments as public goods in the matter suggested, especially if they embody a large time investment and if they do not themselves attract academic reward.

\footnotetext{
${ }^{34}$ In addition there are the web-based simplified models referred to above, as well as some web-based developments including the French model OpenFisca http://www.openfisca.fr/
} 
If the benefits of an open and collaborative approach are to be realised the main challenges are to find ways of organising and funding such arrangements that take account of the long term investment aspect, due to the need to maintain models as well as engage in initial construction. This would include developing an incentive structure that recognised the academic value of the work done on the "public good" research infrastructure while eliciting contributions in some form from the users of the models who might otherwise "free ride". In the end, cooperation within the microsimulation community and particularly between academic researchers and policy makers will contribute to the integration of use of microsimulation for policy analysis into the mainstream of economic policy-making (Atkinson, 2009). 


\section{References}

Aaberge, R., M. Bhuller, A. Langørgen, and M. Mogstad (2010a). The distributional impact of public services when needs differ. Journal of Public Economics 94(9-10), 549-562.

Aaberge, R. and U. Colombino (2013). Designing optimal taxes with a microeconometric model of household labour supply. Scandinavian Journal of Economics 115(2), 449-475.

Aaberge, R., U. Colombino, E. Holmoy, B. Strøm, and T. Wennemo (2007). Population ageing and fiscal sustainability: integrating detailed labour supply models with CGE models. In A. Harding and A. Gupta (Eds.), Modelling Our Future: Population Ageing, Social Security and Taxation, Volume 15 of International Symposia in Economic Theory and Econometrics, Chapter 10, pp. 259-290. Amsterdam: Elsevier.

Aaberge, R., U. Colombino, S. Strøm, and T. Wennemo (2000). Joint labour supply of married couples: efficiency and distribution effects of tax and labour market reforms. In L. Mitton, H. Sutherland, and M. Weeks (Eds.), Microsimulation modelling for policy analysis: challenges and innovations, Chapter 13, pp. 269-291. Cambridge: Cambridge University Press.

Aaberge, R., J. K. Dagsvik, and S. Strøm (1995). Labour supply responses and welfare effects of tax reforms. Scandinavian Journal of Economics 97(4), 635-659.

Aaberge, R., A. Langørgen, and P. Lindgren (2010b). The impact of basic public services on the distribution of income in European countries. In A. B. Atkinson and E. Marlier (Eds.), Income and Living Conditions in Europe, Eurostat statistical books, Chapter 15, pp. 329344. Luxembourg: Publications Office of the European Union.

Abramovksy, L., O. Attanasio, and D. Phillips (2012). Demand responses to changes in consumer prices in Mexico: Lessons for policy and an application to the 2010 Mexican tax reforms. Royal Economic Society conference paper.

Adam, S., M. Brewer, and A. Shephard (2006a). Financial work incentives in Britain: comparisons over time and between family types. IFS Working Papers 20, The Institute for Fiscal Studies.

Adam, S., M. Brewer, and A. Shephard (2006b). The poverty trade-off: Work incentives and income redistribution in Britain. The Joseph Rowntree Foundation. Bristol: The Policy Press.

Alm, J. (2012). Measuring, explaining, and controlling tax evasion: lessons from theory, experiments, and field studies. International Tax and Public Finance 19, 54-77.

Alm, J., T. L. Cherry, M. Jones, and M. McKee (2012). Social programs as positive inducements for tax participation. Journal of Economic Behavior \& Organization 84(1), $85-96$.

Alm, J., J. Deskins, and M. McKee (2009). Do individuals comply on income not reported by their employer? Public Finance Review 37(2), 120-141.

Alm, J., G. H. McClelland, and W. D. Schulze (1992). Why do people pay taxes? Journal of Public Economics 48(1), 21-38.

Anderson, B., P. D. Agostini, and T. Lawson (2014). Estimating the small area effects of austerity measures in the UK. In G. Dekkers, M. Keegan, and C. O'Donoghue (Eds.), New Pathways in Microsimulation, Chapter 2, pp. 11-28. Farnham: Ashgate.

Anderson, P. M. and B. D. Meyer (1997). Unemployment insurance takeup rates and the after-tax value of benefits. The Quarterly Journal of Economics 112(3), 913-937.

Andreoni, J., B. Erard, and J. Feinstein (1998). Tax compliance. Journal of Economic Literature 36(2), 818-860. 
Atkinson, A. B. (2009). An enlarged role for tax-benefit models. In O. Lelkes and H. Sutherland (Eds.), Tax and Benefit Policies in the Enlarged Europe: Assessing the Impact with Microsimulation Models, Chapter 2, pp. 33-46. Vienna: Ashgate.

Atkinson, A. B., F. Bourguignon, and P.-A. Chiappori (1988). What do we learn about tax reform from international comparisons? France and Britain. European Economic Review 32(2-3), 343 - 352.

Atkinson, A. B., F. Bourguignon, C. O'Donoghue, H. Sutherland, and F. Utili (2002). Microsimulation of social policy in the European Union: Case study of a European minimum pension. Economica 69, 229-243.

Atkinson, A. B., M. A. King, and H. Sutherland (1983). The analysis of personal taxation and social security. National Institute Economic Review 103, 63-74.

Atkinson, A. B. and E. Marlier (2010). Living conditions in Europe and the Europe 2020 agenda. In A. B. Atkinson and E. Marlier (Eds.), Income and Living Conditions in Europe, Eurostat statistical books, Chapter 1, pp. 21-35. Luxembourg: Publications Office of the European Union.

Atkinson, A. B. and H. Sutherland (1989). Scaling the "poverty mountain": Methods to extend incentives to all workers. In A. Bowen and K. Mayhew (Eds.), Improving Incentives for the Low Paid. London: NEDO, Macmillan.

Atta-Darkua, V. and A. Barnard (2010). Distributional effects of direct taxes and social transfers (cash benefits). In A. B. Atkinson and E. Marlier (Eds.), Income and living conditions in Europe, Eurostat statistical books, Chapter 16, pp. 345-368. Luxembourg: Publications Office of the European Union.

Auerbach, A. J. and D. Feenberg (2000). The significance of federal taxes as automatic stabilizers. The Journal of Economic Perspectives 14(3), 37-56.

Avram, S., F. Figari, C. Leventi, H. Levy, J. Navicke, M. Matsaganis, E. Militaru, A. Paulus, O. Rastrigina, and H. Sutherland (2013). The distributional effects of fiscal consolidation in nine EU countries. EUROMOD Working Paper EM2/13, University of Essex, Colchester.

Azzolini, D., M. Bazzoli, S. De Poli, S. Poy, and C. Fiorio (2014). TREMOD: il modello di microsimulazione per il Trentino. Working Paper 2014-01, FBK-IRVAPP, Trento.

Banbura, M., D. Giannone, and L. Reichlin (2011). Nowcasting. In M. P. Clements and D. F. Hendry (Eds.), The Oxford Handbook of Economic Forecasting. Oxford: Oxford University Press.

Bargain, O. (Ed.) (2007). Microsimulation in action: policy analysis in Europe using EUROMOD, Volume 25 of Research in Labor Economics. Elsevier.

Bargain, O. (2012a). Decomposition analysis of distributive policies using behavioural simulations. International Tax and Public Finance 19(5), 708-731.

Bargain, O. (2012b). The distributional effects of tax-benefit policies under New Labour: A decomposition approach. Oxford Bulletin of Economics and Statistics 74(6), 856-874.

Bargain, O. and T. Callan (2010). Analysing the effects of tax-benefit reforms on income distribution: A decomposition approach. Journal of Economic Inequality 8(1), 1-21.

Bargain, O., M. Dolls, C. Fuest, D. Neumann, A. Peichl, N. Pestel, and S. Siegloch (2013a). Fiscal union in Europe? Redistributive and stabilizing effects of a European tax-benefit system and fiscal equalization mechanism. Economic Policy 28(75), 375-422.

Bargain, O., M. Dolls, H. Immervoll, D. Neumann, A. Peichl, N. Pestel, and S. Siegloch (2013b). Partisan tax policy and income inequality in the U.S., 1979-2007. IZA Discussion Paper 7190. 
Bargain, O., H. Immervoll, and H. Viitamäki (2012). No claim, no pain. Measuring the nontake-up of social assistance using register data. Journal of Economic Inequality 10(3), 375-395.

Bargain, O. and K. Orsini (2007). Beans for breakfast? How portable is the British workfare model? In O. Bargain (Ed.), Microsimulation In Action: Policy Analysis in Europe using EUROMOD, Volume 25 of Research In Labor Economics, pp. 165-198. Elsevier.

Bargain, O., K. Orsini, and A. Peichl (2014, forthcoming). Comparing labor supply elasticities in Europe and the US: New results. Journal of Human Resources.

Benedek, D. and O. Lelkes (2011). The distributional implications of income under-reporting in Hungary. Fiscal Studies 32(4), 539-560.

Bennett, F. and H. Sutherland (2011). The importance of independent income: understanding the role of non-means-tested earnings replacement benefits. ISER Working Paper 201109, University of Essex, Colchester.

Betson, D., D. Greenberg, and R. Kasten (1982). A simulation analysis of the economic efficiency and distribution effects of alternative program structures: the negative income tax versus the credit income tax. In I. Garfinkel (Ed.), Universal versus Income-tested Programs. New York: Academic Press.

Betti, G., G. Donatiello, and V. Verma (2011). The Siena Microsimulation Model (SM2) for net-gross conversion of EU-SILC income variables. International Journal of Microsimulation 4(1), 35-53.

Bingley, P. and I. Walker (1997). The labour supply, unemployment and participation of lone mothers in in-work transfer programmes. The Economic Journal 107(444), 1375-1390.

Bingley, P. and I. Walker (2001). Housing subsidies and work incentives in Great Britain. The Economic Journal 111(471), C86-C103.

Bitler, M. P., J. Currie, and J. K. Scholz (2003). WIC eligibility and participation. The Journal of Human Resources 38, 1139-1179.

Blank, R. M. and P. Ruggles (1996). When do women use Aid to Families with Dependent Children and Food Stamps? The dynamics of eligibility versus participation. The Journal of Human Resources 31(1), 57-89.

Blazevski, N. M., M. Petreski, and D. Petreska (2013). Increasing labour market activity of the poor and females: Let's make work pay in Macedonia. EUROMOD Working Paper EM16/13, University of Essex, Colchester.

Blundell, R. (2006). Earned income tax credit policies: Impact and optimality. The Adam Smith Lecture, 2005. Labour Economics 13(4), 423-443. Special Issue: European Association of Labour Economists, 2nd World Conference SOLE/EALE, USA, 2-5 June 2005.

Blundell, R. (2012). Tax policy reform: the role of empirical evidence. Journal of the European Economic Association 10(1), 43-77.

Blundell, R., P. Chiappori, T. Magnac, and C. Meghir (2007). Collective labour supply: heterogeneity and nonparticipation. Review of Economic Studies 74, 417-445.

Blundell, R., V. Fry, and I. Walker (1988). Modelling the take-up of means-tested benefits: The case of housing benefits in the United Kingdom. The Economic Journal 98(390), 5874.

Blundell, R. and A. Shepard (2012). Employment, hours of work and the optimal taxation of low income families. Review of Economic Studies 79, 481-510. 
Boadway, R. and D. Wildasin (1995). Taxation and savings: A survey. Fiscal Studies 15(3), 19-63.

Borella, M. and F. Coda Moscarola (2010). Microsimulation of pension reforms: Behavioural versus non behavioural approach. Journal of Pension Economics and Finance 9(4), 583607.

Bourguignon, F. and M. Bussolo (2013). Income distribution in computable general equilibrium modelling. In P. B. Dixon and D. W. Jorgenson (Eds.), Handbook of Computable General Equilibrium Modelling, Volume 1A and 1B, Chapter 21, pp. 13831437. Elsevier.

Bourguignon, F., P. A. Chiappori, and R. Hugounenq (1993). Exploring the distribution and incentive effects of tax harmonization. In A. Heimler and D. Meulders (Eds.), Empirical Approaches to Fiscal Policy Modelling. London: Chapman and Hall.

Bourguignon, F., A. S. Robilliard, and S. Robinson (2005). Representative versus real households in the macroeconomic modelling of inequality. In T. J. Kehoe, T. N. Srinivasan, and J. Whalley (Eds.), Frontiers in applied general equilibrium modelling, Chapter 10, pp. 219-254. Cambridge: Cambridge University Press.

Bourguignon, F. and A. Spadaro (2006). Microsimulation as a tool for evaluating redistribution policies. Journal of Economic Inequality 4(1), 77-106.

Bozio, A., B. Fabre, J. Goupille, and Q. Lafféter (2012). Le modéle de micro-simulation TAXIPP - version 0.2. Technical report, Institut des Politiques Publique, Paris.

Brandolini, A., F. D’Amuri, and I. Faiella (2013). Country case study - Italy. In S. P. Jenkins, A. Brandolini, J. Micklewright, and B. Nolan (Eds.), The Great Recession and the Distribution of Household Income, Chapter 7, pp. 130-152. Oxford: Oxford University Press.

Brewer, M., J. Browne, A. Hood, R. Joyce, and L. Sibieta (2013). The short- and mediumterm impacts of the recession on the UK income distribution. Fiscal Studies 34(2), 179201.

Brewer, M., J. Browne, and R. Joyce (2011). Child and working-age poverty from 2010 to 2020. IFS Commentary C121, The Institute for Fiscal Studies, London.

Brewer, M., M. Francesconi, P. Gregg, and J. Grogger (2009). In-work benefit reform in a cross-national perspective - introduction. The Economic Journal 119(535), F1-F14.

Brewer, M. and C. O'Dea (2012). Measuring living standards with income and consumption: evidence from the UK. ISER Working Paper 2012-05, University of Essex, Colchester.

Brewer, M., E. Saez, and A. Shephard (2010). Means-testing and tax rates on earnings. In J. Mirrlees, S. Adam, T. Besley, R. Blundell, S. Bond, R. Chote, M. Gammie, P. Johnson, G. Myles, and J. Poterba (Eds.), Dimensions of Tax Design: The Mirrlees Review, Institute for Fiscal Studies (IFS), Chapter 2, pp. 90-173. Oxford University Press.

Brown, L. J., A. Harris, M. Picton, L. Thurecht, M. Yap, A. Harding, P. B. Dixon, and J. Richardson (2009). Linking microsimulation and macro-economic models to estimate the economic impact of chronic disease prevention. In A. Zaidi, A. Harding, and P. Williamson (Eds.), New Frontiers in Microsimulation Modelling, Chapter 20, pp. 527555. Vienna: Ashgate.

Bruckmeier, K. and J. Wiemers (2012). A new targeting: a new take-up? Non-take-up of social assistance in Germany after social policy reforms. Empirical Economics 43(2), 565580 .

Caldwell, S. B. (1990). Static, Dynamic and Mixed Microsimulation. New York: Department of Sociology, Cornell University, Ithaca. 
Callan, T., K. Coleman, and J. R. Walsh (2007). Assessing the impact of tax-transfer policy changes on poverty: methodological issues and some European evidence. In O. Bargain (Ed.), Micro-Simulation in Action: Policy Analysis in Europe Using EUROMOD, Volume 25 of Research in Labor Economics. Elsevier.

Callan, T., B. Nolan, and J. Walsh (1999). Income tax and social welfare policies. In Budget Perspectives 1999. Dublin: ESRI.

Callan, T. and H. Sutherland (1997). The impact of comparable policies in European countries: Microsimulation approaches. European Economic Review 41(3-5), 627-633. Paper and Proceedings of the Eleventh Annual Congress of the European Economic Association.

Cameron, G. and R. Ezzeddin (2000). Assessing the direct and indirect effects of social policy: integrating input-output and tax microsimulation models at Statistics Canada. In L. Mitton, H. Sutherland, and M. Weeks (Eds.), Microsimulation Modelling for Policy Analysis: Challenges and Innovations, Chapter 3, pp. 42-65. Cambridge: Cambridge University Press.

Cantó, O., M. Adiego, L. Ayala, H. Levy, and M. Paniagua (2014). Going regional: The effectiveness of different tax-benefit policies in combating child poverty in Spain. In G. Dekkers, M. Keegan, and C. O’Donoghue (Eds.), New Pathways in Microsimulation, Chapter 12, pp. 183-202. Farnham: Ashgate.

Capéau, B., A. Decoster, and D. Phillips (2014, forthcoming). Micro-simulation models of consumption and indirect taxation. In C. O'Donoghue (Ed.), Handbook of Microsimulation Modelling. Emerald.

Carone, G., H. Immervoll, D. Paturot, and A. Salomäki (2004). Indicators of unemployment and low-wage traps (marginal effective tax rates on employment incomes). Social, Employment and Migration Working Papers 18, OECD.

Ceriani, L., C. V. Fiorio, and C. Gigliarano (2013). The importance of choosing the data set for tax-benefit analysis. International Journal of Microsimulation 6(1), 86-121.

Chan, M. K. (2013). A dynamic model of welfare reform. Econometrica 81(3), 941-1001.

Clark, T. and A. Leicester (2004). Inequality and two decades of British tax and benefit reforms. Fiscal Studies 25(2), 129-158.

Cleveland, R. W. (2005). Alternative income estimates in the United States: 2003. Current Population Reports P60-228, U.S. Census Bureau.

Clotfelter, C. (1983). Tax evasion and tax rates: An analysis of individual returns. The Review of Economics and Statistics 65(3), 363-373.

Colombino, U. (2013). A new equilibrium simulation procedure with discrete choice models. International Journal of Microsimulation 6(3), 25-49.

Cowell, F. A. (2000). Measurement of inequality. In A. B. Atkinson and F. Bourguignon (Eds.), Handbook of Income Distribution, Volume 1, Chapter 2, pp. 87-166. Elsevier.

Creedy, J. (1999a). Lifetime versus annual income distribution. In J. Silber (Ed.), Handbook on Income Inequality Measurement. Kluwer Academic Publishing.

Creedy, J. (1999b). Modelling indirect taxes and tax reform. Northampton, Mass.: Edward Elgar.

Creedy, J. (2004). Survey reweighting for tax microsimulation modelling. Research in Economic Inequality 12, 229-249.

Creedy, J. and A. Duncan (2002). Behavioural microsimulation with labour supply responses. Journal of Economic Surveys 16(1), 1-39. 
Creedy, J. and N. Hérault (2011). Decomposing inequality and social welfare changes: The use of alternative welfare metrics. Melbourne Institute Working Paper 8/11, University of Melbourne.

Creedy, J. and G. Kalb (2005). Discrete hours labour supply modelling: Specification, estimation and simulation. Journal of Economic Surveys 19(5), 697-734.

Creedy, J., G. Kalb, and H. Kew (2007). Confidence intervals for policy reforms in behavioural tax microsimulation modelling. Bulletin of Economic Research 59(1), 37-65.

Currie, J. (2004). The take up of social benefits. NBER Working Paper 10488.

Daponte, B. O., S. Sanders, and L. Taylor (1999). Why do low-income households not use Food Stamps? Evidence from an experiment. The Journal of Human Resources 34(3), 612-628.

De Lathouwer, L. (1996). A case study of unemployment scheme for Belgium and the Netherlands. In A. Harding (Ed.), Microsimulation and Public Policy, Number 232 in Contributions to economic analysis, Chapter 4, pp. 69-92. Amsterdam: North-Holland, Elsevier.

de Mooij, R. and M. Keen (2013). 'Fiscal devaluation' and fiscal consolidation: The VAT in troubled times. In A. Alesina and F. Giavazzi (Eds.), Fiscal Policy after the Financial Crisis, Chapter 11, pp. 443-485. University of Chicago Press.

de Vos, K. and A. Zaidi (1996). The use of microsimulation to update poverty statistics based on household budget surveys: A pilot study for the UK. In A. Harding (Ed.), Microsimulation and Public Policy, Number 232 in Contributions to economic analysis, Chapter 6, pp. 111-128. Amsterdam: North-Holland, Elsevier.

Decancq, K., A. Decoster, K. Spiritus, and G. Verbist (2012). MEFISTO: A new microsimulation model for Flanders. FLEMOSI Discussion Paper 14.

Decoster, A., J. Loughrey, C. O'Donoghue, and D. Verwerft (2010). How regressive are indirect taxes? A microsimulation analysis for five European countries. Journal of Policy Analysis \& Management 29(2), 326-350.

Decoster, A., J. Loughrey, C. O'Donoghue, and D. Verwerft (2011). Microsimulation of indirect taxes. International Journal of Microsimulation 4(2), 41-56.

Decoster, A. and G. Van Camp (2000). The unit of analysis in microsimulation models for personal income taxes: fiscal unit or household? In L. Mitton, H. Sutherland, and M. Weeks (Eds.), Microsimulation modelling for policy analysis: challenges and innovations, Chapter 2, pp. 15-41. Cambridge: Cambridge University Press.

Decoster, A. and G. Van Camp (2001). Redistributive effects of the shift from personal income taxes to indirect taxes: Belgium 1988-93. Fiscal Studies 22(1), 79-106.

Dekkers, G., H. Buslei, M. Cozzolino, R. Desmet, J. Geyer, D. Hofmann, M. Raitano, V. Steiner, P. Tanda, S. Tedeschi, and F. Verschueren (2010). The flip side of the coin: The consequences of the European budgetary projections on the adequacy of social security pensions. European Journal of Social Security 12(2), 94-121.

Dekkers, G., M. Keegan, and C. O’Donoghue (Eds.) (2014). New Pathways in Microsimulation. Asghate.

Doerrenberg, P. and D. Duncan (2013). Distributional implications of tax evasion: Evidence from the lab. Public Finance Review.

Dolls, M., C. Fuest, and A. Peichl (2012). Automatic stabilizers and economic crisis: US vs. Europe. Journal of Public Economics 96(3-4), 279-294. 
Dorsett, R. and C. Heady (1991). The take-up of means-tested benefits by working families with children. Fiscal Studies 12(4), 22-32.

Dowling, R., J. Skabardonis, J. Halkias, G. McHale, and G. Zammit (2004). Guidelines for calibration of microsimulation models: Framework and applications. Transportation Research Record: Journal of the Transportation Research Board 1876(1), 1-9.

Duclos, J.-Y. (1995). Modelling the take-up of state support. Journal of Public Economics 58(3), $391-415$.

Duclos, J.-Y. (1997). Estimating and testing a model of welfare participation: the case of supplementary benefits in Britain. Economica 64(253), 81-100.

DWP (2013). Households below average income: An analysis of the income distribution 1994/95-2011/12. Technical report, Department for Work and Pensions, London.

Elbers, C., J. Lanjouw, and P. Lanjouw (2003). Micro-level estimation of poverty and inequality. Econometrica 71(1), 355-364.

Elffers, H., H. S. Robben, and D. J. Hessing (1992). On measuring tax evasion. Journal of Economic Psychology 13(4), 545 - 567.

Erard, B. (1993). Taxation with representation: An analysis of the role of tax practitioners in tax compliance. Journal of Public Economics 52(2), 163-197.

Erard, B. (1997). Self-selection with measurement errors. A microeconometric analysis of the decision to seek tax assistance and its implications for tax compliance. Journal of Econometrics 81(2), 319-356.

Erard, B. and C.-C. Ho (2001). Searching for ghosts: who are the nonfilers and how much tax do they owe? Journal of Public Economics 81(1), 25-50.

European Commission (2013). Study on the impacts of fiscal devaluation. Number 36 in Taxation papers. Luxembourg: Publications Office of the European Union.

Feenberg, D. R. and E. Coutts (1993). An introduction to the TAXSIM model. Journal of Policy Analysis and Management 12(1), 189-194.

Feinstein, J. S. (1991). An econometric analysis of income tax evasion and its detection. The RAND Journal of Economics 22(1), 14-35.

Feldstein, M. S. and D. R. Feenberg (1983). Alternative tax rules and personal saving incentives: Microeconomic data and behavioral simulations. In M. S. Feldstein (Ed.), Behavioral Simulation Methods in Tax Policy Analysis. Chicago, London.

Fernández Salgado, M., F. Figari, H. Sutherland, and A. Tumino (2014). Welfare compensation for unemployment in the Great Recession. Review of Income and Wealth 60, S177-S204.

Figari, F. (2010). Can in-work benefits improve social inclusion in the southern European countries? Journal of European Social Policy 20(4), 301-315.

Figari, F., M. Iacovou, A. J. Skew, and H. Sutherland (2012a). Approximations to the truth: Comparing survey and microsimulation approaches to measuring income for social indicators. Social Indicators Research 105(3), 387-407.

Figari, F., H. Immervoll, H. Levy, and H. Sutherland (2011a). Inequalities within couples in Europe: Market incomes and the role of taxes and benefits. Eastern Economic Journal 37, 344-366.

Figari, F., H. Levy, and H. Sutherland (2007). Using the EU-SILC for policy simulation: prospects, some limitations and suggestions. In Comparative EU Statistics on Income and Living Conditions:Issues and Challenges, Eurostat Methodologies and Working Papers, pp. 345-373. Luxembourg: Office for Official Publications of the European Communities. 
Figari, F. and A. Paulus (2013, forthcoming). The distributional effects of taxes and transfers under alternative income concepts: the importance of three 'I's. Public Finance Review.

Figari, F., A. Paulus, and H. Sutherland (2011b). Measuring the size and impact of public cash support for children in cross-national perspective. Social Science Computer Review 29(1), 85-102.

Figari, F., A. Paulus, H. Sutherland, P. Tsakloglou, G. Verbist, and F. Zantomio (2012b). Taxing home ownership: distributional effects of including net imputed rent in taxable income. EUROMOD Working Paper EM4/12, University of Essex, Colchester.

Figari, F., A. Salvatori, and H. Sutherland (2011c). Economic downturn and stress testing European welfare systems. In H. Immervoll, A. Peichl, and K. Tatsiramos (Eds.), Who Loses in the Downturn? Economic Crisis, Employment and Income Distribution, Volume 32 of Research in Labor Economics, pp. 257-286. Emerald Group Publishing Limited.

Flood, L. (2007). Can we afford the future? An evaluation of the new Swedish pension system. In A. Harding and A. Gupta (Eds.), Modelling Our Future: Population Ageing, Social Security and Taxation, Volume 15 of International Symposia in Economic Theory and Econometrics, Chapter 2, pp. 33-54. Amsterdam: Elsevier.

Forest, A. and S. M. Sheffrin (2002). Complexity and compliance: An empirical investigation. National Tax Journal 55(1), 75-88.

Fortin, N., T. Lemieux, and S. Firpo (2011). Decomposition methods in economics. In O. Ashenfelter and D. Card (Eds.), Handbook of Labor Economics, Volume 4, Part A, Chapter 1, pp. 1-102. Elsevier.

Frick, J. R., M. M. Grabka, T. M. Smeeding, and P. Tsakloglou (2010). Distributional effects of imputed rents in five European countries. Journal of Housing Economics 19(3), 167179.

Fuest, C., J. Niehues, and A. Peichl (2010). The redistributive effects of tax benefit systems in the enlarged EU. Public Finance Review 38(4), 473-500.

Fullerton, D. and G. E. Metcalf (2002). Tax incidence. In A. J. Auerbach and M. Feldstein (Eds.), Handbook of Public Economics, Volume 4, Chapter 26, pp. 1787-1872. Elsevier.

Goedemé, T., K. Van den Bosch, L. Salanauskaite, and G. Verbist (2013). Testing the statistical significance of microsimulation results: A plea. International Journal of Microsimulation 6(3), 50-77.

Gomulka, J. (1992). Grossing up revisited. In R. Hancock and H. Sutherland (Eds.), Microsimulation Models for Public Policy Analysis: New Frontiers, Number 17 in STICERD Occasional Papers, pp. 121-132. London: London School of Economics.

Gupta, A. and A. Harding (Eds.) (2007). Modelling Our Future: Population Ageing, Health and Aged Care, Volume 16 of International Symposia in Economic Theory and Econometrics. Amsterdam: Elsevier.

Gupta, A. and V. Kapur (Eds.) (2000). Microsimulation in Government Policy and Forecasting. Number 247 in Contributions to economic analysis. Amsterdam: NorthHolland.

Haan, P. (2010). A multi-state model of state dependence in labour supply. Labour Economics 17(2), 323-335.

Haider, S. J., A. Jacknowitz, and R. F. Schoeni (2003). Food Stamps and the elderly: Why is participation so low? The Journal of Human Resources 38, 1080-1111.

Hancock, R. (2000). Charging for care in later life: an exercise in dynamic microsimulation. In L. Mitton, H. Sutherland, and M. Weeks (Eds.), Microsimulation modelling for policy 
analysis: challenges and innovations, Chapter 10, pp. 226-237. Cambridge: Cambridge University Press.

Hancock, R. and G. Barker (2005). The quality of social security benefit data in the British Family Resources Survey: implications for investigating income support take-up by pensioners. Journal of the Royal Statistical Society: Series A (Statistics in Society) 168(1), 63-82.

Hancock, R., J. Malley, R. Wittenberg, M. Morciano, L. Pickard, D. King, and A. ComasHerrera (2013). The role of care home fees in the public costs and distributional effects of potential reforms to care home funding for older people in England. Health Economics, Policy and Law 8(1), 47-73.

Hancock, R. and S. Pudney (2014). Assessing the distributional impact of reforms to disability benefits for older people in the UK: implications of alternative measures of income and disability costs. Ageing and Society 34(2), 232-257.

Hancock, R., S. Pudney, G. Barker, M. Hernandez, and H. Sutherland (2004). The take-up of multiple means-tested benefits by British pensioners: Evidence from the Family Resources Survey. Fiscal Studies 25(3), 279-303.

Harding, A. (1993). Lifetime income distribution and redistribution. Application of a microsimulation model. Number 221 in Contributions to economic analysis. Amsterdam: North-Holland.

Harding, A. (1996a). Introduction and overview. In A. Harding (Ed.), Microsimulation and Public Policy, Number 232 in Contributions to economic analysis, Chapter 1, pp. 1-22. Amsterdam: North-Holland, Elsevier.

Harding, A. (Ed.) (1996b). Microsimulation and public policy. Number 232 in Contributions to economic analysis. Amsterdam: North-Holland, Elsevier. Selected papers from the IARIW Special Conference on Microsimulation and Public Policy, Canberra, 5-9 December, 1993.

Harding, A. and A. Gupta (Eds.) (2007). Modelling Our Future: Population Ageing, Social Security and Taxation, Volume 15 of International Symposia in Economic Theory and Econometrics. Amsterdam: Elsevier.

Hérault, N. (2010). Sequential linking of computable general equilibrium and microsimulation models: Comparison of behavioural and reweighting techniques. International Journal of Microsimulation 3(1), 35-42.

Hernandez, M. and S. Pudney (2007). Measurement error in models of welfare participation. Journal of Public Economics 91(1-2), 327-341.

Hernandez, M., S. Pudney, and R. Hancock (2007). The welfare cost of means-testing: pensioner participation in Income Support. Journal of Applied Econometrics 22(3), 581598.

Hernanz, V., F. Malherbet, and M. Pellizzari (2004). Take-up of welfare benefits in OECD countries: A review of the evidence. Social, Employment and Migration Working Papers 17, OECD.

HM Treasury (2013). Budget 2013: Policy costings. Technical report, London.

HMRC (2012). The Exchequer effect of the 50 per cent additional rate of income tax. Technical report, HM Revenue \& Customs.

Hungerford, T. L. (2010). The redistributive effect of selected federal transfer and tax provisions. Public Finance Review 38(4), 450-472. 
Hurst, E., G. Li, and B. Pugsley (2014). Are household surveys like tax forms: evidence from income underreporting of the self-employed. Review of Economics \& Statistics 96(1), 1933.

Ilmakunnas, S. and S. Pudney (1990). A model of female labour supply in the presence of hours restrictions. Journal of Public Economics 41(2), 183-210.

Immervoll, H. (2004). Average and marginal effective tax rates facing workers in the EU: A micro-level analysis of levels, distributions and driving factors. Social, Employment and Migration Working Papers 19, OECD.

Immervoll, H. (2005). Falling up the stairs: The effects of 'bracket creep' on household incomes. Review of Income and Wealth 51(1), 37-62.

Immervoll, H., H. J. Kleven, C. T. Kreiner, and E. Saez (2007). Welfare reform in European countries: a microsimulation analysis. The Economic Journal 117(516), 1-44.

Immervoll, H., H. Levy, C. Lietz, D. Mantovani, C. O'Donoghue, H. Sutherland, and G. Verbist (2006a). Household incomes and redistribution in the European Union: Quantifying the equalizing properties of taxes and benefits. In D. Papadimitriou (Ed.), The Distributional Effects of Government Spending and Taxation, pp. 135-165. Palgrave Macmillan.

Immervoll, H., H. Levy, C. Lietz, D. Mantovani, and H. Sutherland (2006b). The sensitivity of poverty rates to macro-level changes in the European Union. Cambridge Journal of Economics 30(2), 181-199.

Immervoll, H. and C. O'Donoghue (2001). Imputation of gross amounts from net incomes in household surveys: an application using EUROMOD. EUROMOD Working Paper EM1/01, University of Cambridge.

Immervoll, H. and C. O'Donoghue (2004). What difference does a job make? The income consequences of joblessness in Europe. In D. Gallie (Ed.), Resisting Marginalisation: Unemployment Experience and Social Policy in the European Union, Chapter 5. Oxford: Oxford University Press.

Isaacs, J. B. and O. Healy (2012). The recession's ongoing impact on children, 2012. Technical report, The Urban Institute.

Jara, H. X. and A. Tumino (2013). Tax-benefit systems, income distribution and work incentives in the European Union. International Journal of Microsimulation 6(1), 27-62.

Jenkins, S. P. (2011). Changing Fortunes: Income Mobility and Poverty Dynamics in Britain. Oxford University Press.

Johns, A. and J. Slemrod (2010). The distribution of income tax noncompliance. National Tax Journal 63(3), 397-418.

Keane, C., T. Callan, M. Savage, J. Walsh, and K. Timoney (2013). Identifying policy impacts in the crisis: Microsimulation evidence on tax and welfare. Journal of the Statistical and Social Inquiry Society of Ireland 42, 1-14.

Keane, M. P. (2010). Structural vs. atheoretic approaches to econometrics. Journal of Econometrics 156(1), 3-20.

Keane, M. P. and R. Moffitt (1998). A structural model of multiple welfare program participation and labor supply. International Economic Review 39(3), 553-589.

Kim, K. and P. J. Lambert (2009). Redistributive effect of U.S. taxes and public transfers, 1994-2004. Public Finance Review 37(1), 3-26. 
King, M. A. (1983). The distribution of gains and losses from changes in the tax treatment of housing. In M. Feldstein (Ed.), Behavioural Simulation Methods in Tax Policy Analysis. Chicago,: University of Chicago Press.

Klepper, S. and D. Nagin (1989). The anatomy of tax evasion. Journal of Law, Economics, \& Organization 5(1), 1-24.

Kleven, H. J., M. B. Knudsen, C. T. Kreiner, S. Pedersen, and E. Saez (2011). Unwilling or unable to cheat? Evidence from a tax audit experiment in Denmark. Econometrica 79(3), 651-692.

Klevmarken, N. A. (1997). Behavioral modeling in micro simulation models. A survey. Department of Economics, Working Paper 31, Uppsala University. Unpublished manuscript.

Klevmarken, N. A. (2002). Statistical inference in micro-simulation models: incorporating external information. Mathematics and Computers in Simulation 59(1-3), 255-265.

Klevmarken, N. A. (2008). Dynamic microsimulation for policy analysis: Problems and solutions. In A. Klevmarken and B. Lindgren (Eds.), Simulating an Ageing Population: A Microsimulation Approach Applied to Sweden, Volume 285 of Contributions to Economic Analysis, Chapter 2, pp. 31-53. Emerald Group Publishing Limited.

Kotlikoff, L. J. and D. Rapson (2007). Does it pay, at the margin, to work and save? Measuring effective marginal taxes on Americans' labor supply and saving. Tax Policy and the Economy 21, 83-143.

Lanjouw, P., M. Marra, and C. Nguyen (2013). Vietnam's evolving poverty map: patterns and implications for policy. Policy Research Working Paper 6355, The World Bank, Washington, DC.

Laury, S. and S. Wallace (2005). Confidentiality and taxpayer compliance. National Tax Journal 58(3), 427 - 438.

Lelkes, O. and H. Sutherland (Eds.) (2009). Tax and Benefit Policies in the Enlarged Europe: Assessing the Impact with Microsimulation Models, Volume 35 of European Centre Vienna, Public Policy and Social Welfare. Vienna: Ashgate.

Leventi, C., M. Matsaganis, and M. Flevotomou (2013). Distributional implications of tax evasion and the crisis in Greece. EUROMOD Working Paper EM17/13, University of Essex, Colchester.

Levy, H., C. Lietz, and H. Sutherland (2007a). A guaranteed income for europe's children? In S. P. Jenkins and J. Micklewright (Eds.), Inequality and Poverty Re-examined. Oxford: Oxford University Press.

Levy, H., C. Lietz, and H. Sutherland (2007b). Swapping policies: Alternative tax-benefit strategies to support children in Austria, Spain and the UK. Journal of Social Policy 36, 625-647.

Levy, H., M. Matsaganis, and H. Sutherland (2013). Towards a European Union child basic income? Within and between country effects. International Journal of Microsimulation 6(1), 63-85.

Levy, H., L. Morawski, and M. Myck (2009). Alternative tax-benefit strategies to support children in Poland. In O. Lelkes and H. Sutherland (Eds.), Tax and Benefit Policies in the Enlarged Europe: Assessing the Impact with Microsimulation Models, Volume 35 of Public Policy and Social Welfare, Chapter 6, pp. 125-151. Vienna: Asghate.

Li, J. and C. O'Donoghoue (2013). A methodological survey of dynamic microsimulation models. International Journal of Microsimulation 6(2), 3-55. 
Liégeois, P. and G. Dekkers (2014). Combining EUROMOD and LIAM tools for the deveopment of dynamic cross-sectional microsimulation models: a snack preview. In G. Dekkers, M. Keegan, and C. O'Donoghue (Eds.), New Pathways in Microsimulation, Chapter 13, pp. 203-216. Farnham: Ashgate.

Lymer, S., L. Brown, A. Harding, and M. Yap (2009). Predicting the need for aged care services at the small area level: The CAREMOD Spatial Microsimulation Model. International Journal of Microsimulation 2(2), 27-42.

Lynn, P., A. Jäckle, S. P. Jenkins, and E. Sala (2012). The impact of questioning method on measurement error in panel survey measures of benefit receipt: evidence from a validation study. Journal of the Royal Statistical Society: Series A (Statistics in Society) 175(1), 289308.

Lyssiotou, P., P. Pashardes, and T. Stengos (2004). Estimates of the black economy based on consumer demand approaches. The Economic Journal 114(497), 622-640.

Mabbett, D. and W. Schelke (2007). Bringing macroeconomics back into the political economy of reform: the Lisbon Agenda and the 'fiscal philosophy' of EMU. JCMS: Journal of Common Market Studies 45(1), 81-103.

Mahler, V. A. and D. K. Jesuit (2006). Fiscal redistribution in the developed countries: new insights from the Luxembourg Income Study. Socio-Economic Review 4(3), 483-511.

Mantovani, D., F. Papadopoulos, H. Sutherland, and P. Tsakloglou (2007). Pension incomes in the European Union: Policy reform strategies in comparative perspective. In O. Bargain (Ed.), Microsimulation In Action: Policy Analysis in Europe using EUROMOD, Volume 25 of Research In Labor Economics, pp. 27-71. Elsevier.

Martinez-Vazquez, J. and M. Rider (2005). Multiple modes of tax evasion: Theory and evidence. National Tax Journal 58(1), 51-76.

Marx, I., P. Vandenbroucke, and G. Verbist (2012). Can higher employment levels bring down relative income poverty in the EU? Regression-based simulations of the Europe 2020 target. Journal of European Social Policy 22(5), 472-486.

Matsaganis, M. and M. Flevotomou (2008). A basic income for housing? Simulating a universal housing transfer in the Netherlands and Sweden. Basic Income Studies 2(2).

Matsaganis, M. and C. Leventi (2013). The distributional impact of the Greek crisis in 2010. Fiscal Studies 34(1), 83-108.

Matsaganis, M., H. Levy, and M. Flevotomou (2010). Non-take up of social benefits in Greece and Spain. Social Policy \& Administration 44(7), 827-844.

Matsaganis, M., C. O’Donoghue, H. Levy, M. Coromaldi, M. Mercader-Prats, C. F. Rodrigues, S. Toso, and P. Tsakloglou (2006). Reforming family transfers in Southern Europe: Is there a role for universal child benefits? Social Policy \& Society 5(2), 189-197.

McFadden, D. (1974). Conditional logit analysis of qualitative choice behaviour. In P. Zerembka (Ed.), Frontiers in Econometrics. Academic Press.

Merz, J. (1986). Structural adjustment in static and dynamic microsimulation models. In G. Orcutt, J. Merz, and H. Quinke (Eds.), Microanalytic Simulation Models to Support Social and Financial Policy. North-Holland.

Merz, J. (1991). Microsimulation - a survey of principles, developments and applications. International Journal of Forecasting 7(1), 77 - 104.

Meyer, B. D., W. K. C. Mok, and J. X. Sullivan (2009). The under-reporting of transfers in household surveys: Its nature and consequences. NBER Working Paper 15181. 
Meyer, B. D. and J. X. Sullivan (2011). Further results on measuring the well-being of the poor using income and consumption. Canadian Journal of Economics 44(1), 52-87.

Mirrlees, J., S. Adam, T. Besley, R. Blundell, S. Bond, R. Chote, M. Gammie, P. Johnson, G. Myles, and J. Poterba (Eds.) (2010). Dimensions of Tax Design: The Mirrlees Review. Oxford: Oxford University Press.

Mitton, L., H. Sutherland, and M. Weeks (Eds.) (2000). Microsimulation Modelling for Policy Analysis: Challenges and Innovations. Cambridge: Cambridge University Press.

Moffitt, R. (1983). An economic model of welfare stigma. The American Economic Review 73(5), 1023-1035.

Morawski, L. and M. Myck (2010). 'Klin'-ing up: Effects of Polish tax reforms on those in and on those out. Labour Economics 17(3), 556 - 566.

Navicke, J., O. Rastrigina, and H. Sutherland (2013, forthcoming). Nowcasting indicators of poverty risk in the European Union: A microsimulation approach. Social Indicators Research.

Nelissen, J. H. (1998). Annual versus lifetime income redistribution by social security. Journal of Public Economics 68(2), 223-249.

Nolan, B., T. Callan, and B. Maître (2013). Country case study - Ireland. In S. P. Jenkins, A. Brandolini, J. Micklewright, and B. Nolan (Eds.), The Great Recession and the Distribution of Household Income, Chapter 4, pp. 113-129. Oxford: Oxford University Press.

OBR (2013). Fiscal sustainability report. London: The Stationery Office.

O'Donoghue, C. (2001). Dynamic microsimulation: A methodological survey. Brazilian Electronic Economic Journal 4.

O'Donoghue, C. (Ed.) (2014, forthcoming). Handbook of Microsimulation Modelling. Emerald.

O'Donoghue, C., M. Baldini, and D. Mantovani (2004). Modelling the redistributive impact of indirect taxes in Europe: an application of EUROMOD. EUROMOD Working Paper EM7/01, University of Cambridge.

O'Donoghue, C., J. Lennon, and S. Hynes (2009). The Life-Cycle Income Analysis Model (LIAM): a study of a flexible dynamic microsimulation modelling computing framework. International Journal of Microsimulation 2(1), 16-31.

OECD (2012). Taxing wages 2011. OECD Publishing.

Orcutt, G., S. Caldwell, and R. Wertheimer (1976). Policy explorations through microanalytic simulation. Washington, DC: The Urban Institute.

Orcutt, G., M. Greenberger, J. Korbel, and A. Rivlin (1961). Microanalysis of SocioEconomic Systems: A Simulation Study. New York: Harper and Row.

Orcutt, G. H. (1957). A new type of socio-economic system. The Review of Economics and Statistics 39(2), 116-123.

Paulus, A., F. Figari, and H. Sutherland (2013). The design and distributional effects of fiscal consolidation measures in the European Union. IZA Workshop on the Future of Labor 'The Effects of the Economic Crisis on the Labor Market, Unemployment and Income Distribution', Bonn, February 21-22, 2013.

Paulus, A. and A. Peichl (2009). Effects of flat tax reforms in Western Europe. Journal of Policy Modeling 31(5), 620 - 636. 
Paulus, A., H. Sutherland, and P. Tsakloglou (2010). The distributional impact of in-kind public benefits in European countries. Journal of Policy Analysis \& Management 29(2), $243-266$.

Paulus, A., M. Čok, F. Figari, P. Hegedüs, S. Kralik, N. Kump, O. Lelkes, H. Levy, C. Lietz, D. Mantovani, L. Morawski, H. Sutherland, P. Szivos, and A. Võrk (2009). The effects of taxes and benefits on income distribution in the enlarged EU. In O. Lelkes and H. Sutherland (Eds.), Tax and Benefit Policies in the Enlarged Europe: Assessing the Impact with Microsimulation Models, Volume 35 of Public Policy and Social Welfare, Chapter 4, pp. 65-90. Vienna: Asghate.

Pechman, J. A. (1973). Responsiveness of the federal individual income tax to changes in income. Brookings Papers on Economic Activity (2), 385-427.

Peichl, A. (2009). The benefits and problems of linking micro and macro models - evidence from a flat tax analysis. Journal of Applied Economics 12(2), 301 - 329.

Peichl, A. and S. Siegloch (2012). Accounting for labor demand effects in structural labor supply models. Labour Economics 19(1), 129-138.

Perotti, R. (1996). Fiscal consolidation in Europe: Composition matters. The American Economic Review 86(2), 105-110.

Piketty, T. and E. Saez (2007). How progressive is the U.S. federal tax system? A historical and international perspective. The Journal of Economic Perspectives 21(1), 3-24.

Pissarides, C. A. and G. Weber (1989). An expenditure-based estimate of Britain's black economy. Journal of Public Economics 39, 17-32.

Popova, D. (2014). Distributional impacts of cash allowances for children: a microsimulation analysis for Russia and Europe. EUROMOD Working Paper EM2/14, University of Essex, Colchester.

Pudney, S., R. Hancock, and H. Sutherland (2006). Simulating the reform of means-tested benefits with endogenous take-up and claim costs. Oxford Bulletin of Economics and Statistics 68(2), 135-166.

Pudney, S. and H. Sutherland (1994). How reliable are microsimulation results? An analysis of the role of sampling error in a U.K. tax-benefit model. Journal of Public Economics 53(3), 327-365.

Pudney, S. and H. Sutherland (1996). Statistical reliability in microsimulation models with econometrically-estimated behavioural responses. In A. Harding (Ed.), Microsimulation and Public Policy, Number 232 in Contributions to economic analysis, Chapter 21, pp. 473-503. Amsterdam: North-Holland, Elsevier.

Randelović, S. and J. Ž. Rakić (2013). Improving work incentives in Serbia: evaluation of a tax policy reform using SRMOD. International Journal of Microsimulation 6(1), 157-176.

Redmond, G., H. Sutherland, and M. Wilson (1998). The arithmetic of tax and social security reform. A user's guide to microsimulation methods and analysis. Cambridge: Cambridge University Press.

Riphahn, R. T. (2001). Rational poverty or poor rationality? The take-up of social assistance benefits. Review of Income and Wealth 47(3), 379-398.

Robilliard, A.-S., F. Bourguignon, and S. Robinson (2008). Examining the social impact of the Indonesian financial crisis using a macro-micro model. In F. Bourguignon, M. Bussolo, and L. A. Pereira da Silva (Eds.), The Impact of Macroeconomic Policies on Poverty and Income Distribution: Macro-Micro Evaluation Techniques and Tools, Chapter 4, pp. 93-118. New York: The World Bank and Palgrave Macmillan. 
Rodrigues, C. F. (2007). Income in EU-SILC - Net/gross conversion techniques for building and using EU-SILC databases. In Comparative EU Statistics on Income and Living Conditions: Issues and Challenges, Eurostat Methodologies and Working Papers, pp. 157172. Luxembourg: Office for Official Publications of the European Communities.

Salanauskaite, L. and G. Verbist (2013). Is the neighbour's grass greener? Comparing family support in Lithuania and four other New Member States. Journal of European Social Policy 23(3), 315-331.

Shorrocks, A. (2013). Decomposition procedures for distributional analysis: a unified framework based on the Shapley value. Journal of Economic Inequality 11(1), 99 - 126.

Slemrod, J. (2007). Cheating ourselves: The economics of tax evasion. The Journal of Economic Perspectives 21(1), 25-48.

Spielauer, M. (2011). What is social science microsimulation? Social Science Computer Review 29(1), 9-20.

Stiglitz, J. E. (2012). The price of inequality. New York: W. W. Norton \& Co.

Sutherland, H. (1995). Static microsimulation models in Europe: A survey. Working Papers in Economics 9523, University of Cambridge.

Sutherland, H. (2014, forthcoming). Multi-country microsimulation. In C. O'Donoghue (Ed.), Handbook of Microsimulation Modelling, Chapter 3. Emerald.

Sutherland, H. and F. Figari (2013). EUROMOD: the European Union tax-benefit microsimulation model. International Journal of Microsimulation 6(1), 4-26.

Sutherland, H., R. Hancock, J. Hills, and F. Zantomio (2008). Keeping up or falling behind? The impact of benefit and tax uprating on incomes and poverty. Fiscal Studies 29(4), 467498.

Sutherland, H., R. Taylor, and J. Gomulka (2002). Combining household income and expenditure data in policy simulations. Review of Income and Wealth 48(4), 517-536.

Tanton, R. and K. Edwards (Eds.) (2013). Spatial Microsimulation: A Reference Guide for Users. New York: Springer.

Tanton, R., J. McNamara, A. Harding, and T. Morrison (2009). Small area poverty estimates for Australia's eastern seaboard in 2006. In A. Zaidi, A. Harding, and P. Williamson (Eds.), New Frontiers in Microsimulation Modelling, Chapter 3, pp. 79-95. Vienna: Asghate.

Tanton, R., Y. Vidyattama, B. Nepal, and J. McNamara (2011). Small area estimation using a reweighting algorithm. Journal of the Royal Statistical Society: Series A (Statistics in Society) 174(4), 931-951.

Thoresen, T. O. (2004). Reduced tax progressivity in Norway in the nineties: The effect from tax changes. International Tax and Public Finance 11(4), 487-506.

Urzúa, C. M. (Ed.) (2012). Fiscal inclusive development: Microsimulation models for Latin America. Instituto Tecnológico y de Estudios Superiores de Monterrey (ITESM). International Development Research Centre, United Nations Development Programme.

van Soest, A. (1995). Structural models of family labor supply: A discrete choice approach. The Journal of Human Resources 30(1), 63-88.

Verbist, G. (2007). The distribution effect of taxes on pensions and unemployment benefits in the EU-15. In O. Bargain (Ed.), Microsimulation In Action: Policy Analysis in Europe using EUROMOD, Volume 25 of Research In Labor Economics, pp. 73-99. Elsevier. 
Verbist, G. and F. Figari (2014, forthcoming). The redistributive effect and progressivity of taxes revisited: An international comparison across the European Union. FinanzArchiv/Public Finance Analysis.

Waddell, P., A. Borning, M. Noth, N. Freier, M. Becke, and G. Ulfarsson (2003). Microsimulation of urban development and location choices: Design and implementation of UrbanSim. Networks and Spatial Economics 3(1), 43-67.

Wagstaff, A., E. van Doorslaer, H. van der Burg, S. Calonge, T. Christiansen, G. Citoni, U.G. Gerdtham, M. Gerfin, L. Gross, U. Häkinnen, J. John, P. Johnson, J. Klavus, C. Lachaud, J. Lauridsen, R. E. Leu, B. Nolan, E. Peran, C. Propper, F. Puffer, L. Rochaix, M. Rodríguez, M. Schellhorn, G. Sundberg, and O. Winkelhake (1999). Redistributive effect, progressivity and differential tax treatment: Personal income taxes in twelve OECD countries. Journal of Public Economics 72(1), 73-98.

Wang, C., K. Caminada, and K. Goudswaard (2012). The redistributive effect of social transfer programmes and taxes: A decomposition across countries. International Social Security Review 65(3), 27-48.

Wheaton, L. (2007). Underreporting of means-tested transfer programs in the CPS and SIPP. In 2007 Proceedings of the American Statistical Association, Social Statistics Section, Alexandria, VA, pp. 3622-3629. American Statistical Association.

Wheaton, L., L. Giannarelli, M. Martinez-Schiferl, and S. R. Zedlewski (2011). How do States' safety net policies affect poverty? Working Families Paper 19, The Urban Institute, Washington, DC.

Whelan, S. (2010). The take-up of means-tested income support. Empirical Economics 39(3), $847-875$.

Wilkinson, K. (2009). Adapting EUROMOD for use in a developing country - the case of South Africa and SAMOD. EUROMOD Working Paper EM5/09, University of Essex, Colchester.

Wolf, D. A. (2004). Book review of Microsimulation in Government Policy and Forecasting (2000), Gupta, A. and Kapur, V. (eds). Journal of Artificial Societies and Social Simulation 7(1).

Wolfson, M. (2009). Preface - Orcutt's vision 50 years on. In A. Zaidi, A. Harding, and P. Williamson (Eds.), New Frontiers in Microsimulation Modelling, pp. 21-29. Vienna: Ashgate.

World Bank (2013). Poverty prospects in Europe: Assessing progress towards the Europe 2020 poverty and social exclusion targets in New European Union Member States. Report no: ACS4943, Human Development and Poverty Reduction and Economic Management Units.

Wright, G., M. Noble, and H. Barnes (2014). NAMOD: a Namibian tax-benefit microsimulation model. EUROMOD working paper EM7/14, University of Essex, Colchester.

Wu, B. and M. Birkin (2013). Moses: a dynamic spatial microsimulation model for demographic planning. In R. Tanton and K. L. Edwards (Eds.), Spatial Microsimulation: A Reference Guide for Users, Understanding Population Trends and Processes, pp. 171194. New York: Springer.

Zaidi, A., A. Harding, and P. Williamson (Eds.) (2009). New Frontiers in Microsimulation Modelling, Volume 36 of European Centre Vienna, Public policy and social welfare. Vienna: Ashgate. 
Zaidi, A. and K. Rake (2001). Dynamic microsimulation models: A review and some lessons for SAGE. SAGE Discussion Paper 2, London School of Economics.

Zantomio, F., S. Pudney, and R. Hancock (2010). Estimating the impact of a policy reform on benefit take-up: The 2001 extension to the Minimum Income Guarantee for UK pensioners. Economica 77(306), 234-254. 


\section{Appendix A: Increasing UK Child Benefit in 2001 and 2013: the net effects}

In both 2001 and 2013 the UK Child Benefit was delivered as a universal benefit for all children under the age of 19 in full time non-advanced education. In both years there were two rates, one for the oldest child (£15.50 and $£ 20.30$ respectively, per week) and one for any other children ( $£ 10.35$ and $£ 13.40$ respectively, per week). As an illustration, we double these values and use EUROMOD to calculate the net budgetary cost after the operation of the rest of the tax and benefit systems, and also show how the gain per child would vary across the household income distribution.

In 2001 Child Benefit was disregarded by the income tax system but was taken into account for the assessment of Income Support (and income-related Job Seeker's Allowance), Housing Benefit and Council Tax Benefit, some of the main UK means-tested benefits for working age people and their families. (Working Families Tax Credit disregarded Child Benefit.) As the table shows, while the gross cost of the increase in Child Benefit is estimated as $£ 8.85$ billion per year, once the reduced entitlements to these benefits are taken into account, the net cost falls to $£ 7.01$ billion or (79\% of the gross).

In contrast, in the 2013 system, Child Benefit is disregarded in the assessment of all meanstested payments but higher-income parents who pay income tax at the $40 \%$ (or higher) marginal rate have the value of their Child Benefit included in their tax calculation. Thus, as shown in the table, the cost of the increase in Child Benefit is offset to a small extent by an increase in income tax liabilities. In addition, in 2013 there was a cap on the overall sum of benefits that could be received by families in some circumstances. This would result in some families not receiving all or any of their Child Benefit increase. In 2013 the gross cost of the increase in Child Benefit is estimated as $£ 11.55$ billion per year and once the reduced 
entitlements to these benefits are taken into account, the net cost falls to $£ 11.14$ billion or (96\% of the gross).

Gross and net cost of doubling Child Benefit 2001 and 2013

\begin{tabular}{lcccc}
\hline & \multicolumn{2}{c}{2001} & \multicolumn{2}{c}{2013} \\
\hline & $£$ million per & \% of gross & $£$ million per & \% of gross \\
year & cost & year & cost \\
Child Benefit & $\mathbf{8 , 8 5 0}$ & $\mathbf{1 0 0}$ & $\mathbf{1 1 , 5 4 9}$ & $\mathbf{1 0 0}$ \\
Income tax & 0 & 0 & -290 & -3 \\
Income Support & $-1,606$ & -18 & 0 & 0 \\
Housing Benefit & -152 & -2 & 0 & 0 \\
Council Tax & -81 & -1 & 0 & 0 \\
Benefit & & & & \\
Benefit cap & 0 & 0 & -123 & -1 \\
Net cost & $\mathbf{7 , 0 1 1}$ & $\mathbf{7 9}$ & $\mathbf{1 1 , 1 3 6}$ & $\mathbf{9 6}$ \\
\hline Sourc: EUROM
\end{tabular}

Source: EUROMOD version F6.20 using Family Resources Survey data for 2008/9, adjusted to 2001 and 2013 prices and incomes.

There are different distributional consequences of these differences between gross and net effects, as shown in the Figure below. This shows the average net weekly increase in income per child by decile group of equivalised household income under the 2001 and 2013 policy systems. Under the 2001 system those in the lower income groups receive less, because some of the additional income is withdrawn as reduced entitlement to means-tested benefit. (This applies to a lesser extent in the bottom decile group where families simulated to not take up their entitlements to means-tested benefits are mainly located.) In 2013 however, it is children in higher income households who benefit to a lesser extent, due to the claw-back through income tax (the effect of the benefit cap is small and concentrated in the lowermiddle of the distribution). 


\section{Doubling child benefit in the UK: average net gain per child in $£ /$ week}
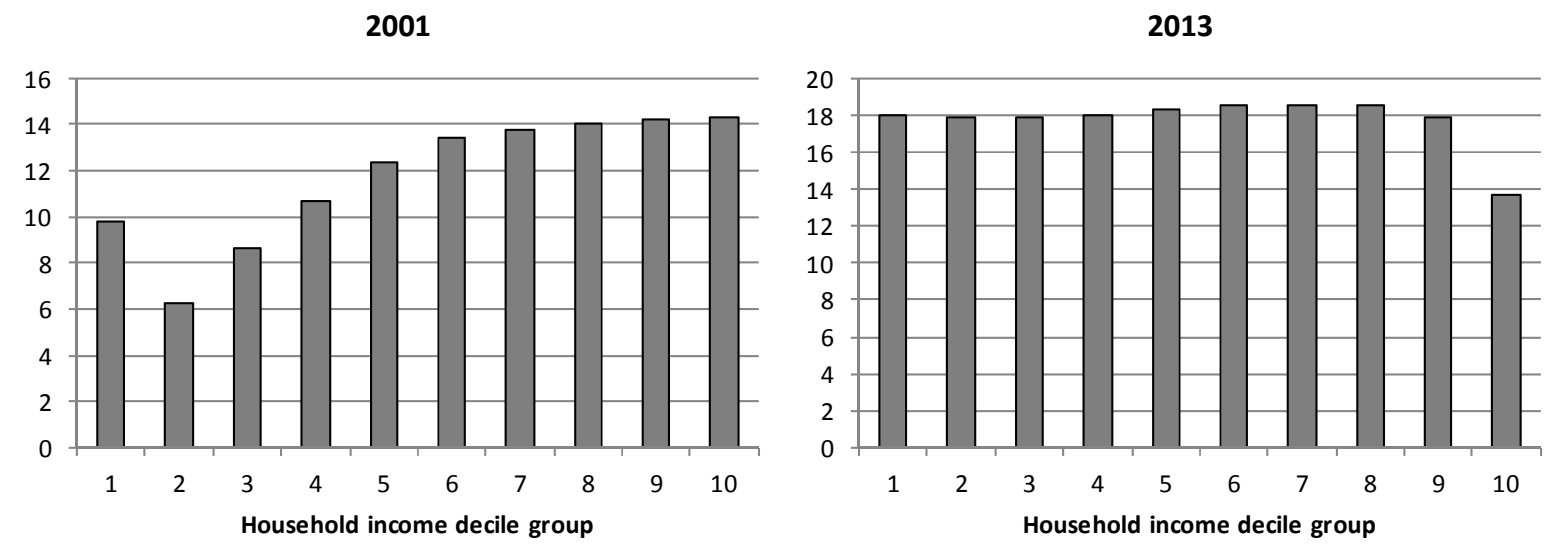

Notes: Deciles are based on equivalised household disposable income in the respective years and are constructed using the modified OECD equivalence scale to adjust incomes for differences in household size and composition. The lowest income group is labelled "1" and the highest "10". Source: EUROMOD version F6.20 using Family Resources Survey data for 2008/9, adjusted to 2001 and 2013 prices and incomes.

The point of this illustration is to demonstrate how the interactions matter and need to be understood in designing policy scenarios. Similarly, the policy analyst needs to account for the interactions in order to understand the effects of policy changes. If in 2001 a policymaker had wanted to double the payment made to all children they would have needed to increase child amounts within the other benefits as well as in Child Benefit. On the other hand, if the goal had been to reduce the number of families subject to means tests (without anyone losing) then the illustrative reform would have done just that (for example, reducing the number of all households receiving Council Tax Benefit). If the goal in 2013 had been to reduce the reach of means-testing, the means-tested payment rates for children would have needed to be reduced at the same time as the Child Benefit increase. 


\section{Appendix B: Comparison of simulated estimates of income tax with administrative statistics, UK 2010/11}

Here we illustrate the type of validation of simulated income tax that can be carried out when published tables from administrative data of tax revenue by income band are available. The exercise also suggests ways in which the input micro-data might be adjusted, or not. Here, the input data are the UK Family Resources Survey (FRS) 2009/10 updated to 2010/11 incomes and prices.

Simulated income tax liabilities are compared with statistics on income tax paid by band of taxable income, published by the UK revenue authority (HMRC, Table 3.3). The first point to note is that tax paid in any year may not match liability for tax on income earned in that year, because of adjustments carried over from previous years.

The first row in the top panel of the table below shows the ratio of microsimulation model (EUROMOD) estimates to those of HMRC in three dimensions: the number of taxpayers (defined as individuals with positive taxable income before deduction of any personal allowances), their total taxable income (before deduction of allowances), and the total tax liability/revenue. The number of taxpayers is under-estimated by $7 \%$ and taxable income by more: $13 \%$. Also shown are the ratios for the lowest taxable income group (under $£ 10,000$ per year) and highest income group (over £150,000). ${ }^{35}$

\footnotetext{
${ }^{35}$ The HMRC statistics provide more detail for top incomes (the top two groups being $£ 0.5$ million to $£ 1$ million and £1million+). However, although the overall sample size of the FRS is large by international standards $(31,644$ individuals in 2009/10) the numbers with very high incomes are too small to analyse. There are 99 observations with taxable income in excess of $£ 150,000$, including 13 with more than $£ 500,000$ and just 2 with more than $£ 1$ million (after adjustment to 2010/11 income levels). As explained in the main text, this is partly due to under-representation of, or under reporting by, people with very high incomes in the survey. However, even if their incomes were properly represented, based on the HMRC statistics there would still be fewer than 30 observations with incomes above $£ 500,000$ in a sample of this size.
} 


\section{Ratio of EUROMOD estimates to HMRC statistics}

\begin{tabular}{|c|c|c|c|}
\hline & Taxpayers & Taxable income & Tax revenue \\
\hline \multicolumn{4}{|l|}{ EUROMOD } \\
\hline All & 0.93 & 0.87 & 0.85 \\
\hline taxable income $<£ 10 \mathrm{~K}$ & 0.99 & 0.98 & 0.76 \\
\hline taxable income $£ 150 \mathrm{~K}+$ & 0.46 & 0.42 & 0.46 \\
\hline \multicolumn{4}{|c|}{ EUROMOD with proportional adjustment to number of taxpayers (adj1) } \\
\hline All & 1.00 & 0.93 & 0.91 \\
\hline taxable income $<£ 10 \mathrm{~K}$ & 1.06 & 1.05 & 0.82 \\
\hline taxable income $£ 150 \mathrm{~K}+$ & 0.50 & 0.45 & 0.49 \\
\hline \multicolumn{4}{|c|}{ EUROMOD with adjustment to number of taxpayers by income band (adj2) } \\
\hline All & 1.00 & 0.98 & 1.05 \\
\hline taxable income $<£ 10 \mathrm{~K}$ & 1.00 & 1.00 & 0.79 \\
\hline taxable income $£ 150 \mathrm{~K}+$ & 1.00 & 0.89 & 0.98 \\
\hline
\end{tabular}

Notes: EUROMOD-adj1 makes a proportional adjustment to the number of taxpayers in each income group, to match HMRC. EUROMOD-adj2 adjusts the number of taxpayers in each income group to match those given by HMRC. Sources: EUROMOD version F6.20 using Family Resources Survey 2009/10 updated to 2010/11 incomes. HMRC http://www.hmrc.gov.uk/statistics/income-by-year.htm\%202010-11\%20Table\%203.3.

The low income group and their taxable income is well-represented by the FRS data but the tax revenue simulated by EUROMOD is too low by $24 \%$. The difference in tax liability based on current year incomes (EUROMOD calculations) and tax revenue (HMRC) can arise if the latter contains tax due on higher previous year incomes, for example by the self-employed. The symmetrical effect (revenue smaller than liability, as incomes rise), which in general is equally likely, is not observable because it is distributed throughout the rest of the distribution of taxable income.

The high income group of taxpayers and their income and tax paid are all under-represented by more than $50 \%$. This is consistent with either or both the under-representation of very high income-earners in the survey, or the under-reporting of high incomes.

More detail of the pattern of tax revenue by range of taxable income can be seen in the Figure below. The black bars show the HMRC estimates and the white bars, those using 
EUROMOD simulations. EUROMOD shows some shortfall in most income ranges but the effect is concentrated in the highest income group.

\section{Estimates of income tax revenue by range of taxable income 2010/11}

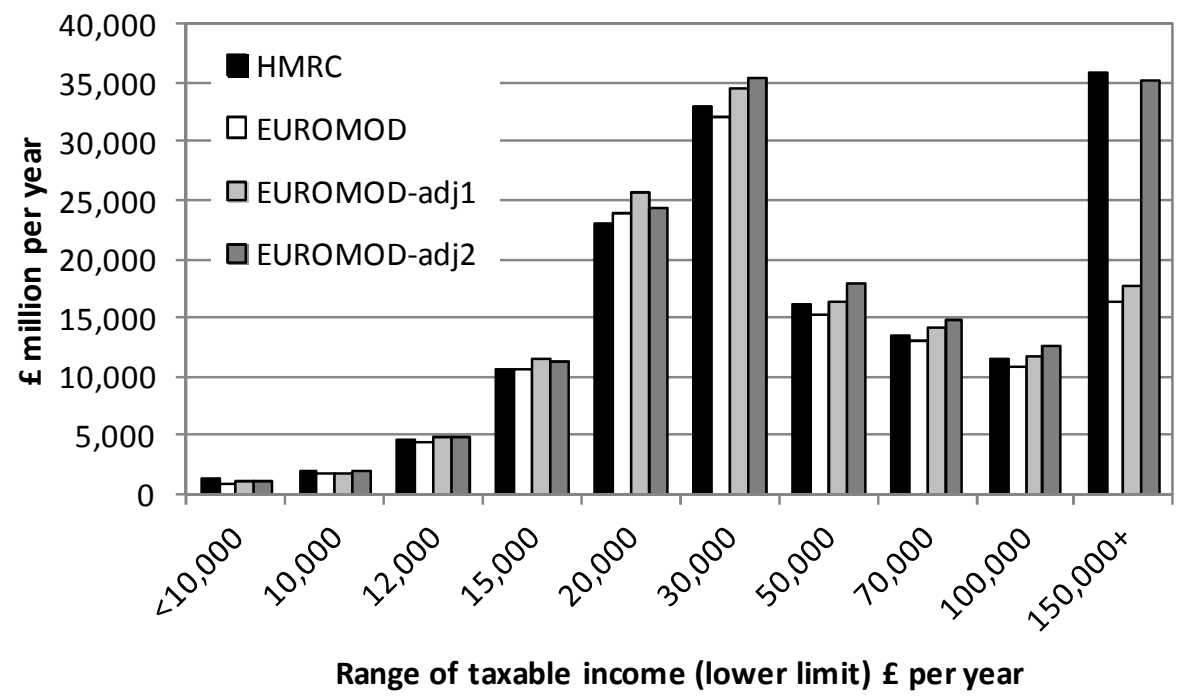

Notes: EUROMOD-adj1 makes a proportional adjustment to the number of taxpayers in each income group, to match HMRC. EUROMOD-adj2 adjusts the number of taxpayers in each income group to match those given by HMRC. Sources: EUROMOD version F6.20 using Family Resources Survey 2009/10 updated to 2010/11 incomes. HMRC http://www.hmrc.gov.uk/statistics/income-by-year.htm\%202010-11\%20Table\%203.3.

The overall shortfall in taxpayers might be explained by under-reporting of income by the whole distribution or parts of it, or by the fact that a proportion of UK income taxpayers are not resident in UK households and hence not captured by the survey data. ${ }^{36}$ We carry out two adjustments to the comparison of EUROMOD and HMRC statistics (not to the micro-data) in order to explore these possibilities. First (adj1) we make a proportional adjustment to the three statistics reported in the table such that the total number of taxpayers matches that given by HMRC (i.e. an increase of $7 \%$ in the EUROMOD statistic). The middle panel in the table shows that this has the effect of reducing the overall shortfall in taxable income and tax revenue by almost half but does little to rectify the shortfalls in the top income group. The effect on tax revenue in each income group is shown by the pale grey bars in the Figure. This

\footnotetext{
${ }^{36} \mathrm{We}$ do not pursue this second possibility further.
} 
suggests that a general tendency to under-report is part of the explanation for the shortfall in tax revenue but not the whole story.

A second adjustment accounts for the shortfall in taxpayers within each income group. The effect of this is shown by the darker-grey bar in the figure and the bottom panel in the table. The overall shortfall in taxable income all but disappears but tax revenue is over-estimated by $5 \%$. The shortfall in taxable income in the top income group is greatly reduced to $11 \%$ while tax revenue almost matches that in HMRC statistics for this group. The remaining shortfall in taxable income at the top suggests that there is a problem of lack of response by high income earners. The relative over-estimation of tax revenue suggests that the simulation of tax liability is missing the effect of some tax reliefs and deductions that cannot be simulated due to lack of information in the data. Tax evasion is also a possible explanation. From the figure, it seems that these effects are more important at higher incomes.

To summarise, the validation exercise of the simulated income tax in the UK component of EUROMOD provides some useful insights that should be considered in interpreting microsimulation results for other countries as well, although of course the specific explanations may differ and additional factors may be present. The UK FRS data appear to (a) under-represent people with high taxable incomes, and (b) under-report taxable incomes to some degree, across the whole distribution, although in countries characterised by large tax evasion the taxable income reported in the survey can be larger than the one reported in the tax revenue statistics. Simulated tax liabilities do not match tax revenue statistics because of between-year adjustments. The income tax simulations do not take account of all reliefs and deductions, nor of tax evasion, and this may lead to over-estimation of tax payments particularly towards the top of the distribution. 